\title{
COMPARAÇÃO ENTRE TRÊS ÍNDICES DE FLUOROSE DENTÁRIA NA DENTIÇÃO PERMANENTE, OBSERVADOS EM ESCOLARES DE 12 A 14 ANOS DE IDADE, RESIDENTES EM ÁREAS COM DIFERENTES CONCENTRAÇÕES DE FLÚOR NAS ÁGUAS DE CONSUMO.
}

\author{
Antonio Carlos Pereira \\ Doutorando \\ Ben-Hur Wey Moreira \\ Orientador
}

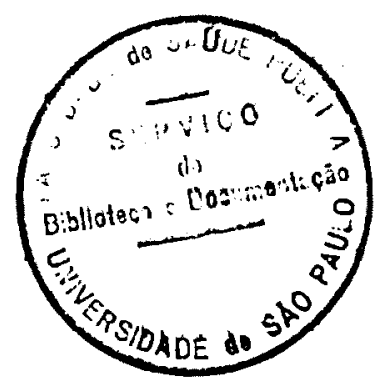

Tese de Doutorado apresentada à Faculdade de Saúde Pública-USP para a obtençăo do título de Doutor em Saúde Pública, área de concentração Serviços de Saúde Pública.

São Paulo 


\section{Índice:}

Pág.

Dedicatória

Agradecimentos

Agradecimento Especial

1- Resumo

01

2- Introdução

02

3- Objetivos

04

4- Revisão Bibliográfica

05

5- Material e Métodos

38

6- Resultados

46

7- Discussão

65

8- Conclusões 78

9- Summary

79

10-Referências Bibliográficas $\quad 80$

11- Anexos

96 


\title{
DEDICATÓRIA
}

\author{
À meus pais Antonio e Isabel, \\ minha esposa Cláudia e \\ minha irmã Cristina, pelo \\ amor e carinho que me dispensaram, \\ conforto no desespero, \\ alento nos momentos tristes, \\ companhia nos alegres e \\ pelo simples fato de existirem.
}


À meu Orientador Ben-Hur Wey Moreira pela paciência e persistência, que com certeza foram necessários em todos estes anos de convivência. 


\section{Agradecimentos}

Ao Diretor da Faculdade de Saúde Pública da Universidade de São Paulo;

Ao incansável Sr. Etevaldo, secretário do Departamento de Prática na Faculdade de Saúde Pública, que em inúmeros momentos durante o transcorrer do curso me socorreu sempre com boa vontade e profissionalismo;

Aos meus colegas do Mestrado Profs Silvio Rocha Correa da Silva, Marlívia Gonçalves e Paulo Capel Narvai pela amizade e ajuda nos momentos dificeis;

Ao Diretor da Faculdade de Odontologia de Piracicaba-FOP, Dr. José Ranali;

Aos professores e funcionários do Departamento de Odontologia Social da FOP-UNICAMP pela colaboração em todas as fases de minha pós-graduação;

Ao casal Márcia e Sandro Bíscaro pela grande amizade e colaboração na fase prática da tese;

À THD Débora Gazola pela colaboração na fase prática;

Ao querido amigo Prof. Francisco Groppo pela colaboração nas fases críticas em que era necessário a tecnologia do computador;

Aos meus grandes amigos Profs. Marcelo Meneghim e Eduardo Hebling que me auxiliaram em todas as atividades diárias do Departamento e pela paciência na convivência do dia a dia;

À todos que por esquecimento não tenha citado e que de algum modo tenham me auxiliado a desviar de todos os obstáculos desta fase. 


\title{
Agradecimento Especial
}

\author{
À Deus por vossa infinita \\ compreensão, me dando a \\ indispensável coragem para \\ atingir os meus propósitos.
}




\section{1- RESUMO}

Os estudos referentes à fluorose dentária têm sido alvo de muitas pesquisas em diversos países do mundo. O objetivo deste trabalho foi comparar os indices de fluorose dentária de DEAN, T-F e TSIF quanto às prevalências por superficie, dente e localidade, além de verificar a correlação estatística entre os mesmos. A amostra consistiu de 461 escolares, idade entre 12 e 14 anos, nascidos ou residentes desde os dois anos de idade, sendo 153 da cidade de Cesário Lange com concentração de $1,4 \mathrm{ppm}$ de flúor nas águas de consumo, 142 de Piracicaba $(0,7 \mathrm{ppm} \mathrm{F})$ e 166 de Iracemápolis $(<0,3 \mathrm{ppm} \mathrm{F})$. O exame foi efetuado após escovação dos dentes e consistiu do uso de sonda exploradora, espelho bucal, secagem dos dentes e iluminação artificial. Os resultados demonstraram que os dentes mais severamente afetados foram os pré-molares e 20 s molares, ambas as arcadas, enquanto as superficies oclusais foram as mais atingidas. Concluiu-se que os três indices apresentaram prevalências semelhantes de fluorose nas populações,ou seja, as percentagens de crianças afetadas nas três cidades foram de $32,7 \%, 16,9 \%$ e $4,2 \%$, respectivamente, para o índice de Dean; enquanto para o índice T-F as prevalências foram de $33,7 \%, 17,6 \%$ e $4,2 \%$ e para o TSIF foram estimadas percentagens de $32,7 \%, 16,9 \%$ e $4,2 \%$, respectivamente. Não houve dificuldades para a utilização dos três índices, nos trabalhos de campo, podendo-se sugerir o emprego de qualquer um deles em áreas com concentrações de flúor semelhantes ao deste estudo. 


\section{2- INTRODUÇĀO}

A descoberta do íon flúor como agente preventivo da cárie dentária foi um dos capitulos mais significativos na história da Odontologia. Iniciou-se com as verificações de $\mathrm{McKAY}^{117}$ e $\mathrm{DEAN}^{32,33}$, relacionando alterações no esmalte dentário, que variavam de finas linhas esbranquiçadas ao longo das periquimáceas até a total destruição da camada de esmalte, além da presença de manchas escuras que comprometiam a estética. Essas alterações foram primeiramente denominadas de esmalte moteado (KUHNS ${ }^{87}$ ) e posteriormente de fluorose dentária (DEAN \& ARNOLD ${ }^{35}$ ) que pode ser definida como um distúrbio específico na formação dos dentes, causado por aumento crônico de depósito de flúor durante o período de mineralização dos dentes (LESAN ${ }^{96}$ ). Estes estudos concluíram que havia uma forte correlação positiva entre prevalência de esmalte moteado e concentração do íon flúor nas águas de consumo humano e também que havia uma forte correlação negativa entre presença de íon flúor nas águas de consumo público e prevalência de cárie dentária .

Nos últimos 50 anos, o flúor tem sido largamente utilizado, em escala mundial, como método de prevenção da cárie dentária, nas mais diversas formas por via sistêmica (água de consumo, sal, comprimidos, gotas) ou local (aplicação tópica de flúor, bochechos fluoretados, dentifrícios, vernizes), sendo sua eficácia demonstrada em diversos trabalhos científicos (USPHS ${ }^{177}$ ).

Recentemente têm sido constatadas algumas mudanças no quadro epidemiológico, a saber: a) a prevalência de cárie dentária vem declinando em países desenvolvidos, b) a prevalência das formas leves de fluorose está gradualmente aumentando devido principalmente ao uso difundido de métodos preventivos com flúor, c) flúor por via tópica é o principal efeito cariostático e d) suplementos dietéticos de flúor são um fator de risco para a fluorose dentária (SZPUNAR \& BURT ${ }^{170}$ ). Devido principalmente aos dois primeiros tópicos, especialistas têm pesquisado os instrumentos disponíveis para aferição das principais alterações de esmalte, buscando uma reavaliação da situação vigente (OSUJ, NIKIFORUK \& LEAKE ${ }^{133}$ ). 
Vários índices foram propostos para a mensuração dos defeitos de esmalte, podendo ser divididos em dois grupos distintos: a) índices específicos de fluorose e b) índices descritivos, incorporando todos os tipos de defeitos. Os índices específicos de fluorose são empregados para verificar os defeitos de esmalte devido à ingestão crônica acumulada de flúor, sendo o índice mais difundido o de DEAN ${ }^{34}$, caracterizado por verificar as alterações estéticas do esmalte em decorrência do consumo de flúor, e, mais recentemente, o índice T-F (THYLSTRUP \& FEJERSKOV ${ }^{173}$ ) que se preocupa com os aspectos biológicos da ação do flúor no esmalte e o TSIF, Índice de Fluorose por Superficie Dentária, (HOROWITZ et al. ${ }^{75}$ ), que apresenta uma classificação enfatizando somente os aspectos estéticos.

A diferenciação diagnóstica entre as formas leves de fluorose e opacidades de esmalte de origem não fluorótica é outro aspecto relevante estudado (HOROWITZ ${ }^{74}$; SZPUNAR \& BURT ${ }^{170}$ ), que precisa ser melhor desenvolvido devido às dificuldades inerentes, principalmente em áreas com baixas concentrações de flúor nas águas de consumo. 


\section{3- OBJETIVOS}

Mediante o exposto, o presente estudo tem por objetivo:

a) Comparar os índices de fluorose de DEAN, T-F e TSIF quanto às prevalências por:

- superficie

- dente

- localidade

b) Estudar a correlação estatística entre os diferentes índices utilizados. 


\section{4- REVISÃO BIBLIOGRÁFICA}

\subsection{Aspectos Históricos}

Provavelmente as primeiras constatações da presença de fluorose dentária "esmalte moteado" foram feitas por KUHNS ${ }^{87}$, o qual descreveu manchas escuras em dentes de uma família em DURANGO (México).

Na cidade de Nápoles, EAGER ${ }^{46}$ observou uma alta proporção de pessoas com uma curiosa peculiaridade nos dentes, conhecida como "denti di chiae", apresentando algumas manchas marrons e outras finas linhas brancas no esmalte dentário . Nesse mesmo ano, a Sociedade Dentária de Colorado Springs (EUA) começou os estudos sobre o chamado esmalte moteado, reunindo vários dentistas (McKAY $\left.{ }^{117}\right)$.

McKAY ${ }^{117}$ examinou crianças de Colorado Springs e descreveu a presença de pequenas manchas brancas, amarelas ou marrons, as quais podiam se unir formando áreas espalhadas irregularmente na superficie do dente, podendo ser uma condição em que a superficie inteira do dente possuísse aspecto esbranquiçado. Esta constatação fortaleceu a idéia de que o esmalte moteado era verificado em pessoas que residiam em áreas geográficas definidas, ficando mais elucidado quando McKAY observou que três cidades de Arkansas, separadas por alguns quilômetros, na qual crianças apresentavam sinais de esmalte moteado, recebiam água de abastecimento da mesma fonte (Fountain Creek), levando-o a acreditar que as águas de abastecimento eram responsáveis pelo esmalte moteado.

Isso viria a ser confirmado por CHURCHILL ${ }^{22}$ que encontrou altas concentrações de flúor, até 13,8 ppm, na cidade de Bauxite (EUA).

Nesse mesmo ano, o Serviço de Saúde Pública dos Estados Unidos confiou ao jovem Dr. H. Trendley DEAN e equipe a função de pesquisar a relação entre águas de abastecimento público, esmalte moteado e cárie dentária.

Em 1933, DEAN ${ }^{32}$ publicou um artigo no qual apresentava uma distribuição de fluorose nos EUA (70 regiões).Posteriormente desenvolveu um índice de fluorose dentária, baseado em aspectos estéticos, no qual classificava os indivíduos dentro de 7 categorias, dependendo do grau de alteração no esmalte (DEAN, DIXON \& COHEN ${ }^{38}$ ), sendo modificado por DEAN ${ }^{34}$ reduzindo o número de categorias para 6(seis), havendo uma escala variando de 0 (esmalte normal) a 4 (esmalte com caso severo). Este índice foi modificado posteriormente 
(MOLLER ${ }^{119}$; WHO ${ }^{187}$; GASPAR, PEREIRA \& MOREIRA ${ }^{64}$ ). Seu objetivo, no entanto, era medir a dose-efeito mínima do flúor, que traria ao esmalte dentário uma ação preventiva máxima em relação à cárie dentária .

"O aumento na concentração de flúor nas águas de abastecimento traz consigo um aumento na prevalência e severidade da fluorose dentária" foi a conclusão de DEAN \& ELVOVE ${ }^{37}$, sendo essa afirmação confirmada por estudos em animais (McCOLLUM et al. ${ }^{116}$; SEBRELL et al. ${ }^{155}$ ).

Em relação à estética, DEAN \& ELVOLVE ${ }^{37}$ verificaram que quantidades de flúor presentes nas águas de abastecimento menores que 1 ppm não tinham significado em saúde pública.

Finalmente, em 1939, DEAN \& McKAY ${ }^{39}$ sumarizaram os conhecimentos, até a época, sobre a fluorose dentária, à Seção Epidemiológica da Associação Americana de Saúde Pública, concluindo que "havia uma conclusiva e direta evidência de que o aparecimento dos sinais de fluorose dentária era diretamente relacionado às concentrações de flúor nas águas de abastecimento", após verificarem que havia 375 áreas, em 26 estados norte americanos, onde a fluorose dentária se apresentava com vários graus de prevalência e severidade.

\subsection{Fluorose dentária e Cárie dentária}

A relação inversa entre cárie dentária e esmalte moteado foi primeiramente constatado por McKAY ${ }^{117}$, que observou uma menor prevalência de cárie dentária em dentes com esmalte moteado.

AINSWORTH ${ }^{5}$, em 1933, verificou que a experiência de cárie, em áreas com altas concentrações de flúor nas águas de abastecimanto, é menor do que nas áreas que não apresentavam flúor.

DEAN et al. ${ }^{40}$ examinando 885 crianças, de 12 a 14 anos, em 4 cidades do Estado de Illinois (EUA), Calesburg e Moumouth (contendo 1,8 e 1,7 $\mathrm{ppm}$ de flúor na água) e Macomb e Quincy (contendo $0,2 \mathrm{ppm}$ de flúor), encontraram uma prevalência duas vezes menor em relação à cárie dentária nas duas primeiras cidades, incentivando a novas investigações para o conhecimento mais profundo da relação da concentração de flúor nas águas e cárie dentária.

DEAN, ARNOLD \& ELVOVE ${ }^{36}$ conduziram uma pesquisa sistemática de cárie dental em relação á quantidade de flúor nas águas de consumo em 21 cidades dos EUA. Verificaram que a prevalência de cárie era inversamente proporcional às concentrações de flúor nas águas de consumo. Essa dose-efeito 
evidenciou que o flúor era associado com a redução na prevalência de cárie dentária.

A associação entre aumento da concentração de flúor nas águas de abastecimento e a diminuição de cárie na população, com uma máxima ação preventiva em concentrações em torno de $1 \mathrm{ppm}$ de flúor, foi concluída por DEAN, ARNOLD \& ELVOVE ${ }^{36}$.

Porém as conclusões de DEAN tomavam por base áreas geográficas definidas, aparentemente não constatando que a concentração ótima de flúor pode variar conforme as diferenças climáticas. Essa variável foi estudada posteriormente por HODGE ${ }^{11}$, GALAGAN \& LAMSON ${ }^{62}$, GALAGAN \& VERMILLION ${ }^{63} \mathrm{e}$ RICHARDS et al. ${ }^{145}$, que associaram a quantidade de flúor ingerido à temperatura média anual de uma determinada região, pois quanto maior a temperatura, maior seria a ingestão de água e, conseqüentemente, a quantidade de flúor presente, recomendando concentrações ótimas de flúor nas águas de consumo entre 0,7 e 1,2 ppm.

A ingestão de água fluoretada tem sido considerada o mais significante meio de consumo diário, sendo que os teores de flúor consumido dependerão:

a) da idade do paciente

b) das condições climáticas

c) dos hábitos dietéticos (MOLLER ${ }^{120}$ ).

FORREST \& JAMES ${ }^{60}$, em 1965, relacionaram cárie dentária, fluorose e concentrações de flúor nas águas de consumo em quatro regiões com teores de flúor em suas águas de 5,8;3,5;2,0 e 0,9 ppm acrescidos de duas regiões sem traços de flúor. Examinaram 324 crianças, idades de 12 a 14 anos, em regiões fluoretadas e 259 crianças em regiões não fluoretadas. Os autores concluíram que a prevalência de cárie era menor nas regiões fluoretadas do que em regiões não fluoretadas, enquanto a prevalência e severidade da fluorose dentária era diretamente relacionada com a quantidade de flúor nas águas de abastecimento.

BINDER ${ }^{12}$, examinando crianças em três localidades com diferentes concentrações de flúor, entre $1,0 \mathrm{ppm}$ e $1,8 \mathrm{ppm}$, verificou uma clara associação entre o aumento da concentração de flúor nas águas e a diminuição da cárie dentária acrescido de um aumento da prevalência de fluorose dentária, sendo esta conclusão concorde com SZPUNAR \& BURT ${ }^{169}$, os quais examinaram 1103 crianças de 6 a 12 anos em quatro localidades com concentrações de flúor variando de 0,8 a 1,2 ppm e GASPAR, PEREIRA \& MOREIRA ${ }^{64}$, que examinaram 411 escolares de 10 a 14 anos em duas áreas com concentrações de 0,3 e 0,7 ppm de flúor. 
BINDER ${ }^{13}$ examinou 1460 crianças de 7 a 14 anos, em três regiões com diferentes concentrações de flúor nas águas de abastecimento (A-1,0 ppm; B1,5 a $1,8 \mathrm{ppm}$; C-3,0 ppm),primeiramente em 1959 , reexaminando-as após 10 anos. No primeiro exame encontrou uma associação inversa entre concentração de flúor nas águas e prevalência de cárie dentária. No segundo exame foi encontrada uma maior prevalência de cárie na região $\mathrm{B}$, sendo que o autor acredita que isto se deva à influência da má higiene oral e à nutrição, sendo que a percentagem de crianças com fluorose era maior conforme se aumentava a concentração de flúor nas águas de abastecimento.

DRISCOLL et al. ${ }^{43}$ estudaram sete comunidades de Illinois, com concentrações ótima, duas vezes, três vezes e quatro vezes os teores ideais de flúor para as mesmas. Foram examinadas 870 crianças de 8 a 16 anos, utilizando-se o índice de DEAN para medir a prevalência e severidade da fluorose e o índice CPOD para a prevalência de cárie dentária. Os autores concluíram que, conforme se aumenta a concentração de flúor nas águas de abastecimento, há um progressivo aumento da prevalência e severidade da fluorose dentária e acrescentaram que a adicional proteção do flúor ao aumento da prevalência de cárie dentária pode ser diminuída se as concentrações nas águas forem muito altas (FORSMAN ${ }^{61}$; OLSSON ${ }^{130}$ ), sendo que a comunidade com concentração quatro vezes a ótima teve redução do índice CPOD menor que as comunidades com concentrações duas e três vezes a ótima, em relação às comunidades controle (concentrações de flúor $<0,3 \mathrm{ppm}$ nas águas de consumo). Essa constatação pode ser explicada devido ao esmalte hipoplásico encontrado em dentes fluoróticos, permitir uma maior penetração de ácidos e possivelmente bactérias, não sendo capaz de resistir à dissolução do esmalte pelos ácidos (LESAN ${ }^{96}$ ), sendo esta hipótese sustentada por achados histológicos que indicam que o espaço entre os prismas de esmalte é aumentado e irregular em esmalte com fluorose severa (THYLSTRUP ${ }^{11}$ ).

LARSEN et al. ${ }^{93}$ examinaram crianças de 14 a 16 anos, divididas em três grupos (residentes desde o nascimento e imigradas antes e após a completa mineralização dos dentes), as quais residiam em áreas com concentrações de flúor nas águas, variando de 1,0 a 2,1 ppm. Os autores não constataram diferenças significantes na prevalência de cárie entre os grupos de crianças, possivelmente devido ao largo uso de flúor tópico naquele país (Dinamarca), embora a prevalência de fluorose fosse estatisticamente maior nos grupos de crianças residentes desde 0 nascimento e imigrantes que chegaram nas áreas estudadas antes da completa mineralização dos dentes.

KAMINSKY et al. ${ }^{82}$ listaram 14 estudos conduzidos em áreas não fluoretadas, verificando que a prevalência de cárie dentária diminuiu entre $17 \mathrm{e}$ $60 \%$, nas últimas décadas. Acrescentaram que os índices nacionais de cárie dentária não tem diminuído em todos os países, notadamente Brasil e França, onde 
os índices permanecem inalterados, sendo que no Japão, Nigéria e Tailândia vêm aumentando gradativamente os índices, enquanto em países como EUA, Austrália, Inglaterra, Irlanda e Nova Zelândia têm diminuído(NEWBRUN ${ }^{127}$ ) . RENSON ${ }^{142}$ tem sugerido diversas razões para este declínio, entre as quais: a) aumento da defesa imunológica ou uso mais difundido de novos antibióticos, embora ainda não existam dados que suportem esta teoria, b) diminuição da exposição a produtos cariogênicos (principalmente açúcar), c) programas de saúde que realizam escovação regular, profilaxia bucal, educação para a saúde e uso de flúor gel. Adicionalmente o uso mais extensivo, em alguns países, de comprimidos e dentifrícios fluoretados, apontados como potenciais agentes de prevenção da cárie dentária, vem acompanhando essa tendência de declínio temporal, sendo largamente utilizado em muitos países.

LEWIS \& BANTING ${ }^{103}$ afirmaram, ao comparar estudos recentes sobre a fluoretação das águas de consumo, que as diferenças entre as prevalências de fluorose e cárie dentária ,em áreas fluoretadas e não fluoretadas, têm diminuído rapidamente. A prevalência e severidade da fluorose dentária têm aumentado desde 1945 , todavia a proporção de fluorose relacionada à fluoretação das águas é atualmente menor ( $40 \%$ ) comparada com aquela atribuída a outros recursos de flúor $(60 \%)$.

Esta relação inversa entre fluorose dentária e cárie dentária pode ser interpretada de dois modos: a) é possível que a camada mais externa do esmalte fluorótico tenha uma relativa alta concentração de flúor, e no processo de desmineralização, este flúor possa ser liberado, portanto interferindo na formação de lesões de cárie superficial; b) alternativamente, pode ser que uma relativa alta quantidade de proteínas no esmalte fluorótico possa retardar o nível de desmineralização. (FEJERSKOV et al. ${ }^{58}$ ).

\section{3 Índices de fluorose}

Quanto aos aspectos clínicos, podemos medir a prevalência e severidade da fluorose dentária através de índices, os quais se baseiam em sistemas de classificações.

DEAN ${ }^{33}$ desenvolveu um índice de fluorose que classificava os indivíduos em 7 categorias, dependendo do grau de alteração do esmalte, o qual era baseado na identificação dos 2 dentes mais severamente afetados, dando valores ordinais conforme se aumentava a severidade da alteração do esmalte, sendo posteriormente modificado (DEAN ${ }^{34}$; MOLLER ${ }^{119}$; WHO ${ }^{187}$ ). O índice de fluorose $\left(D E A N{ }^{34}\right.$ ) foi desenvolvido com o propósito de identificar geograficamente grupos populacionais com fluorose dentária, facilitando uma comparação dos graus de 
fluorose em diferentes populações, sendo calculado somando-se os índices individuais (baseados nos 2 dentes mais severamente afetados) e divididos pelo número de indivíduos examinados. Posteriormente DEAN \& ARNOLD ${ }^{35}$ propuseram um significado em saúde pública de acordo com o quadro a seguir.

Quadro 1. Significado para a saúde pública dos valores do índice de fluorose de Dean (DEAN \& ARNOLD ${ }^{35}$ ).

\begin{tabular}{|l|l|l|}
\hline Concentração & Grau & Significado em saúde pública \\
\hline $\begin{array}{l}0,0 \text { a } 0,4 \\
0,4 \text { a } 0,6\end{array}$ & $\begin{array}{l}\text { negativo } \\
\text { zona } \\
\text { limite }\end{array}$ & $\begin{array}{l}\text { índice sem importância para a saúde } \\
\text { pública em relação à fluorose, porém de } \\
\text { alto valor sob o ponto de vista da } \\
\text { prevenção de cárie. }\end{array}$ \\
\hline 0,6 a 1,0 & leve & \\
\hline 1,0 a 2,0 & médio & \\
\hline 2,0 a 3,0 & grave & Recomendada a remoção do excesso de \\
\hline 3,0 a 4,0 & $\begin{array}{l}\text { muito } \\
\text { grave }\end{array}$ & fluoretos na água \\
\hline
\end{tabular}

THYLSTRUP \& FEJERSKOV ${ }^{173}$ desenvolveram um índice baseado nos aspectos biológicos da fluorose dentária, classificando os indivíduos em 10 categorias designadas para caracterizar o grau macroscópico da fluorose em relação aos aspectos histológicos. Na classificação original examinavam-se as superficies vestibulares, oclusais e linguais, sendo que, levando em consideração que na época de erupção todas as superfícies dos dentes estão igualmente afetadas, recomendaram que somente as superficies vestibulares fossem examinadas.

HOROWITZ et al. ${ }^{75}$ desenvolveram o índice de fluorose por superficie dentária (TSIF), baseado em aspectos estéticos, classificando os indivíduos em 8 categorias. Neste índice um valor é dado para cada superficie de dentes anteriores não restaurados (vestibular e lingual) e três valores para as superficies de dentes posteriores (vestibular, lingual e oclusal).

Outros índices de fluorose dentária foram desenvolvidos, porém sem grande utilização em estudos deste tipo, VENKATESWARLY, RAO \& RAO ${ }^{179}$; SMITH, HARRIS \& KIRK ${ }^{162}$; KAWAHARA \& KAWAHARA ${ }^{83}$; CLARKSON \& O’MULLANE ${ }^{26}$; Índice de Risco de Fluorose descrito por PENDRYS ${ }^{135}$.

A comparação dos diversos índices de fluorose dentária foi relatada em escassos artigos científicos. GRANATH, WIDENHEIN 
$\mathrm{BIRKHED}^{66}$,comparando os índices de DEAN e T-F, concluíram que o segundo era mais detalhado e sensível, pois o mesmo era baseado em aspectos biológicos, onde há um aumento da hipomineralização com simultâneo aumento na profundidade da superficie de esmalte em direção à junção amelo-dentinária, enquanto o índice de DEAN enfatizava os aspectos estéticos da fluorose dentária. Os autores ainda analisaram que o código 0,5 de DEAN deveria ser excluído e transformado em código 1, o que poderia facilitar posteriores comparações e recomendaram que, em estudos epidemiológicos, o código 1 do indice T-F deveria ser transformado em código 0 , pois os primeiros sinais de fluorose com estreitas linhas brancas no esmalte, poderiam ser superestimadas, nesse código.

THYLSTRUP \& FEJERSKOV ${ }^{173}$, no trabalho que deu origem ao índice T-F, consideram que o indice de DEAN não é capaz de distinguir diferentes aspectos da severidade da fluorose dentária em áreas com altas concentrações de flúor nas águas de abastecimento (acima de $3 \mathrm{ppm} \mathrm{F}$ ), sendo esta conclusão sustentada por MOLLER ${ }^{120}$ e WENZEL \& THYLSTRUP ${ }^{182}$. Os autores verificaram ainda que, em $47 \%$ das crianças examinadas, havia uma concordância nos dois índices utilizados, com respeito ao aumento da severidade da fluorose dentária . Afirmaram ainda que a classificação de DEAN ${ }^{34}$ era capaz de esboçar a severidade da fluorose dentária em populações residentes em áreas com menos que 3 ppm de $\mathrm{F}$ nas águas de abastecimento.

BURGER et al. ${ }^{18}$, comparando os índices T-F e DEAN na dentição primária, em crianças de 1 a 9 anos de idade, na Tanzânia, afirmaram que os dois sistemas de classificação reproduziam quase a mesma prevalência, mas o valor de severidade variava nas escalas, ou seja, geralmente o índice T-F apresentava um score mais alto que o índice de DEAN. Os autores concluíram, recomendando o índice T-F para futuros estudos em campo, devido à facilidade de uso e critérios mais bem definidos.

FEJERSKOV, MANJI \& BAELUM ${ }^{54}$ afirmaram que além do índice T-F ser mais preciso, sensível e fácil na utilização em campo em relação ao índice de DEAN, tem a vantagem adicional de permitir a comparação de dados obtidos pelos dois indices, sendo isto particularmente importante, se fosse necessário comparar-se dados de estudos anteriores, os quais utilizaram o índice de DEAN.

CLEATON-JONES \& HARGREAVES ${ }^{28}$ compararam os três indices de fluorose (DEAN, T-F e TSIF),em dentição decídua, verificando que a prevalência da fluorose, em dentes individuais, era mais freqüentemente diagnosticado pelo índice $T-F$, concluindo que este é o mais indicado para trabalhos onde são necessárias informações detalhadas sobre o problema. 
MABELYA, KONIG \& HELDERMAN ${ }^{107}$, comparando os índices de DEAN e T-F, em 1565 crianças de 11 a 18 anos de idade, constataram que os valores da estatística KAPPA(LANDIS \& $\mathrm{KOCH}{ }^{90}$ ), para o erro interexaminador, era melhor para $o$ índice T-F. $O$ indice de DEAN apresentava dificuldades de avaliação nas categorias questionável e muito leve, podendo explicar a relativa melhor confiança do indice T-F. O indice T-F discriminava melhor as formas severas da fluorose dentária, enquanto era mais apto a revelar frequências maiores de fluorose dentária em comunidades com prevalências baixa ou moderada, porém em comunidades onde mais que $85 \%$ dos dentes exibiam um código de DEAN $>$ ou $=1$. Ambos os índices revelavam prevalências semelhantes.

GASPAR, PEREIRA \& MOREIRA ${ }^{64}$, examinando 411 crianças de 10 a 14 anos, utilizando os índices de DEAN e T-F, verificaram prevalências semelhantes para os dois índices, em localidades com concentração ótima e baixa de flúor nas águas de consumo.

\subsection{Histopatologia da fluorose dentária}

O estudo da histopatologia da fluorose dentária iniciou-se com publicações de BLACK ${ }^{15}$; WILLIAMS ${ }^{183}$ e AINSWORTH ${ }^{\text {s. }}$.

Estudos com microscópio de luz polarizada foram efetuados por GUSTAFSON ${ }^{68}$; FEJERSKOV et al. ${ }^{57}$; THYLSTRUP \& FEJERSKOV, ${ }^{173}$, enquanto SILNESS \& GUSTAVSEN ${ }^{158}$; FEJERSKOV et al. ${ }^{57}$; utilizaram microrradiografias e SILNESS \& GUSTAVSEN 158; FEJERSKOV, JOHNSON \& SILVERSTONE ${ }^{53}$; FEJERSKOV, THYLSTRUP \& LARSEN ${ }^{s 5}$ e THYLSTRUP ${ }^{172}$, utilizaram microscópio eletrônico.

FEJERSKOV et al. ${ }^{57}$ confirmaram que a fluorose dentária abrange áreas de hipomineralização difusa ou porosidades mais pronunciadas no terço mais externo do esmalte, abaixo de uma camada superficial mineralizada.

THYLSTRUP \& FEJERSKOV ${ }^{173}$ constataram que o volume de poros , em dentes com fluorose, variava de $5 \%$ (leve) até um nível de $25 \%$ em dentes afetados com fluorose severa, cujas lesões se estendiam quase à junção amelodentinária na região cervical, explicando ainda que a hipomineralização ou a porosidade aumentada é o resultado do aumento nos espaços intercristalinos (ocupados por água e proteínas), tanto no prisma de esmalte como na substância interprismática. Porém a largura, espessura e forma da secção transversal dos cristais individuais de esmalte estão dentro de uma variação normal. 
FEJERSKOV, JOHNSON \& SILVERSTONE ${ }^{53}$ afirmaram que, mesmo em casos severos de fluorose, a orientação dos prismas parece normal e regular, indicando que os ameloblastos são aptos a produzir matriz de esmalte normal, mas que o processo de maturação é modificado pelas altas concentrações de íon flúor.

THYLSTRUP \& FEJERSKOV ${ }^{174}$ observaram que as depressões de esmalte, nos casos mais graves de fluorose dentária, ocorrem devido a uma quebra pós-eruptiva da superficie do esmalte.

Resumindo, o efeito do flúor na formação do esmalte pode seguir os seguintes caminhos patogênicos (FEJERSKOV, THYLSTRUP \& LARSEN ${ }^{55}$ ):

1) efeito nos ameloblastos

a) fase secretora

diminuição da produção de matriz

mudança na composição da matriz

mudança de mecanismos de transporte de íons

b) fase de maturação

diminuição da remoção de proteínas e água

2) efeitos na nucleação e crescimento dos cristais em todos os estágios de formação do esmalte

3)efeito na homeostase do cálcio, geralmente com a fluorose dentária, sendo este fato um resultado indireto.

O esmalte fluorótico contém mais proteínas no tecido poroso do que o esmalte normal não fluorótico embora não se saiba se esta diferença na composição do esmalte é o resultado direto de um efeito do flúor na síntese da matriz de esmalte ou um efeito indireto do flúor sobre a amelogênese (EKSTRAND , FEJERSKOV \& SILVERSTONE ${ }^{48}$ ).

FEJERSKOV , MANJI \& BAELUM ${ }^{54}$, especularam que o flúor pode afetar a maturação dos ameloblastos, influenciando sua capacidade de remover proteínas e água do esmalte maturo e/ou pode interferir na capacidade dos ameloblastos em produzir enzimas proteolíticas necessárias a iniciar o desarranjo da amelogenina.

DEN BESTEN \& THARIANI ${ }^{42}$ afirmaram que a fluorose era caracterizada por uma retenção de amelogeninas nos estágios iniciais de maturação e pela formação de um esmalte mais poroso com hipomineralização subsuperficial. Os mecanismos pelos quais o flúor afeta o desenvolvimento do esmalte inclui efeitos específicos nos ameloblastos e no desenvolvimento da matriz do esmalte, 
parecendo que há, no esmalte com fluorose, maior rapidez no estágio maturativo dos ameloblastos e redução na atividade proteolítica.

LIMEBACK ${ }^{105}$ afirmou que $\mathbf{o}$ flúor interfere nos processos responsáveis pela remoção eficiente dos componentes da matriz orgânica, resultando na retenção de proteinas e desorganização da formação dos cristais de esmalte, ou desregulando a atividade das células do órgão do esmalte, a qual indiretamente interfere na formação dos cristais normais. Isto estaria associado com pobre formação dos cristais, hipocalcificação, menor incorporação do flúor e amolecimentos do tecido subsuperficial na fase inorgânica do esmalte. $\mathrm{O}$ autor cita que o estágio de maturação do esmalte tem sido apontado por RICHARDS et al. ${ }^{144}$, ISHII \& SUCKLING $"$ e DEN BESTEN \& CRENSHAW ${ }^{41}$ como a fase responsável pelo aparecimento da fluorose dentária, enquanto KEMPF \& McKAY ${ }^{84}$ e ROZIER \& DUDNEY ${ }^{150}$ apontam o estágio de secreção da atividade ameloblástica como a fase responsável.

\subsection{Concentração de flúor no esmalte e fluorose dentária}

Nas duas últimas décadas, a relação entre o nível de flúor no esmalte, cárie dentária e grau de severidade de fluorose tem recebido especial atenção (AASENDEN et al. ${ }^{3}$; VAN DER MERWE et al. ${ }^{178}$; SCHAMSCHULA et al. ${ }^{154}$; GROEBLER, VAN WYK \& KOTZE ${ }^{67}$ ), embora as conclusões sejam muito conflitantes devido a algumas variáveis (FEJERSKOV, THYLSTRUP \& LARSEN $^{s 5}$ ):
a) profundidade de esmalte da amostra
b) técnica da amostra
c) idade do dente
d) variação de área para área na superficie do dente.

KIDD et al. ${ }^{85}$, estudando 3 localidades com concentrações de flúor nas águas de 0,2 (baixa concentração), 1,4(ótima) e 3,6 ppm F(alta), na Dinamarca, utilizando biópsia das cúspides de pré-molares, encontraram uma similar concentração de flúor no esmalte, nas áreas com concentrações baixa e ótima de flúor, porém na área com concentração alta de flúor havia diferenças estatisticamente significantes em relação às outras áreas estudadas, sendo que esta conclusão foi concorde com estudos de GROEBLER, VAN WYK \& KOTZE ${ }^{67} \mathrm{e}$ VAN DER MERWE et al. ${ }^{178}$. 
A medida que aumenta a severidade da fluorose dentária, a concentração de flúor no esmalte não só aumenta superficialmente, como também em camadas mais profundas (RICHARDS, FEJERSKOV \& BAELUM ${ }^{143}$ ), sendo esta conclusão contraditória com a de OLSEN \& JOHANSEN ${ }^{129}$, que não verificaram nenhuma associação entre concentração de flúor no esmalte mais superficial $(100 \mathrm{vm})$ e fluorose.

\subsection{Diagnóstico diferencial de formas leves de fluorose e opacidades de origem não fluorótica}

O diagnóstico diferencial de formas leves de fluorose, em relação às opacidades de esmalte de origem não fluorótica, tem sido um problema, principalmente para examinadores inexperientes em epidemiologia da fluorose dentária.

Algumas classificações de opacidades têm sido baseadas somente na aparência clínica da lesão (YOUNG ${ }^{188}$; AL-ALOUSI et al. ${ }^{6}$; JACKSON, JAMES \& WOLFE ${ }^{80}$; MURRAY \& SHAW ${ }^{124}$ ), enquanto alguns autores propõem classificações de defeitos de esmalte (AINAMO et al. ${ }^{4}$; SUCKLING \& PEARCE ${ }^{167}$ ) baseadas em considerações etiológicas (SMALL \& MURRAY ${ }^{161}$ ).

Alguns autores (ZIMMERMAN ${ }^{189}$; RUSSEL ${ }^{151}$; NEVITT, FRANKEL \& WITTER ${ }^{126}$ e CUTRESS \& SUCKLING ${ }^{30}$ ) propuseram critérios para o diagnóstico diferencial de opacidades de esmalte não fluorótico e formas leves de fluorose dentária.

A relação entre prevalência de fluorose dentária e opacidades de esmalte foi feita por WENZEL \& THYLSTRUP ${ }^{182}$ que examinaram crianças de três comunidades da Dinamarca com concentrações de $0,2 \mathrm{ppmF}, 1,0 \mathrm{ppm} F$ e 2,4 ppm, encontrando uma prevalência de fluorose de $5 \%, 52 \%$ e $93 \%$, ao passo que as prevalências de opacidades não fluoróticas foram de $43 \%, 37 \%$ e $33 \%$, concluindo que a diminuição proporcional de opacidades localizadas de esmalte em relação ao aumento da prevalência da fluorose dentária pode indicar que as porosidades do esmalte, induzidas pelo flúor, mascaram as localizações das opacidades. Outros autores constataram a mesma relação, estudando áreas com concentrações de flúor nas águas de abastecimento, próximas ao estudo citado (FORREST \& JAMES ${ }^{60}$; RICHARDS et al. ${ }^{146}$; GASPAR, PEREIRA \& MOREIRA ${ }^{64}$ ). 


\subsection{Características clínicas}

Com relação às características clínicas da fluorose dentária, pode-se tecer alguns comentários sobre sua distribuição. A fluorose dentária apresenta distribuição simétrica na boca, como comprovado por estudos de DEAN ${ }^{33}$; LARSEN et al. ${ }^{93}$; FEJERSKOV, MANJI \& BAELUM ${ }^{54}$.

TYLSTRUP \& FEJERSKOV ${ }^{13}$ afirmaram que a probabilidade de se obter um par homólogo de superficies, onde pode haver desvio de mais ou menos 1 categoria (o índice T-F apresenta 9 categorias), em relação à superficie do lado oposto é de $85 \%$, enquanto WENZEL \& THYLSTRUP ${ }^{182}$ encontraram uma probabilidade de $97,7 \%$ e MANJI, BAELUM \& FEJERSKOV ${ }^{109}$ constataram uma probabilidade de $93 \%$.

Em princípio, seria esperado que todas as superficies de um determinado dente apresentassem um mesmo grau de fluorose, porém como as várias superficies são inevitavelmente expostas aos diversos fatores pós-eruptivos, não se deveria esperar que o mesmo índice fosse fixado para todas as superficies nos dentes expostos ao meio bucal, no mesmo período (EKSTRAND, FEJERSKOV $\&$ SILVERSTONE ${ }^{48}$.

WENZEL \& THYLSTRUP ${ }^{182}$ afirmaram que as superficies vestibulares eram as que apresentavam maior severidade de fluorose enquanto que THYLSTRUP \& FEJERSKOV ${ }^{173}$ mostraram que as superficies linguais dos molares e pré-molares superiores apresentavam-se mais afetadas.

NANDA et al. ${ }^{125}$, mostraram que os caninos, pré-molares e segundos molares da dentição permanente eram os dentes mais afetados pela fluorose dentária, enquanto MOLLER ${ }^{120}$ afirma que os mais afetados eram os pré-molares, segundos molares, incisivos superiores e caninos, respectivamente, sendo que os incisivos inferiores foram os menos afetados. Esta distribuição se apresentou similar às de HOROWITZ et al. ${ }^{75}$, BURGER et al. ${ }^{18}$, LESAN $^{96}$ e GASPAR, PEREIRA \& MOREIRA ${ }^{64}$, enquanto outros estudos apontam os incisivos superiores como os mais afetados (MOLLER et al. ${ }^{122}$; POULSEN \& MOLLER ${ }^{139}$ ).

CLEATON-JONES \& HARGREAVES ${ }^{28}$ e THYLSTRUP \& FEJERSKOV ${ }^{173}$ concluíram que os dentes da arcada superior foram os mais afetados pela fluorose dentária.

A fluorose dentária na dentição primária geralmente foi citada como menos severa em relação à dentição permanente (FEJERSKOV, THYLSTRUP \& LARSEN ${ }^{55}$ ), sendo esta constatação atribuída à barreira placentária ao flúor

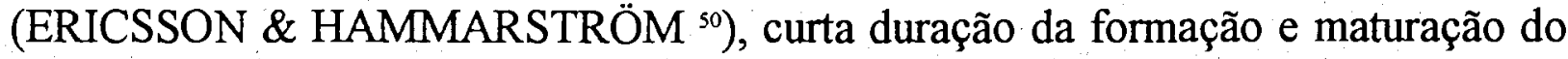


esmalte dos dentes decíduos ( THYLSTRUP ${ }^{\prime \prime}$; MOLLER ${ }^{120}$ ) ou pela espessura do esmalte (THYLSTRUP \& FEJERSKOV ${ }^{173}$ ).

Os dentes mais severamente afetados pela fluorose dentária na dentição decídua são os segundos molares de acordo com THYLSTRUP ${ }^{17}$, enquanto os primeiro molares, caninos e incisivos, respectivamente, foram os mais afetados no estudo de BURGER et al. ${ }^{18}$.

Conforme as faixas etárias de estudo, verifica-se um padrão diferente de severidade da fluorose. HOROWITZ et al. "s, utilizando o índice TSIF, examinaram crianças em duas faixas etárias distintas, sendo que os primeiros molares e incisivos, em crianças de 8 a 10 anos, eram mais afetados pela fluorose, que os mesmos dentes de crianças nas idades de 13 a 16 anos, concluindo que crianças em faixas etárias mais avançadas tinham uma prevalência e severidade de fluorose menores que crianças mais jovens, podendo este fato ocorrer devido a fatores pós-eruptivos, principalmente à gradual abrasão ou contínua mineralização no decorrer do tempo na superficie do esmalte (AASENDEN \& PEEBLES ${ }^{2}$ ), enquanto HEIFETZ et al. ${ }^{70}$ salientaram que crianças mais jovens têm uma maior disponibilidade de fluoretos durante a fase de mineralização dos dentes (fórmulas infantis, ingestão de dentrifrícios fluoretados, suplementação de flúor na dieta ou suplementação prescrita sem conhecimento do total de fluoretos já presentes nas águas de consumo).

ISMAIL et al. ${ }^{79}$ e MOLLER \& POULSEN ${ }^{121}$. não verificaram nenhuma diferença estatisticamente significante entre a prevalência de fluorose em relação ao sexo dos examinados.

\subsection{Variáveis que afetam a fluorose}

\section{A) Fator nutricional}

O fator nutricional é um ponto polêmico em relação à fluorose dentária. Estudos em países em desenvolvimento (NANDA et al. ${ }^{125}$; MOLLER et al. ${ }^{122}$; MANJ, BAELUM \& FEJERSKOV ${ }^{109}$ ) têm encontrado uma prevalência maior que o esperado, sendo isto explicado, segundo os autores, pela menor freqüência de ingestão de refeições das crianças nestes países em relação a países desenvolvidos, ocorrendo casos com somente uma ou menos refeição/dia, sendo o flúor absorvido diretamente no estômago vazio, o que favoreceria uma absorção maior (FEJERSKOV, MANJ \& BAELUM ${ }^{54}$ ). Contudo tal relação necessita ser melhor explorada (FEJERSKOV et al. ${ }^{58}$ ). 


\section{B) Aspecto sócio-econômico}

O aspecto sócio-econômico, em relação à fluorose, foi abordado por ISMAIL et al. ${ }^{79}$, utilizando o índice TSIF em crianças de duas cidades (Sherbrooke, $0,1 \mathrm{ppm} F$ e Trois-Riviere, 1,0 ppm F nas águas de consumo), escolares provenientes de escolas públicas e privadas, constatando prevalências de $31,1 \%$ e $30,1 \%$ na cidade de Sherbrooke e $45,6 \%$ e $58,0 \%$ em Trois-Riviere, respectivamente, sendo que na cidade de Trois-Riviere houve diferença estatisticamente significante entre os escolares das duas escolas.

PENDRYS \& KATZ ${ }^{136}$, comparando famílias com ganhos médios anuais entre 1800 a 3800 dólares em relação a famílias com ganhos anuais maiores de 18000 dólares, concluíram que uma exposição a suplementos de flúor, combinada com um maior status sócio-econômico, conferiram maior risco de desenvolvimento de fluorose dentária.

NUNN et al. ${ }^{128}$ e ELLWOOD \& O'MULLANE ${ }^{49}$ destacaram que crianças pertencentes a classes sociais privilegiadas apresentavam prevalências maiores de opacidades de esmalte difusas, medidas pelo índice DDE, índice de Desenvolvimento de Defeitos de Esmalte (AINAMO et al. ${ }^{4}$ ), característico da fluorose dentária.

\section{C) Temperatura}

A influência da temperatura na prevalência de fluorose tem sido largamente investigado na literatura (DEAN ${ }^{34}$; GALAGAN \& VERMILLION ${ }^{63}$; RICHARDS et al. ${ }^{145}$ ), mas nos últimos anos foram verificadas prevalências altas em áreas com baixas concentrações de flúor nas águas de abastecimento. MANJ, BAELUM \& FEJERSKOV ${ }^{109}$ e MANJ et al. "10 levantaram diversas hipóteses, ainda em estudo, sobre possiveis explicações a este fato: aumento de ingestão de flúor em consequência do aumento do consumo de água em zonas de alta temperatura, resultado de práticas dietéticas das populações em questão e contribuição do fator de má-nutrição. (FEJERSKOV et al. ${ }^{58}$ ).

\section{D) Inalação de gases}

A susceptibilidade do indivíduo à fluorose dentária pode ser aumentada através da inalação de gases com altas concentrações de flúor. A poeira de rochas fosfáticas, usadas na produção de fertilizantes e criolita (utilizada para produção de alumínio), pode conter flúor em concentrações acima de $4,2 \%$ ou 42000 ppm. Outros produtos industriais foram estudados por SAVARA, NOYES \& SUHER ${ }^{153} \mathrm{e}$ WHO ${ }^{187}$, concluindo que estes produtos podem liberar na atmosfera gases com 
concentrações tão altas capazes de aumentar a prevalência e severidade da fluorose dentária nas populações residentes nessa região.

MOLLER \& POULSEN ${ }^{121}$, examinando 707 crianças de 7 a 14 anos, cidade de Khouribga (Marrocos),as quais estavam expostas à liberação de gases, contendo uma concentração de flúor de $2 \%(20000 \mathrm{ppm})$, verificaram uma prevalência média entre as idades de $96,6 \%$, sendo muito alta em relação à baixa concentração de flúor nas águas de consumo $(0,38 \mathrm{ppm})$.

\section{E) Altitude}

A correlação entre altitude e prevalência de fluorose dentária foi primeiramente estudada por MANJ et al. ${ }^{110,111}$, que verificaram altas prevalências de fluorose em populações de altas altitudes no Kenya, em comparação àquelas de baixas altitudes, para uma concentração padronizada de flúor nas águas de abastecimento. Os autores verificaram ainda que dieta e temperatura média anual não pareciam afetar as variações observadas em prevalência e severidade da fluorose dentária, concluindo que condições hipobáricas, em altas altitudes, poderiam causar mudanças fisiológicas, as quais exacerbariam o efeito tóxico do flúor durante a formação do esmalte dentário.

\section{F) Flúor - Tabletes}

A ingestão de flúor através dos diferentes métodos de prevenção da cárie dentária e a sua relação com fluorose dentária têm recebido atenção nas duas últimas décadas. Tabletes e drops de flúor, utilizados como método alternativo de administração sistêmica de flúor em áreas com águas de consumo não fluoretada, podem ser considerados um fator de risco da fluorose dentária.

AASENDEN \& PEEBLES ${ }^{1}$ encontraram uma prevalência de $84 \%$ de fluorose em crianças que ingeriam tabletes de flúor $(1 \mathrm{ppm} \mathrm{F})$ e $63 \%$ em crianças que residiam em áreas com águas de consumo com concentração ótima de flúor para a região.

HOLM \& ANDERSSON ${ }^{22}$, estudando crianças de 12 anos de idade, com conhecida exposição ao flúor por consumo de tabletes fluoretados, desde os anos iniciais de vida, verificaram uma prevalência de $81 \%$ de fluorose naquelas que iniciaram o consumo aos 6 meses de idade, $59 \%$ nas que iniciaram aos 12 meses e $38 \%$ nas que iniciaram após 24 meses, acrescentando que havia uma probabilidade de $5.4,3.9$ e 2.3 vezes maior de apresentar fluorose, nos três grupos, 
respectivamente, em relação ao grupo de crianças que não tinham sido expostas a nenhum recurso de flúor.

THYLSTRUP et al. ${ }^{175}$, avaliando crianças de 7 anos de idade na Dinamarca, as quais ingeriram tabletes, contendo $1 \mathrm{ppm}$ de flúor, desde os cinco anos de idade, verificaram que houve uma maior prevalência de fluorose nestas crianças, em comparação às do grupo controle, que não eram expostas ao flúor.

Investigando o consumo de tabletes com flúor em crianças de 3 a 12 anos de idade $(0,5 \mathrm{mg} /$ dia do nascimento à idade de 3 anos e $1 \mathrm{mg} /$ dia dos 3 aos 12 anos), HARGREAVES et al. ${ }^{69}$ verificaram que $52 \%$ das crianças apresentavam fluorose ,comparado com $15 \%$ das crianças do grupo controle não expostas ao flúor.

ANDERSON \& GRAHNEN ${ }^{8}$, estudando crianças de 8 a 10 anos de idade na Suécia, após o consumo de tabletes com flúor durante os cinco primeiros anos de vida e GRANATH, WIDENHEIN \& BIRKHED ${ }^{66}$, obtendo amostra de crianças de 13 anos de idade, as quais consumiram tabletes com flúor por no mínimo 5 anos (entre 0,5 a 6 anos de idade), não verificaram nenhum aumento da prevalência de fluorose dentária, em comparação ao grupo controle.

\section{G)Flúor- Dentifrícios}

Com relação aos dentifrícios fluoretados, OSUJI et al. ${ }^{134}$, estudando crianças de 8 a 10 anos de idade no Canadá, encontraram um risco relativo de presença de fluorose dentária, onze vezes maior em crianças que escovavam os dentes com pastas dentais fluoretadas, desde os 25 meses de idade, comparada com crianças que iniciavam a escovação com estas pastas, em períodos posteriores.

A associação entre o consumo de dentifrícios fluoretados e o aumento das prevalências de fluorose dentária foi verificada também por PENDRYS \& KATZ ${ }^{136}$, WOLGENS, ETTY \& NIEWLAND ${ }^{186}$, SKOTOWSKY et al. ${ }^{160}$, LEVY \& ZAREI $^{102}$ e LALUMANDIER ${ }^{89}$.

Porém,HOUWINK \& WAGG ${ }^{76}$, HOLM \& ANDERSSON ${ }^{72}$, LEVINE, BEAL \& FLEMING ${ }^{99}$, RIORDAN \& BANKS ${ }^{147}$, RIPA ${ }^{148}$ e CLARK ${ }^{24}$ não encontraram evidências de que o uso de flúor em dentifrícios possa ser capaz de produzir níveis não aceitáveis de fluorose dentária.

STOOKEY ${ }^{166}$ fez uma revisão sobre a influência dos dentifrícios fluoretados como fator de risco da fluorose dentária, conforme resumo abaixo (Tabela 1). 
Tabela 1. Revisão de estudos sobre a influência dos dentifrícios como fator de risco da fluorose.

\begin{tabular}{|c|c|c|}
\hline Autores & Faixa etária de estudo & Associação \\
\hline HOUWINK \& WAGG $^{16}$ & $9-12$ & NEGATIVO \\
\hline HOLM \& ANDERSSON & 12 & NEGATIVO \\
\hline LEVINE, BEAL \& FLEMING ${ }^{99}$ & & NEGATIVO \\
\hline RIORDAN \& BANKS ${ }^{147}$ & $9-11$ & NEGATIVO \\
\hline RIPA ${ }^{148}$ & -...-..- & NEGATIVO \\
\hline CLARK $^{24}$ & $-\cdots$ & NEGATIVO \\
\hline PENDRYS \& KATZ ${ }^{136}$ & $11-14$ & POSITIVO \\
\hline OSUJI et al. ${ }^{134}$ & $11-14$ & POSITIVO \\
\hline $\begin{array}{l}\text { WOLGENS, } \\
\text { NIEWLAND }{ }^{186}\end{array}$ & $6-12$ & POSITIVO \\
\hline SKOTOWSKY et al. ${ }^{160}$ & crianças & POSITIVO \\
\hline LEVY \& ZAREI 102 & crianças & POSITIVO \\
\hline LALUMANDIER $^{89}$ & $5-19$ & POSITIVO \\
\hline
\end{tabular}

Fonte: STOOKEY ${ }^{166}$

\section{H)Flúor- Suplementação}

ISMAIL ${ }^{78}$ afirmou que os suplementos de flúor são um fator de risco da fluorose dentária, embora sua contribuição seja menor que a da água de consumo e dos dentifrícios fluoretados, devido ao seu consumo menor e mais limitado. Acrescentou, ainda, que os níveis ótimos de flúor em bebidas consumidas de áreas não fluoretadas aumentam $o$ questionamento se suplementos de flúor são necessários nos anos 90 , e se esta é a hora de se considerar a quantidade total de flúor consumido, não apenas da água de consumo, mas também de comidas, bebidas e dentifrícios, os quais, associados com os suplementos de flúor prescritos, podem aumentar o risco da fluorose dentária.

\section{I)Flúor- Bochechos Fluoretados}

SZPUNAR \& BURT ${ }^{168}$, OSUJI et al. ${ }^{134}$, RIPA ${ }^{148}$ e JOHNSTON ${ }^{81}$ não encontraram elementos que permitissem associar o uso de bochechos fluoretados com aumento da prevalência de fluorose dentária, enquanto BOHATY et al. ${ }^{16}$ discordaram dessa afirmação. 


\section{J)Flúor- Aplicação Tópica de flúor}

STOOKEY ${ }^{166}$, revendo a aplicação profissional de flúor (NaF $2 \%, \mathrm{NaF}$ $1,1 \%$, APF $1,23 \%$, SnF2 $8 \%$ e SnF2 0,4\%) como fator de risco da fluorose dentária, verificou que não havia associação entre aplicação tópica de flúor e aumento da prevalência de fluorose, concorde com as afirmações de LARSEN et al. ${ }^{92}$, BUTLER, SEGRETO \& COLLINS ${ }^{19}$, OSUJ et al. ${ }^{134}$, SZPUNAR \& BURT ${ }^{169}$, RIPA ${ }^{148}$ e JOHNSTON ${ }^{81}$, enquanto BELL et al. ${ }^{11}$ e BOHATY et al. ${ }^{16}$ afirmam haver suporte para a associação das aplicações tópicas de flúor como fator de risco do aparecimento da fluorose dentária.

\section{L) Flúor - Produtos Alimentícios}

Produtos alimentícios têm sido relatados como fatores que poderiam afetar a prevalência da fluorose dentária. MYERS ${ }^{123}$ afirma que no peixe, especialmente o salmão e sardinhas enlatadas, cujos ossos e espinhas são ingeridos, havia uma quantidade de flúor acima de $20 \mathrm{ppm}$. Todavia, mesmo numa situação de relativo alto consumo de peixe, não excederia $0,2 \mathrm{mg}$ de flúor por dia. As plantas (vegetais e frutas) podem ter quantidades de flúor na dieta, que variam de 0,1 a 0,4 ppm, providenciando pouca quantidade do halógeno, sendo que a quantidade de flúor em dietas sólidas variam de 0,6 a $0,7 \mathrm{mg}$ em áreas não fluoretadas, e aproximadamente de 1,3 a 2,2 mg diárias em áreas fluoretadas.

McCLURE ${ }^{115}$ afirma que a dieta sólida pode contribuir no máximo com $0,27 \mathrm{mg}$ de flúor ao dia e PURCZINSKY et al. ${ }^{141}$, estudando os produtos sólidos e líquidos, utilizados na alimentação de crianças e jovens, constataram uma concentração média de $0,24 \mathrm{ppm}(0,17-0,32 \mathrm{ppm})$, concluindo que a quantidade de flúor presente nestes produtos não seria suficiente para aumentar a susceptibilidade do indivíduo à fluorose dentária.

\section{M) Flúor - Bebidas}

A quantidade de flúor presente em bebidas (excetuando-se as águas de abastecimento público) tem sido estudada em seus diferentes componentes. MOLLER ${ }^{120}$ afirma que o leite é um produto de nível baixo e constante de flúor, na ordem de 0,1 a $0,2 \mathrm{ppm}$ de flúor, embora formulações feitas com leite evaporado e leite contendo água de torneira( $1 \mathrm{ppmF}$ ) podem atingir níveis de $0,9 \mathrm{ppm} \mathrm{F}$. 
LARSEN et al. ${ }^{94}$, estudando duas localidades (Narssaq, Groelândia com 1,1 ppm F e Vordingborg, Dinamarca com 1,4 a 1,6 ppm F nas águas de consumo), nas quais utilizavam leite em suspensão com água, contendo 0,05 a 0,16 ppm F ionizával (Narssaq) e leite natural (Vordingborg), constataram que na primeira foi encontrada uma prevalência maior de fluorose na dentição primária, em comparação com Vordingborg. Com relação à dentição permanente, os incisivos centrais e laterais apresentavam as maiores prevalências em Narssaq, enquanto na

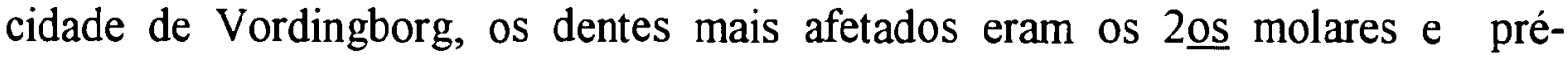
molares. Essas diferenças podem ser explicadas pelo consumo mais freqüente de leite nos anos iniciais da vida, portanto esclarece a alta prevalência de fluorose na dentição primária na cidade de Narssaq, que utilizava leite com altas concentrações de flúor. No entanto, com o decorrer do tempo e a diminuição do consumo do leite, esta prevalência atinge niveis normais.

As folhas de chá acumulam flúor derivado do solo, podendo ser liberado pela infusão do mesmo, sendo responsável por eventuais contribuições na quantidade de flúor total consumido diariamente.

DUCKWORTH \& DUCKWORTH ${ }^{45}$ pesquisaram o hábito do consumo de chá de 213 britânicos, calculando a quantidade média de flúor consumido por dia, a qual variou de $0,3 \mathrm{mg}$ em crianças menores de 7 anos de idade a $0,85 \mathrm{mg}$ nas idades posteriores.

SHCHORI et al. ${ }^{157}$ encontraram altas concentrações de flúor nas superficies molares de ratos, os quais tinham chá como fonte líquida de consumo, em comparação com grupos controle.

MANN et al. ${ }^{112}$, estudando 475 jovens árabes, nas idades de 6 a 8 anos e 16 a 18 anos, encontraram uma correlação positiva entre o número de copos de chá consumidos ao dia $(0,2 \mathrm{mg} F$ por copo) com o aparecimento de sinais de fluorose e redução das médias do índice CPOD. Esses estudos têm sugerido que consumidores de grandes quantidades de chá teriam relativamente menores níveis de cárie dentária, os quais deveriam ser acompanhados de prevalências maiores de fluorose.

Sucos de frutas frescas têm uma quantidade pequena de flúor, entre 0,1 a 0,3 ppm de flúor, sendo que os sucos de frutas reconstituídos com água fluoretada variavam de 0,3 a $2,5 \mathrm{ppm}$, concluindo-se que a quantidade de flúor ingerida por dia seria insuficiente para produzir sinais de fluorose (MOLLER ${ }^{120}$ ). 


\section{N) Flúor- Fórmulas Infantis}

Com relação à quantidade e concentrações de flúor em fórmulas infantis, PENDRYS \& STAMM ${ }^{131}$ verificaram que a média nas concentrações de flúor é menor que em estudos da década anterior, sendo que nenhuma alta concentração foi verificada, discordante dos dados de STAMM \& KUO ${ }^{164}$, SINGER, OPHANG \& HARLAND ${ }^{159}$ e DABEKA et al. ${ }^{31}$ que encontraram altas concentrações de flúor em alguns produtos. Verificaram ainda que fórmulas infantis oleosas apresentam maiores concentrações de flúor que as fórmulas leitosas, enquanto fórmulas preparadas com água fluoretada contêm substancialmente maiores concentrações de flúor, comparadas com fórmulas diluídas em água não fluoretada.

McKNIGHT-HANES et al. ${ }^{118}$ concluíram que há necessidade de se reconsiderar a definição da concentração ótima de flúor nos seus modos de administração, pois a natureza da dieta infantil (tipo de fórmula, consumo de flúor total, nível de flúor na água de consumo utilizado no preparo destas fórmulas) pode apresentar-se como risco potencial de fluorose, sendo esta idéia confirmada por LEVERETT ${ }^{s}$.

\subsection{Epidemiologia}

DEAN ${ }^{34}$ examinou crianças de 12-14 anos de idade, oriundas de 21 localidades de 5 estados americanos, com concentrações entre 0,0 a 2,6 ppm F, observando que as percentagens de crianças afetadas pela fluorose dentária variavam de $0,2 \%$ (Waukegan, $\mathrm{IL}-0,0 \mathrm{ppm} \mathrm{F}$ ) a $73,8 \%$ (C. Springs, Co - 2,6 ppm F), (Tab. 2).

MASSLER \& SHOUR ${ }^{114}$, examinando crianças em idade escolar, residentes em Campagno de Roma e Quarto (Itália) contendo 1,3 ppm F em suas águas de abastecimento, verificaram uma prevalência de crianças afetadas pela flurose de $58 \%$ (Tab. 5).

FORREST ${ }^{s 9}$ examinou crianças das cidades de Harwich $(2,0$ ppm F) (Tab.5) e Slough $(0,9 \mathrm{ppm}$ F)(Tab. 6) e verificou que a prevalência de crianças afetadas pela fluorose era de $66 \%$ e $19 \%$, respectivamente.

PU \& LILIENTHAL ${ }^{140}$ examinaram crianças de Formosa, em idade escolar, em comunidades contendo 1,6 ppm $\mathrm{F}(\mathrm{tab} .5), 0,7$ e $0,9 \mathrm{ppm} \mathrm{F}$ (cidades a e $\mathrm{b}$ -Tab. 6), além de outra com $<0,3 \mathrm{ppm} \mathrm{F}$ (Tab. 7), verificando que $84 \%, 54 \%, 83 \%$ 
e $15 \%$ das crianças da amostra eram afetadas pela fluorose dentária, respectivamente.

GALAGAN \& VERMILLION ${ }^{63}$ e SEGRETO et al. ${ }^{156}$ examinaram crianças em idade escolar, 12-14 anos de idade, nascidas e residentes em 16 comunidades do Texas com concentrações de flúor variando de 0,3 a 4,3 fator da concentração ótima de flúor (Tab. 4), sendo que SEGRETO et al. ${ }^{156}$ concluíram que havia uma prevalência maior de fluorose dos estudos da década de 80 em relação aos da década de 40 , porém com padrão semelhante com relação à severidade.

FORREST \& JAMES ${ }^{60}$ examinaram crianças de 8 anos de idade, as quais residiam desde o nascimento nas zonas de Gualchmai (área fluoretada - Tab. 6) e Bodafon (área controle sem flúor - Tab. 7), localizadas na cidade de Anglesey (Inglaterra), observando prevalências de fluorose de $11 \%$ nas duas áreas estudadas, concluindo que não havia diferenças estatisticamente significantes entre as áreas fluoretadas e não fluoretadas.

UCHOA \& SALIBA ${ }^{176}$, utilizando o índice de DEAN para fluorose observaram em Pereira Barreto no Estado de São Paulo, uma área com concentrações de fluoretos de até vinte ppm. $O$ índice de fluorose médio foi 1,3 considerado baixo para as altas concentrações de fluoreto na água de consumo, sendo explicado pela grande percentagem de crianças que não ingeriam água de torneira, devido ao gosto desagradável.

Examinando crianças de 10 anos de idade, nascidas e residentes em Carinthia, 1,0 ppm F(cidade a-Tab. 6); Tyrolia, 1,5 ppm F(cidade b) e Umhausen, $1,8 \mathrm{ppm} F$ (cidade $\mathrm{c}$ - Tab. 5), BINDER ${ }^{13}$ verificou que, respectivamente, 18, $48 \mathrm{e}$ $52 \%$ das crianças apresentavam sinais de fluorose dentária.

Crianças de 8-10 anos de idade, nascidas e residentes em áreas com concentrações de flúor em torno de 1,0 ppm $\mathrm{F}$ (Tab. 6), foram observadas por FORSMAN ${ }^{\circ 1}$, o qual concluiu que $64 \%$ das crianças eram afetadas pela fluorose dentária.

NANDA et al. ${ }^{125}$ investigaram a presença de fluorose dentária em uma amostra que consistia de escolares com idade entre 6 e 17 anos, oriundos da cidade de Lucknow e 23 vilarejos do Distrito de Lucknow(Índia), com concentrações de flúor acima de 1,2 ppm $\mathrm{F}$, observando altas prevalências de fluorose dentária, ou seja, $41 \%$ (cidade de Lucknow) e $54 \%$ (Distrito de Lucknow), (Tab. 5).

A prevalência de fluorose dentária em Khouribga $(0,3 \mathrm{ppm} \mathrm{F})$, Marrocos, foi estimada por MOLLER \& POULSEN ${ }^{121}$ (Tab. 7), ao examinarem crianças de 7-14 anos de idade, encontrando os sinais deste problema em $91 \%$ da 
amostra, em contrastre com a baixa concentração de flúor na água de consumo, devido à inalação de gases contendo altas concentrações de flúor.

ANDO $\%$, utilizando o índice de DEAN, examinou 175 escolares e constatou que $88 \%$ das crianças examinadas apresentavam fluorose dentária. Este estudo foi realizado em Cosmópolis (SP- Brasil) cujas concentrações de flúor variavam entre 9,0 e $11,0 \mathrm{ppm} F$.

GOWARD ${ }^{65}$ examinou crianças em idade escolar, nascidas e residentes em comunidades não fluoretadas, verificando que cerca de $10 \%$ das crianças eram afetadas pela fluorose dentária (Tab. 7).

BISHOFF et al. ${ }^{14}$, examinando adolescentes de 14 a 23 anos de idade que residiam em Sailspoot (África do Sul), área com alta concentração de flúor nas águas de abastecimento que atingiam até $6,16 \mathrm{ppm} \mathrm{F}$, verificaram uma prevalência de $83 \%$ em crianças da amostra (Tab. 5).

ALCAIDE \& VERONEZI ${ }^{7}$ examinaram 449 crianças, ambos os sexos, 7 a 14 anos de idade, nascidas e criadas em Icém (São Paulo-Br) que ingeriam água de consumo com concentração de flúor que variava de 2,6 a $4,0 \mathrm{ppm}$ flúor, verificando que $84,7 \%$ das crianças apresentavam algum grau de fluorose.

LEVERETT ${ }^{97}$ reportou os resultados de um estudo da prevalência de fluorose dentária em crianças de 7-17 anos de idade, oriundas de comunidades fluoretadas (Tab. 6) e não fluoretadas (Tab. 7). Uma modificação do índice de DEAN (1934) foi utilizada, onde a categoria "Questionável" era anexada dentro da categoria "Normal", para cálculo da prevalência. $\mathrm{O}$ autor concluiu que a prevalência de fluorose com relação às categorias "muito leve"e "leve" eram 3,5 vezes maiores em áreas não fluoretadas e duas vezes maiores em comunidades fluoretadas, quando comparados os dados da década de 80 com os originais da década de 40 .

WENZEL \& THYLSTRUP ${ }^{182}$ verificaram prevalências de superficies afetadas de 3, 47 e $89 \%$, nas localidades de Ry ( $<0,2$ ppm F- cidade a), Naestved ( $1,0 \mathrm{ppm}$ F - cidade b) e Greeve $(2,4 \mathrm{ppm}$ F), Dinamarca, em uma amostra constituída por adolescentes de 12-14 anos de idade (Tab. 8).

Foram examinadas por DRISCOLL et al. ${ }^{43}$ crianças nas idades de 8-16 anos, nascidas e residentes em cidades com altas concentrações de flúor(duas vezes a concentração ótima) nas águas de consumo, no Estado de Illinois (EUA), observando uma prevalência de $53 \%$ (Tab. 5) das crianças com fluorose dentária. Este estudo foi completado posteriormente por DRISCOLL et al. ${ }^{44}$, que examinaram crianças em cidades dos Estados de Iowa e Illinois, com concentrações 
ótima e baixa de flúor nas águas de consumo, verificando uma prevalência de $15 \%$ (Tab. 6) e 2,9\% (Tab. 7) das superficies afetadas pela fluorose.

HOROWITZ et al. ${ }^{\text {is }}$ (Tab. 9), no estudo que deu origem ao TSIF, examinaram crianças de 8-16 anos de idade, nascidas e residentes em comunidades do Estado de Illinois (EUA), agrupadas pela concentração de flúor nas águas de consumo, ou seja: a) concentração ótima de flúor e b) duas vezes o fator ótimo de flúor, verificando que um total de $15,5 \%$ e $41,8 \%$ das superficies eram afetadas na áreas a e b, respectivamente.

Crianças de 6-13 anos de idade, nascidas e residentes em Greeland $(0,1 \mathrm{ppm}$ F), Dinamarca, foram examinadas por LARSEN, RICHARDS \& FEJERSKOV ${ }^{91}$, observando que $10,0 \%$ das superficies dentárias apresentaram sinais de fluorose dentária(índice $\mathrm{T}-\mathrm{F}>0$ ).

PENDRYS et al. ${ }^{138}$ examinaram crianças de $5 \underline{a}$ e 6 a séries do curso inicial, nascidas e residentes em cidades sem flúor nas águas de abastecimento(EUA), estimando uma prevalência de $25,2 \%$ na amostra .

MANJI et al. ${ }^{110}$ (Tab. 8), observaram crianças nascidas e residentes no distrito rural de Machakas, Kenia, idades entre 11 e 15 anos de idade, agrupadas em duas áreas: área a $(0,10-0,46 \mathrm{ppm} \mathrm{F})$ apresentava $78,1 \%$ das crianças com sinais de fluorose em comparação com $91,2 \%$ na área b (0,53-0,66 ppm F); enquanto MANJI et al. "', observaram que $100 \%$ das crianças residentes no vilarejo de Nyandawa(Kenia), localizada a $2400 \mathrm{~m}$ de altitude, apresentavam algum sinal de fluorose.

SZPUNAR \& BURT ${ }^{168}$ examinaram crianças , 6-12 anos de idade, de quatro cidades do Estado de Michigan (EUA), cujas áreas eram divididas de acordo com as concentrações de flúor na água de consumo, ou seja: área a: concentrações baixas $(<0,2 \mathrm{ppm} \mathrm{F})$; áreas $\mathrm{b}, \mathrm{c}$, d(concentração ótima para as localidades) (Tab. 9). Os resultados demonstraram significantes diferenças na prevalência de fluorose dentária entre comunidades fluoretadas e comunidades com concentrações de flúor abaixo do teor ótimo.

Em 1980 e 1985, foram examinadas por HEIFETZ et al. ${ }^{70}$ crianças de 13-15 anos de idade que viveram desde o nascimento em suas respectivas comunidades(Estado de Illinois e Iowa, EUA). Essas comunidades, de acordo com as concentrações de flúor nas águas de consumo, foram agrupadas em: com o fator ótimo de flúor e duas vezes o fator ótimo de flúor. Observou-se que, em 1980, as prevalências por superficies eram de $38,3 \%$ (duas vezes a concentração ótima) e 11,4 \% (concentração ótima). Em 1985 verificou-se um total de 66,5 \% (duas vezes 
a concentração ótima) e 29,4 \% (conc. ótima) afetadas pela fluorose dentária (Tab. 9).

OSUJI et al. ${ }^{134}$ examinaram crianças de 8-10 de idade em comunidades fluoretadas $(0,95 \mathrm{ppm}$ F) de East York, Ontario(Canadá), observando uma prevalência total de superficeis afetadas de $12,9 \%$ (Tab. 8).

KUMAR et al. ${ }^{88}$, examinando crianças na idade escolar, no ano de 1985, provenientes de Newburgh (concentração ótima - Tab. 6) e Kingston (concentrações baixa de flúor - Tab. 7) do Estado de New York (EUA), verificaram prevalências de 9,0 e $9,2 \%$, respectivamente, concluindo que não havia diferenças estatisticamente significantes entre as prevalências de fluorose dentária das amostras oriundas de comunidades fluoretadas em relação às não fluoretadas.

WOLFOLK, FAJA \& BAGRAMIAN ${ }^{185}$ analisaram dados de escolares, 9-13 anos de idade, oriundas de comunidades rurais em Michigan, utilizando o TSIF modificado. Os resultados demonstraram que $22,3 \%$ das crianças e $6,9 \%$ das superficies eram afetadas pela fluorose dentária (Tab. 9).

CAPELLA et al ${ }^{20}$ examinaram 1028 crianças, 10 a 16 anos de idade, ambos os sexos, nascidas e criadas em Urussanga (Santa Catarina - $\mathrm{Br}$ ), as quais consumiam água com altos teores de flúor, verificando que $87,6 \%$ destas apresentavam fluorose dentária.

MALTZ \& FARIAS ${ }^{108}$ pesquisando a prevalência de fluorose em cidades com teores ótimos de fluoretos $(0,7 \mathrm{ppm})$ encontraram uma prevalência de fluorose de 22,3\%, utilizando o TSIF. Este estudo foi desenvolvido na região de Brasilia e a amostra consistia de crianças com idades entre 10 e 14 anos, ambos os sexos.

WILLIAMS \& ZWEMER ${ }^{184}$ estudaram uma amostra que consistía em escolares de 12-14 anos de idade, nascidas e residentes em comunidades rurais do Estado de Michigan (EUA), sendo que os resultados mostraram diferenças significativas entre as prevalências de fluorose em crianças afetadas provenientes de comunidades fluoretadas em relação às não fluoretadas (Tab. 9).

ISMAIL et al. ${ }^{79}$ observaram que em Trois-Riviére( $1,0 \mathrm{ppm} \mathrm{F),} \mathrm{55 \%}$ das crianças de 15-17 anos de idade apresentaram fluorose dentária, em comparação com $31,0 \%$ da amostra de Sherbrooka $(<0,1 \mathrm{ppm} \mathrm{F})$. Essas províncias localizavam-se em Quebec, Canadá .

Crianças na idade de 12 anos de idade, nascidas e residentes em Parth $(0,8 \mathrm{ppm} F)$ e Bunbury $(<0,1 \mathrm{ppm} F)$, Tab.8, foram examinadas por RIORDAN \& 
BANKS ${ }^{147}$, observando que sinais de fluorose dentária estavam presentes em $40,3 \%$ e 33,0\% das superficies dentárias examinadas, respectivamente.

SAMPAIO ${ }^{152}$ examinou 609 escolares de 6 a 14 anos de idade, ambos os sexos, nascidas e criadas nas cidades de Itabaiana e Salgado de São Félix $(0,7$ ppm fluoreto natural) e Mogeiro como cidade controle $(0,4 \mathrm{ppm} \mathrm{F})$, localizadas no Estado da Paraiba, utilizando o índice de DEAN. As percentagens de crianças afetadas foram de 5,0\% (Itabaiana), 9,4\% (SS Félix) e 1,0\% (Mogeiro).

CLARKSON \& O'MULLANE ${ }^{27}$ examinaram crianças nascidas e residentes em comunidades irlandesas, 15 anos de idade, provenientes de áreas com concentrações ótima de flúor (Tab. 6) e baixa de flúor (Tab. 7), verificando prevalêncais baixas, ou seja, $0,6 \%$ e $1,3 \%$, respectivamente.

VIGNARAJAH ${ }^{180}$, examinando crianças de 12-14 anos de idade, nascidas e residentes em áreas urbanas e rurais de Antígua, contendo concentrações de flúor de 0,1-0,3 ppm F(cidade a) e 0,6-1,0 ppm F(cidade b), Tab. 9, verificou percentagens de superficies afetadas na ordem de $4,8 \%$ e $15,9 \%$, respectivamente nas cidades $a \mathrm{e} b$.

MABELYA, KONIG \& HELDERMAN ${ }^{107}$ examinaram escolares de 11-18 anos de idade, nascidas e residentes em Tanga e Singida $(0,6 \mathrm{ppm}$ F), na Tanzânia, observando uma prevalência de $12 \%$ das superficies afetadas pela fluorose dentária (Tab. 8).

CLARK ${ }^{24}$ citou que a literatura vem demonstrando mudanças no padrão epidemiológico da fluorose dentária nos EUA, afirmando que atualmente as prevalências variam de 35 a $60 \%$ em comunidades fluoretadas, e entre 20 e $45 \%$ em comunidades não fluoretadas, dependendo da influência de diferentes condições locais. O aumento tem ocorrido principalmente nas categorias muito leve e leve. Estas afirmações têm sido ressaltadas também por SEGRETO et al. ${ }^{156}$,SZPUNAR \& BURT ${ }^{168}$ e BRUNELLE \& CARLOS ${ }^{17}$, embora DRISCOLL et al. ${ }^{43}$ discordem sobre $o$ assunto .

As razões para estes aumento poderiam ser :

a) $\mathrm{O}$ uso de suplementos de flúor por indivíduos residentes em áreas fluoretadas (KUMAR et al. ${ }^{88}$ ),

b) Consumo de dosagens inadequadas de suplementos de flúor na dieta, em comunidades não fluoretadas (LEVY \& ROZIER ${ }^{101}$; LEVY ${ }^{100}$ ),

c) Uso não supervisionado de dentifrícios contendo flúor, em crianças menores de 6 anos de idade, que poderiam ingerir grandes quantidades de pasta fluoretada durante a escovação ( STOOKEY ${ }^{166}$ ), 
d) Uso de bochechos não supervisionados em crianças menores de 6 anos de idade (CARLOS ${ }^{21}$ ).

CLARK et al. ${ }^{25}$, examinando crianças de 6-14 anos de idade, nascidas e residentes em Vernon ( $<0,1 \mathrm{ppm} F$ ) e Kelowa (1,2 ppm flúor), British Columbia(Canadá), observaram altas prevalências de fluorose, ou seja, 55,0\% (Vernon) e $64 \%$ (Kelowa) das crianças apresentavam TSIF $>$ ou $=1$ em pelo menos 2 dentes da boca (Tab. 9).

GASPAR, PEREIRA \&MOREIRA ${ }^{64}$, examinando crianças de 10-14 anos de idade, oriundas de Piracicaba (fator ótimo de flúor) e Iracemápolis $(0,3$ vezes o fator ótimo de F), utilizando os indices T-F e DEAN, verificaram, em relação ao índice de DEAN, uma percentagem de crianças afetadas de $20,8 \% \mathrm{em}$ Piracicaba (Tab. 6) e 4,5\% em Iracemápolis (Tab. 7), enquanto, em relação ao indice T-F, observaram prevalências de 20,4\% (Piracicaba) e 2,0\% (Iracemápolis - Tab. 8).

A determinação da prevalência de fluorose dentária tem sido muito estudada, principalmente porque há indícios que ocorreu um aumento, notadamente nos últimos 20 anos, principalmente nas formas leves, aceitável esteticamente, sendo mais notada em áreas não fluoretadas em comparação com áreas que contenham concentrações ótimas ou altas de flúor nas águas de consumo. (RIPA ${ }^{148}$; LEWIS \& BANTING, ${ }^{103}$ ).

Os estudos sobre a ocorrência e distribuição da fluorose dentária, em diferentes localidades, vêm sendo publicados desde a década de 30 , sendo que a Tabela 2 apresenta a distribuição em 21 cidades nos EUA (DEAN, ${ }^{34}$ ). 
Tabela 2 . Distribuição percentual de fluorose por código de classificação, indice de DEAN, em 21 cidades estudadas por DEAN ${ }^{34}$.

\begin{tabular}{l|c|c|c|c|c|c|c|c|c|c}
\hline \multicolumn{10}{c}{ Categorias do Índice de DEAN } \\
\hline Cidade & $\begin{array}{c}\text { ppm } \\
\text { F }\end{array}$ & $\mathbf{N}$ & Normal & $\begin{array}{c}\text { Questio } \\
\text { navel }\end{array}$ & $\begin{array}{c}\text { muito } \\
\text { leve }\end{array}$ & leve & $\begin{array}{c}\text { mode } \\
\text { rada }\end{array}$ & severa & CFI & $\begin{array}{c}\% \\
\text { Prev }\end{array}$ \\
\hline C.Springs,CO & 2,6 & 404 & 6.4 & 19.8 & 42.1 & 21.3 & 8.9 & 1.5 & $1.27^{*}$ & 73.8 \\
Galesburg,IL & 1,9 & 273 & 25.3 & 27.1 & 40.3 & 6.2 & 1.1 & 0.0 & 0.69 & 48.0 \\
Elmhurst, IL & 1,8 & 170 & 28.2 & 31.8 & 30.0 & 8.8 & 1.2 & 0.0 & 0.67 & 40.0 \\
Joliet, IL & 1,3 & 447 & 40.5 & 34.2 & 22.2 & 3.2 & 0.0 & 0.0 & 0.46 & 25.3 \\
Maywood, IL & 1,2 & 171 & 39.2 & 27.5 & 29.2 & 4.1 & 0.0 & 0.0 & 0.51 & 33.3 \\
Aurora, IL & 1,2 & 633 & 53.2 & 31.8 & 13.9 & 1.1 & 0.0 & 0.0 & 0.32 & 15.0 \\
E.Moline, IL & 1,2 & 152 & 36.8 & 31.6 & 29.6 & 2.0 & 0.0 & 0.0 & 0.49 & 32.0 \\
Kewanee, IL & 0,9 & 123 & 52.8 & 35.0 & 10.6 & 1.6 & 0.0 & 0.0 & 0.31 & 12.2 \\
Pueblo, CO & 0,6 & 614 & 72.3 & 21.2 & 6.2 & 0.3 & 0.0 & 0.0 & 0.17 & 6.5 \\
Elgin, IL & 0,5 & 403 & 60.5 & 35.3 & 3.5 & 0.7 & 0.0 & 0.0 & 0.22 & 4.2 \\
Marion, OH & 0,4 & 263 & 57.4 & 36.5 & 5.3 & 0.8 & 0.0 & 0.0 & 0.25 & 6.1 \\
Lima, OH & 0,3 & 454 & 84.1 & 13.7 & 2.2 & 0.0 & 0.0 & 0.0 & $0.09^{*}$ & 2.2 \\
Middletown,OH & 0,2 & 370 & 84.3 & 14.6 & 1.1 & 0.0 & 0.0 & 0.0 & $0.08^{*}$ & 1.1 \\
Zanesville, OH & 0,2 & 459 & 85.4 & 13.1 & 1.5 & 0.0 & 0.0 & 0.0 & $0.08^{*}$ & 1.5 \\
Quincy, IL & 0,1 & 330 & 93.0 & 6.7 & 0.3 & 0.0 & 0.0 & 0.0 & $0.04^{*}$ & 0.3 \\
Elkhart, IN & 0,1 & 278 & 91.3 & 8.3 & 0.4 & 0.0 & 0.0 & 0.0 & $0.04^{*}$ & 0.4 \\
Portsmouth, OH & 0,1 & 469 & 88.9 & 9.8 & 1.3 & 0.0 & 0.0 & 0.0 & $0.06^{*}$ & 1.3 \\
Mi. City, IN & 0,1 & 236 & 97.5 & 2.5 & 0.0 & 0.0 & 0.0 & 0.0 & $0.02^{*}$ & 0.0 \\
Evanston, IL & 0,0 & 256 & 91.8 & 6.6 & 1.6 & 0.0 & 0.0 & 0.0 & $0.5^{*}$ & 1.6 \\
Oak Park, IL & 0,0 & 329 & 90.6 & 8.8 & 0.6 & 0.0 & 0.0 & 0.0 & $0.05^{*}$ & 0.6 \\
Waukegan, IL & 0,0 & 423 & 97.9 & 1.9 & 0.2 & 0.0 & 0.0 & 0.0 & $0.1^{*}$ & 0.2 \\
& & & & & & & & & & \\
\hline
\end{tabular}

${ }^{*}$ Calculado por SZPUNAR \& BURT ${ }^{168}$

Em seguida, são apresentados dados referentes a estudos da década de 80 (Tabela 3 e 4), bem como vários estudos espalhados pelo mundo, utilizando o índice de DEAN ${ }^{34}$, em áreas com altas (Tabela 5), ótimas (Tabela 6) e baixas (Tabela 7) concentrações de flúor nas águas de abstecimento. Os estudos referentes aos índices T-F e TSIF são observados nas Tabelas 8 e 9 , respectivamente. 
Tabela 3 . Distribuição percentual de fluorose por código de classificação, indice de DEAN, em 7 comunidades de Illinois e 4 comunidades de Iowa (EUA).

\begin{tabular}{|c|c|c|c|c|c|c|c|c|c|c|}
\hline \multicolumn{11}{|c|}{ Categoria do Índice de DEAN } \\
\hline Cidade & $\begin{array}{c}\text { Fator } \\
\text { do } \\
\text { ótimo }\end{array}$ & $\mathbf{N}$ & Normal & $\begin{array}{l}\text { Ques } \\
\text { tionáv }\end{array}$ & $\begin{array}{l}\text { muito } \\
\text { leve }\end{array}$ & leve & $\begin{array}{l}\text { mode } \\
\text { rada }\end{array}$ & Severa & CFI & $\begin{array}{l}\% \\
\text { Prev. }\end{array}$ \\
\hline $\begin{array}{l}\text { Bushnell \& Table } \\
\text { Grove }\end{array}$ & 4.0 & 136 & 12.5 & 15.4 & 16.9 & 25.0 & 7.4 & 22.8 & 1.88 & 72.1 \\
\hline $\begin{array}{l}\text { Abingdon, Elmwood, } \\
\& \text { Ipava }\end{array}$ & 3.0 & 192 & 22.9 & 26.0 & 15.1 & 19.8 & 7.8 & 8.3 & 1.25 & 51.0 \\
\hline Monmouth & 2.0 & 143 & 18.2 & 28.7 & 23.1 & 16.8 & 8.4 & 4.9 & 1.16 & 53.2 \\
\hline $\begin{array}{l}\text { Kewanee } \\
\text { Belle Plaine, Durant, }\end{array}$ & 1.0 & 336 & 56.0 & 29.5 & 7.4 & 4.8 & 1.8 & 0.6 & 0.39 & 14.6 \\
\hline $\begin{array}{l}\text { Marengo, \& } \\
\text { Missouri Valley, IA }\end{array}$ & $\leq 0.0$ & 316 & 93.0 & 4.1 & 1.9 & 1.0 & 0.0 & 0.0 & 0.06 & 2.9 \\
\hline
\end{tabular}

Fonte: DRISCOLL et al ${ }^{43}$; DRISCOLL et al ${ }^{44}$. 
Tabela 4 . Distribuição percentual de fluorose por código de classificação, índice de DEAN, em 16 comunidades do Texas (EUA), realizado em 1953 e 1981.

\section{Categoria do índice de DEAN}

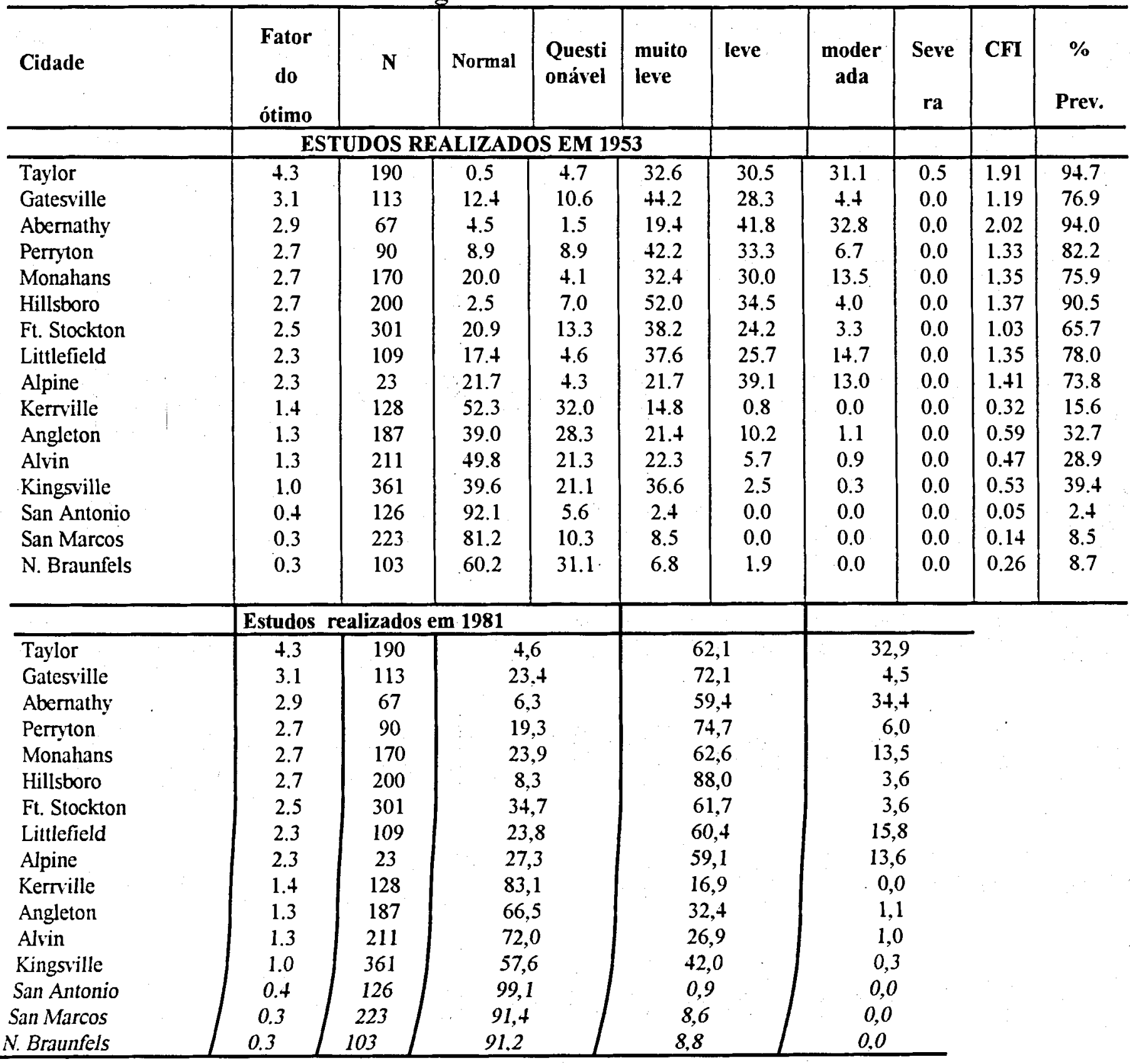

Fonte: GALAGAN \& VERMILLION ${ }^{63}$;SEGRETO et al ${ }^{156}$. 
Tabela 5 Revisão de diversos trabalhos, utilizando o índice de DEAN em áreas com ALTA concentração de flúor.

\begin{tabular}{|c|c|c|c|c|c|c|}
\hline LOCAL & AUTOR & $1^{*}$ & $2^{*}$ & $3^{*}$ & $4^{*}$ & $\begin{array}{l}\text { Prev }^{*} \\
\text { Total }\end{array}$ \\
\hline Itália & $\begin{array}{l}\text { MASSLER \& }^{114} \\
\text { SCHOUR }^{114}\end{array}$ & 23 & 17 & 10 & 8 & 58 \\
\hline Inglaterra & FORREST $^{39}$ & 52 & 4 & 8 & & 66 \\
\hline Taiwan & PU \& LILIENTHAL ${ }^{140}$ & 21 & 37 & 24 & 2 & 84 \\
\hline Inglaterra & $\begin{array}{l}\text { FORREST \& } \\
\text { JAMES }{ }^{60}\end{array}$ & 0 & 0 & 8 & 0 & 8 \\
\hline Áustria & $\begin{array}{l}\text { BINDER }{ }^{13} \text { área } b \\
\text { área c }\end{array}$ & $\begin{array}{l}43 \\
19\end{array}$ & $\begin{array}{c}5 \\
27\end{array}$ & $\begin{array}{l}0 \\
6\end{array}$ & $\begin{array}{l}0 \\
0\end{array}$ & $\begin{array}{l}48 \\
52\end{array}$ \\
\hline India & NANDA et al ${ }^{125}$ & 18 & 16 & 7 & 0 & 41 \\
\hline India & NANDA et al ${ }^{125}$ & 26 & 17 & 23 & 0 & 54 \\
\hline $\begin{array}{l}\text { África do } \\
\text { Sul }\end{array}$ & BISCHOFF et al ${ }^{14}$ & 15 & 27 & 41 & 0 & 83 \\
\hline EUA & DRISCOLL et al ${ }^{43}$ & 23 & 17 & 8 & 5 & 53 \\
\hline
\end{tabular}

* Percentagens

Tabela 6 . Revisão de diversos trabalhos, utilizando o índice de DEAN em áreas com ÓTIMA concentração de flúor.

\begin{tabular}{|c|c|c|c|c|c|c|c|}
\hline LOCAL & AUTOR & $1^{*}$ & $2^{*}$ & $3^{*}$ & $4^{*}$ & $\begin{array}{l}\text { Prev } \\
\text { Total }\end{array}$ & $\begin{array}{l}\text { Prev * } \\
\text { Superf }\end{array}$ \\
\hline Inglaterra & FORREST $^{59}$ & 16 & 2 & 1 & 0 & 19 & \\
\hline TAIWAN & $\begin{array}{c}\text { PU\&LILIENTHAL }^{140} \\
\text { área a }\end{array}$ & 40 & 14 & 5 & 0 & 54 & \\
\hline TAIWAN & $\begin{array}{l}\text { PU\&LILIENTHAL }{ }^{140} \\
\text { área b }\end{array}$ & 36 & 38 & 9 & 0 & 83 & \\
\hline Áustria & $\begin{array}{l}\mathrm{BINDER}^{13} \\
\text { área a }\end{array}$ & 18 & 0 & 0 & 0 & 18 & \\
\hline Suécia & FORSMAN $^{61}$ & 23 & 41 & 0 & 0 & 64 & \\
\hline EUA & LEVERETT $^{97}$ & 23 & 3 & 1 & 0 & & 27 \\
\hline EUA & DRISCOLL et al. ${ }^{44}$ & 7 & 5 & 2 & 1 & & 15 \\
\hline EUA & $\begin{array}{c}\text { KUMAR et al }{ }^{88} \\
\text { Estudo } 1985\end{array}$ & 2 & 7 & 0 & 0 & & 9 \\
\hline Irlanda & $\begin{array}{l}\text { CLARKSON \& } \\
\text { O'MULLANE }^{27}\end{array}$ & 0,6 & 0 & 0 & 0 & & 0,6 \\
\hline Brasil & $\begin{array}{c}\text { GASPAR, PEREIRA \& } \\
\text { MOREIRA }{ }^{64}\end{array}$ & 18,9 & 1,5 & 0,4 & 0 & 20,8 & \\
\hline
\end{tabular}

* Percentagem 
Tabela 7. Revisão de diversos trabalhos, utilizando o índice de DEAN em áreas com BAIXA concentração de flúor.

\begin{tabular}{|c|c|c|c|c|c|c|c|}
\hline LOCAL & AUTOR & $1 *$ & $2 *$ & $3 *$ & $4 *$ & $\begin{array}{l}\text { Prev } \\
\text { Total* }\end{array}$ & $\begin{array}{l}\text { Prev * } \\
\text { Superf }\end{array}$ \\
\hline Taiwan & PU \& LILIENTHAL ${ }^{140}$ & 11 & 4 & 0 & 0 & 15 & \\
\hline Inglaterra & FORREST \& JAMES ${ }^{60}$ & 8 & 1 & 2 & & 11 & \\
\hline Marrocos & MOLLER \& POULSEN $^{121}$ & 20 & 29 & 29 & 13. & 91 & \\
\hline Inglaterra & GOWARD $^{65}$ & 5 & 3 & 0.6 & 1,4 & 10 & \\
\hline EUA & LEVERETT $^{97}$ & $\cdots$ & 2.7 & 1,1 & 0.6 & & 4.4 \\
\hline EUA & DRISCOLL et al. ${ }^{44}$ & 1.9 & 1,0 & 0 & 0 & & 2,9 \\
\hline EUA & $\begin{array}{l}\text { KUMAR et al. } \\
\text { estudo em } 1985^{88}\end{array}$ & -- & 2,2 & 7 & 0 & & 9,2 \\
\hline Irlanda & $\begin{array}{l}\text { CLARKSON \& } \\
\text { O'MULLANE }\end{array}$ & 0,9 & 0,4 & 0 & 0 & & 1,3 \\
\hline Brasil & $\begin{array}{l}\text { GASPAR, PEREIRA \& } \\
\text { MOREIRA }^{64}\end{array}$ & 4,0 & 0,5 & 0 & 0 & 4,5 . & \\
\hline
\end{tabular}

* Percentagem 
Tabela 8. Revisão de diversos trabalhos, utilizando o índice T-F em áreas com ALTA, ÓTIMA E BAIXA concentração de flúor.

\begin{tabular}{|c|c|c|c|c|c|c|c|c|c|c|c|c|}
\hline IOCAL & AUTOR & $1^{*}$ & $2^{\star}$ & $3^{\star}$ & $4^{*}$ & $5^{*}$ & $6^{\star}$ & $7^{*}$ & $8^{*}$ & $9^{*}$ & $\begin{array}{l}\text { Prev } \\
\text { total }\end{array}$ & $\begin{array}{l}\text { Prev }^{\star} \\
\text { sup. }\end{array}$ \\
\hline & \multicolumn{4}{|c|}{ CONCENTRAÇÃO ALTA } & & & & & & & & \\
\hline \multirow[t]{3}{*}{ Dinamarca } & $\begin{array}{c}\text { WENZEL \& } \\
\text { THYLSTRUP } \\
\end{array}$ & 21,0 & 30,0 & 25,0 & 10,0 & 3,0 & & & & & & 89,0 \\
\hline & & & & & & & & & & & & \\
\hline & \multicolumn{4}{|c|}{ CONCENTRAÇĀO ÓTIMA } & & & & & & & & \\
\hline Dinamarca & $\begin{array}{c}\text { WENZEL \& } \\
\text { THYLSTRUP }\end{array}$ & 42,0 & 5,0 & & & & & & & & & 47,0 \\
\hline KENYA & MANJI et al. ${ }^{110}$ & \multicolumn{4}{|c|}{79,4} & \multicolumn{5}{|c|}{11,8} & & 91.2 \\
\hline Canadá & OSUJI et al. ${ }^{134}$ & 10.0 & 2.2 & 0,6 & 0.2 & & & & & & & 12.9 \\
\hline Austrália & RIORDAN \& BANKS $^{147}$ & \begin{tabular}{|l|}
59.8 \\
\end{tabular} & 29 & 8,9 & 2,4 & & & & & & & 40.3 \\
\hline Tanzânia & $\begin{array}{l}\text { MABELYA, KONIG \& } \\
\text { HELDERMAN } 107\end{array}$ & 6,0 & 3,0 & 2,0 & 1,0 & & & & & & & 12,0 \\
\hline \multirow[t]{3}{*}{ Brasil } & $\begin{array}{c}\text { GASPAR PEREIRA e } \\
\text { MOREIRA }\end{array}$ & 4,3 & 14,2 & 1,9 & & & & & & & 20,4 & \\
\hline & & & & & & & & & & & & \\
\hline & \multicolumn{5}{|c|}{ CONCENTRAÇĀO BAIXA } & & & & & & & \\
\hline Dinamarca & $\begin{array}{c}\text { WENZEL \& } \\
\text { THYLSTRUP } \\
182\end{array}$ & 3,0 & & & & & & & & & & 3,0 \\
\hline Kenia & MANJI et al. ${ }^{110}$ & 53.7 & 24,4 & & & & & & & & 78,1 & \\
\hline Austrália & RIORDAN \& BANKS ${ }^{147}$ & 25.5 & 6.9 & 0.6 & & & & & & & & 33,0 \\
\hline BRASIL & $\begin{array}{c}\text { GASPAR, PEREIRA \& } \\
\text { MOREIRA }\end{array}$ & 0,0 & 1,0 & 0,5 & & 0,5 & & & & & & 2,0 \\
\hline
\end{tabular}

* Percentagens 
Tabela 9. Revisão de diversos trabalhos, utilizando o índice TSIF em áreas com ALTA,ÓTIMA E BAIXA concentração de flúor.

\begin{tabular}{|c|c|c|c|c|c|c|c|c|c|c|}
\hline LOCAL & AUTOR & $1^{*}$ & $2^{*}$ & $3^{*}$ & $4^{*}$ & $5^{*}$ & $6^{*}$ & $7 *$ & \begin{tabular}{|l}
$\begin{array}{l}\text { Prev } \\
\text { total }\end{array}$ \\
\end{tabular} & $\begin{array}{l}\text { Prev } \\
\text { sup. }\end{array}$ \\
\hline & \multicolumn{4}{|c|}{ CONCENTRAÇÃO ALTA } & & & & & & \\
\hline EUA & HOROWITZ et al. ${ }^{75}$ & 28.4 & 7.6 & 5.6 & 0,1 & & & & & 41.8 \\
\hline EUA & $\begin{array}{l}\text { HEIFETZ et al. }{ }^{70} \\
\text { Estudo } 1980\end{array}$ & 25,4 & 7,8 & 5,0 & 0,0 & 0,1 & & & & 38,3 \\
\hline \multirow[t]{2}{*}{$\overline{E U A}$} & $\begin{array}{l}\text { HEIFETZ et al. }{ }^{70} \\
\text { Estudo } 1985\end{array}$ & 32,5 & 18,6 & 13,8 & 0,3 & 1,3 & & & & 66,5 \\
\hline & \multicolumn{5}{|c|}{ CONCENTRACÃ̃O ÓTIMA } & & & & & \\
\hline EUA & HOROWITZ et al. $^{75}$ & 12,4 & 2.0 & 1.1 & & & & & 15.5 & \\
\hline EUA & $\begin{array}{|lr|}\text { WILLIAMS } & \& \\
\text { ZWEMER }^{184} & \\
\end{array}$ & 26,7 & 9,6 & 30,6 & 9,6 & 4,5 & & & & 81,0 \\
\hline$\overline{\text { EUA }}$ & $\begin{array}{l}\text { SZPUNAR \& BURT }{ }^{168} \\
\text { área b }\end{array}$ & 31,2 & 0,3 & 0 & 0,1 & & & & 32,5 & 31,6 \\
\hline EUA & $\begin{array}{l}\text { SZPUNAR \& BURT }{ }^{168} \\
\text { área c }\end{array}$ & 49,7 & 1,3 & & & & & & 49,0 & 51,0 \\
\hline EUA. & $\begin{array}{l}\text { SZPUNAR \& BURT }{ }^{168} \\
\text { área d }\end{array}$ & 35,4 & 0,7 & 0,2 & 0 & 0 & 0 & 0,1 & 60,1 & 36,3 \\
\hline EUA & $\begin{array}{l}\text { HEIFETZ et al. }{ }^{70} \\
\text { Estudo } 1980\end{array}$ & 9,1 & 1,5 & 0,8 & & & & & & 11,4 \\
\hline$\overline{E U A}$ & $\begin{array}{l}\text { HEIFETZ et al. }{ }^{70} \\
\text { Estudo } 1985\end{array}$ & 21,6 & 4,9 & 2,8 & 0,1 & & & & & 29,4 \\
\hline ÍNDIA & $\begin{array}{l}\text { VIGNARAJAH }^{180} \\
\text { cidade b }\end{array}$ & 8,3 & 4,3 & 3,3 & & & & & & 15,9 \\
\hline \multirow[t]{3}{*}{ CANADÁ } & CLARK et al. ${ }^{25}$ & 55.0 & 7.0 & $<1$ & $<1$ & 1 & $<1$ & & & 64,0 \\
\hline & \multirow{2}{*}{\multicolumn{5}{|c|}{ CONCENTRAÇÃO BAIXA }} & & & & & \\
\hline & & & & & & & & & & \\
\hline EUA & HOROWITZ et al. $^{75}$ & 39,1 & 9.6 & 6 & 1,3 & & & & & 56,0 \\
\hline$\overline{E U A}$ & $\begin{array}{ll}\text { WILLIAMS } & \& \\
\text { ZWEMER }^{184} & \end{array}$ & 30,9 & 6,9 & 14,7 & 0,5 & 0,9 & & & & 53,9 \\
\hline$\overline{E U A}$ & $\begin{array}{l}\text { SZPUNAR \& BURT }{ }^{168} \\
\text { área a }\end{array}$ & 11,7 & 0,3 & 0,1 & 0,1 & 0,0 & 0,1 & & 15,0 & 12,2 \\
\hline EUA & $\begin{array}{l}\text { WOOLFOLK, FAJA \& } \\
\text { BAGRAMIAN }^{185}\end{array}$ & 6,1 & 0,6 & 0,2 & & & & & 22,3 & 6,9 \\
\hline INDIA & $\begin{array}{l}\text { VIGNARAJAH }^{180} \\
\text { cidade a }\end{array}$ & 3,9 & 0,5 & 0,4 & & & & & & 4,8 \\
\hline CANADÁ & CLARK et al. ${ }^{25}$ & 48.0 & 5.0 & $<1$ & 1 & $<1$ & & & & 55,0 \\
\hline
\end{tabular}

* Percentagens 


\section{5- MATERIAL E MÉTODOS}

5.1 Material e Equipamentos

- Fichas para anotação

- Prancheta

- Lápis e Borracha

- Cubas esmaltadas

- Solução de álcool iodado a $70 \%$

- Papel toalha, sabonete e toalha de pano

- Espelhos bucais planos

- Sondas exploradoras

- Luvas e Máscaras

- Escovas dentárias e dentifrícios sem flúor

- Softwares (Excell versão 5.0; Word for Windows versão 6.0 e SAS)

- Equipamento odontológico standard

- Computador PC AT 486 com impressora

- Disquetes de Computador

\subsection{Recursos Humanos}

- 1 examinador

-1 anotador

- 1 monitor

As funções seguem as orientações da OMS ${ }^{131}$.

\subsection{Amostra e seleção da população a ser estudada}

No estudo foram examinados 461 escolares, 276 do sexo masculino e 183 do sexo feminino, sendo 153 crianças ( 73 do sexo masculino e 80 do sexo feminino) da cidade de Cesário Lange com uma concentração de flúor de $1,4 \mathrm{ppm}$, 142 crianças (81 do sexo masculino e 61 do sexo feminino) de Piracicaba $(0,7 \mathrm{ppm}$ F) e 166 crianças ( 124 do sexo masculino e 42 do sexo feminino) em Iracemápolis $(<0,3 \mathrm{ppm} \mathrm{F})$, matriculados em escolas públicas, entre 12 e 14 anos de idade, ambos os sexos . A faixa etária de estudo foi recomendado por DEAN \& ARNOLD $^{35}$, pois basicamente todos os dentes permanentes estão erupcionados.

As três localidades localizam-se no Estado de São Paulo, sendo que a cidade de Piracicaba dista da capital do Estado (município de São Paulo) cerca de $164 \mathrm{Km}$, enquanto as cidades de Iracemápolis e Cesário Lange distam cerca de 20 e 
$95 \mathrm{Km}$, respectivamente, da cidade de Piracicaba. As concentrações de flúor nas águas de consumo foram verificadas através da coleta de água dos locais de exame e determinadas com o uso de eletrodos de flúor (ORION $\circledast$ ) usando o reagente TISABß.

Os escolares da amostra necessariamente tinham que ser nascidos e/ou residentes na cidade desde os dois anos de idade.

A seleção da amostra foi feita através de sorteio aleatório simples, sendo utilizado para isso a lista dos escolares cedida pelos diretores das escolas, os quais foram esclarecidos previamente sobre o estudo.

5.4 Índices utilizados

Índices de Fluorose

Os índices de fluorose utilizados foram os de DEAN (DEAN, ${ }^{34}$ ), T-F (THYLSTRUP \& FEJERSKOV ${ }^{173}$ ) e TSIF (HOROWITZ et al. ${ }^{15}$ ) Quadros 2,3 e 4. 
Quadro 2. Índice de DEAN para medir a prevalência de fluorose.

\begin{tabular}{|c|c|c|}
\hline CLASSIFICAÇÃO & Código & $\begin{array}{l}\text { CARACTERÍSTICAS } \\
\text { CLINICAS }\end{array}$ \\
\hline Normal & 0 & $\begin{array}{l}\text { Translúcido, vitriforme de } \\
\text { estrutura, superfície lisa, } \\
\text { lustrosa e usualmente cor } \\
\text { branco creme pálido }\end{array}$ \\
\hline Muito Leve & 1 & $\begin{array}{l}\text { Pequenas e opacas áreas } \\
\text { brancas espalhadas pelo } \\
\text { dente não envolvendo mais } \\
\text { que } 25 \% \text { da superficie ( } 1 \text { a } \\
2 \text { mm a partir do topo da } \\
\text { cúspide) }\end{array}$ \\
\hline Suave (Leve) & 2 & $\begin{array}{l}\text { Áreas brancas não } \\
\text { envolvendo mais que } 50 \% \\
\text { da superficie }\end{array}$ \\
\hline Moderada & 3 & $\begin{array}{l}\text { Toda a superfície está } \\
\text { afetada, as superficies } \\
\text { estão sujeitas ao desgaste; } \\
\text { manchas marrons } \\
\text { frequentes. }\end{array}$ \\
\hline Severa & 4 & $\begin{array}{l}\text { Toda a superficie está } \\
\text { afetada e há hipoplasia } \\
\text { com mudança da anatomia } \\
\text { dentária; manchas } \\
\text { marrons, erosões e } \\
\text { aparência de corrosão. }\end{array}$ \\
\hline
\end{tabular}

Fonte: DEAN ${ }^{34}$

Neste estudo excluiu-se o código 0,5 do índice de DEAN, pois o mesmo propicia dúvidas de diagnóstico, sendo esta exclusão recomendada por EKSTRAND, FEJERSKOV \& SILVESTONE ${ }^{48}$ e GRANATH, WIDENHEIN \& BIRKHED ${ }^{\circ}$. 
Quadro 3. Índice T-F para medir a prevalência de fluorose.

\begin{tabular}{|c|c|}
\hline Código & CLASSIFICAÇĀO \\
\hline 0 & $\begin{array}{l}\text { Translucidez normal do esmalte permanece após prolongada } \\
\text { secagem de ar }\end{array}$ \\
\hline 1 & Linhas brancas estreitas correspondendo ao periquimata \\
\hline 2 & $\begin{array}{l}\text { Linhas mais pronunciadas de opacidade que ocasionalmente se } \\
\text { unem a linhas adjacentes }\end{array}$ \\
\hline 3 & $\begin{array}{l}\text { Áreas de opacidades fundidas e irregulares. Delineamento } \\
\text { pronunciado das periquimáceas freqüentemente visivel entre as } \\
\text { opacidades }\end{array}$ \\
\hline 4 & $\begin{array}{l}\text { A superficie inteira exibe opacidade marcada ou parece branco- } \\
\text { calcário (chalky). Locais sujeitos à atrição parecem menos afetados. }\end{array}$ \\
\hline 5 & $\begin{array}{l}\text { A superficie inteira apresenta marcada opacidade com perda focal } \\
\text { de esmalte mais externo, menor que } 2 \mathrm{~mm} \text { de diâmetro, formando } \\
\text { depressões (pits) }\end{array}$ \\
\hline 6 & $\begin{array}{l}\text { As depressões estão regularmente arranjadas em faixas horizontais } \\
\text { menores que } 2 \mathrm{~mm} \text { em extensão vertical }\end{array}$ \\
\hline 7 & $\begin{array}{l}\text { Perda de esmalte mais externo em áreas irregulares, envolvendo } \\
\text { menos que a metade da superficie }\end{array}$ \\
\hline 8 & $\begin{array}{l}\text { Perda de esmalte mais externo, envolvendo mais que a metade da } \\
\text { superficie }\end{array}$ \\
\hline 9 & $\begin{array}{l}\text { Perda da maior parte da camada de esmalte com mudança da } \\
\text { anatomia dentária. A margem cervical de esmalte quase intacta é } \\
\text { freqüentemente notada }\end{array}$ \\
\hline
\end{tabular}

Fonte: THYLSTRUP \& FEJERSKOV ${ }^{173}$ 
Quadro 4. Índice TSIF para medir a prevalência de fluorose..

\begin{tabular}{|c|c|}
\hline SCORE & DESCRIÇÃO \\
\hline 0 & Esmalte não mostra evidência de fluorose \\
\hline 1 & $\begin{array}{l}\text { Esmalte mostra definitiva evidência de fluorose, áreas com aspecto branco-giz atingindo menos } \\
\text { que um terço da superfície visível do esmalte. Esta categoria inclui fluorose confinada apenas } \\
\text { às incisais dos dentes anteriores e ponta de cúspides dos dentes posteriores ("cume de neve"). }\end{array}$ \\
\hline 2 & $\begin{array}{l}\text { Fluorose com bandas branco-giz totalizam pelo menos um terço da superfície visível, mas menos } \\
\text { que dois terços. }\end{array}$ \\
\hline 3 & Fluorose com bandas branco-giz totalizam pelo menos dois terços da superfície visivel. \\
\hline 4 & $\begin{array}{l}\text { Esmalte mostra manchas escuras em conjunto com algum dos níveis anteriores de fluorose. } \\
\text { Mancha é definida como uma área de definitiva descoloração que pode variar da marrom claro } \\
\text { à da marrom escuro. }\end{array}$ \\
\hline 5 & $\begin{array}{l}\text { Discretas cavitações do esmalte, não acompanhadas de evidência de manchas no esmalte } \\
\text { intacto. Uma cavitação é definida como um defeito físico na superfície de esmalte com uma } \\
\text { base áspera, que é delimitada por uma parede de esmalte intacto. A área cavidade é } \\
\text { usualmente manchada ou difere em cores do esmalte adjacente. }\end{array}$ \\
\hline 6 & Discretas cavitações e manchas do esmalte intacto existente. \\
\hline 7 & $\begin{array}{l}\text { Confluentes cavitações da superfície de esmalte intacto existente. Grandes áreas de esmalte } \\
\text { podem estar perdidas e a anatomia do dente pode estar alterada. Manchas marrom escuras } \\
\text { estão usualmente presentes. }\end{array}$ \\
\hline
\end{tabular}

Fonte: HOROWITZ et al. ${ }^{75}$ 
A diferenciação diagnóstica entre graus leves de fluorose dentária e opacidades não fluoróticas foram realizados através dos critérios de RUSSEL ${ }^{151}$. (Quadro 5).

Quadro 5. Diferenciação diagnóstica entre fluorose e opacidades não fluoróticas.

\begin{tabular}{|c|c|c|}
\hline Característica & FLUOROSE (GRAUS LEVES) & OPACIDADES \\
\hline Distribuição & simétrica & $\begin{array}{l}\text { raramente simétrica ou } \\
\text { apenas poucos dentes } \\
\text { afetados }\end{array}$ \\
\hline Localização & $\begin{array}{l}\text { Mais visível nos } 2 / 3 \\
\text { terços incisais ou } \\
\text { oclusais, mais visivel } \\
\text { sobre todo o dente após } \\
\text { secagem }\end{array}$ & $\begin{array}{l}\text { Terço médio ou incisal } \\
\text { das superficies } \\
\text { vestibulares dos } \\
\text { incisivos centrais }\end{array}$ \\
\hline Configuração & $\begin{array}{l}\text { Manchas opacas difusas } \\
\text { horizontais seguindo a } \\
\text { periquimata }\end{array}$ & $\begin{array}{l}\text { Manchas redondas ou } \\
\text { ovais }\end{array}$ \\
\hline Visibilidade & $\begin{array}{l}\text { Luz tangencial não muito } \\
\text { perceptível }\end{array}$ & $\begin{array}{l}\text { Luz perpendicular } \\
\text { claramente diferenciada }\end{array}$ \\
\hline Limite & $\begin{array}{l}\text { Limite da lesão se } \\
\text { confunde com o esmalte } \\
\text { adjacente }\end{array}$ & $\begin{array}{l}\text { Limite claramente } \\
\text { diferenciado do esmalte } \\
\text { adjacente }\end{array}$ \\
\hline Cor & $\begin{array}{l}\text { Levemente mais opaca } \\
\text { que o esmalte normal }\end{array}$ & $\begin{array}{l}\text { Usuaimente pigmentada } \\
\text { na época da erupção; } \\
\text { frequentemente amarelo } \\
\text { creme a laranja } \\
\text { avermelhado }\end{array}$ \\
\hline Hipoplasia & Nenhuma & Pode estar presente \\
\hline
\end{tabular}

Fonte: RUSSEL. 1961 
5.5 Padronização dos exames

Os escolares da amostra foram orientados a realizarem uma escovação prévia ao exame por THDs(Técnicas em Higiene Dentária) devidamente treinadas.

Os exames relativos à fluorose dentária foram realizados em consultórios dentários "standard", localizados nas escolas do estudo, com o auxílio de luz artificial (refletor bifocal) e secagem prévia de 1 minuto. A sistemática do Levantamento envolveu o grupo de trabalho, composto de um examinador, um anotador e um monitor.

Foram utilizados espelhos planos no. 5 e sonda exploradora com o propósito da retirada de depósitos de placa. Para a proteção individual do examinador, foram usädas luvas e máscaras.

Examinaram-se as superficies vestibulares, linguais e oclusais dos dentes posteriores, bem como as superficies vestibulares e linguais dos dentes anteriores. Dentes erupcionados com menos de $2 / 3$ da coroa (OPINYA ${ }^{132}$ ) ou restaurados (HOROWITZ et al. ${ }^{15}$ ) foram excluídos da amostra.

A seqüência dos exames foi a seguinte:

1a. Fase: Exame do Índice de DEAN

Intervalo de 3 dias

2a. Fase: Exame do Índice T-F

Intervalo de 3 dias

3a. Fase: Exame do Índice TSIF

O intervalo entre os exames foi realizado para se diminuir os "vícios" do exame clínico, ou seja, possível memorização.

Previamente à fase de levantamento, foi realizado um treinamento dos 3 índices utilizados e seguiu-se a uma calibração para se medir o erro intraexaminador, utilizando-se para isto o Método de KAPPA (LANDIS \& $\mathrm{KOCH}^{\circ 0}$ ).

A calibração final consistiu de 6 sessões de 4 horas ( 24 horas), na qual examinavam-se 10 crianças no início do período e após o intervalo as mesmas eram reexaminadas. Após os exames, os dados eram apurados e os valores da estatística de KAPPA calculados, sendo que após todas as sessões o valor da estatística KAPPA era superior a 0,70 , para todos os índices, considerado "substancial" por I ANDIS \& KOCH 90 
Para o cálculo das prevalências de fluorose, foi definido como "caso de fluorose" todo indivíduo que apresentasse ao menos uma superficie com código dos índices de DEAN, T-F ou TSIF maior ou igual a 1 (um).

\subsection{Critérios de registro}

Para anotação dos dados foi elaborada uma ficha individual (Anexo 10) para os índices de DEAN (0 a 4), T-F (0 a 9) e TSIF ( 0 a 7 ).

\subsection{Análise estatística}

Foram realizados os seguintes procedimentos:

a) histogramas para estudar a distribuição dos valores dos três índices de fluorose, nas 3 localidades estudadas.

b) utilização do método de KAPPA para medir o erro intra-examinador, relacionado aos 3 índices utilizados no estudo. Para isto foram reexaminados $10 \%$ da amostra (45 crianças, 15 de cada cidade).

c) análise da distribuição percentual por superficie, dente e localidade, utilizando para apuração o software Excell versão 5.0(CONATSER ${ }^{29}$ ).

d) cálculo do coeficiente de correlação de Spearman utilizando o software SAS (SAS Institute ${ }^{165}$ ). Os três indices foram correlacionados dois a dois, segundo a localidade de estudo. 


\section{6- RESULTADOS}

Os resultados deste estudo são apresentados da seguinte forma:

a) as tabelas 10 a 18 e os gráficos 1 a 9 demonstram os dados relativos ao número e percentagem de superfícies afetadas por código, analisados nas cidades do estudo e divididos por índice utilizado.

b) os gráficos 10 a 18 apresentam os dados relativos ao número de dentes afetados na superficie vestibular, segundo o índice e a cidade do estudo. A superficie vestibular foi a escolhida pois é a que tem maior comprometimento estetico, sendo recomendada a sua ênfase por EKSTRAND, FEJERSKOV E SILVERSTONE ${ }^{48}$.

c) a tabela 19 apresenta o número e percentagem de crianças afetadas segundo $o$ indice e a cidade.

d) as tabelas cruzadas ( 20 a 28 ) apresentam a distribuição percentual entre os índices do estudo, segundo a cidade.

e) a tabela 29 apresenta os valores da estatística KAPPA para os três índices utilizados, calculados após o reexame de 45 crianças da amostra.

f) a tabela 30 apresenta os valores do coeficiente de correlação de Spearman, segundo o índice e a cidade. 
Tabela 10. Número e percentagem de superficies afetadas por código, indice de DEAN, em Cesário Lange.

\begin{tabular}{ccccccccccccc}
\hline \multicolumn{4}{c}{ Número de superficies } & \multicolumn{1}{c}{ Percentagem de superficies } \\
\hline Sup. & 0 & 1 & 2 & 3 & 4 & Total & 0 & 1 & 2 & 3 & 4 & Total \\
\hline L & 3656 & 295 & 95 & 38 & 0 & 4084 & $89.5 \%$ & $7,2 \%$ & $2.3 \%$ & $0,9 \%$ & $0.0 \%$ & $100,0 \%$ \\
O & 1364 & 320 & 145 & 26 & 0 & 1855 & $73.5 \%$ & $17,3 \%$ & $7,8 \%$ & $1,4 \%$ & $0,0 \%$ & $100,0 \%$ \\
V & 3538 & 357 & 105 & 34 & 8 & 4042 & $87,5 \%$ & $8,8 \%$ & $2,6 \%$ & $0,8 \%$ & $0,2 \%$ & $100.0 \%$ \\
\hline Total & $\mathbf{8 5 5 8}$ & 972 & 345 & 98 & 8 & 9981 & $85,7 \%$ & $9,7 \%$ & $3,5 \%$ & $1,0 \%$ & $0,1 \%$ & $100,0 \%$ \\
\hline
\end{tabular}

Gráfico 1. Composição percentual dos códigos do índice de DEAN, por superfície, em Cesário

\section{Lange.}

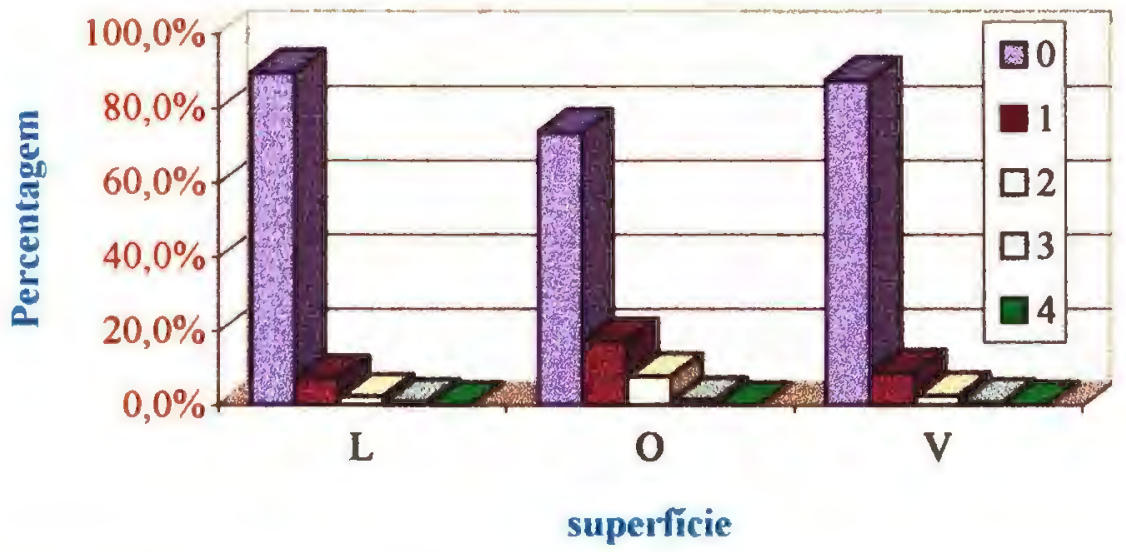




\begin{tabular}{|c|c|c|c|c|c|c|c|c|c|c|c|c|c|c|c|c|}
\hline \multicolumn{9}{|c|}{ Número de superficies } & \multicolumn{8}{|c|}{ Percentagem de superficies } \\
\hline Sup. & 0 & 1 & 2 & 3 & 4 & 5 & 6 & Total & 0 & 1 & 2 & 3 & 4 & 5 & 6 & Total \\
\hline L & 3627 & 163 & 196 & 91 & 5 & 2 & 0 & 40184 & $88,8 \%$ & $4,0 \%$ & $4,8 \%$ & $2,2 \%$ & $0,1 \%$ & $0,0 \%$ & $0,0 \%$ & $100,0 \%$ \\
\hline 0 & 1345 & 0 & 493 & 11 & 6 & 0 & 0 & 1855 & $72.5 \%$ & $0.0 \%$ & $26,6 \%$ & $0,6 \%$ & $0,3 \%$ & $0,0 \%$ & $0.0 \%$ & $100.0 \%$ \\
\hline V & 3509 & 206 & 220 & 85 & 5 & 7 & 10 & 4042 & $86,8 \%$ & $5,1 \%$ & $5,4 \%$ & $2.1 \%$ & $0,1 \%$ & $0,2 \%$ & $0,2 \%$ & $100,0 \%$ \\
\hline Total & 8481 & 369 & 909 & 187 & 16 & 9 & 10 & 9981 & $85,0 \%$ & $3,7 \%$ & $9,1 \%$ & $1,9 \%$ & $0,2 \%$ & $0,1 \%$ & $0,1 \%$ & $100,0 \%$ \\
\hline
\end{tabular}

\section{Gráfico 2. Composição Percentual dos códigos do} índice T-F, por superfície, em Cesário Lange.

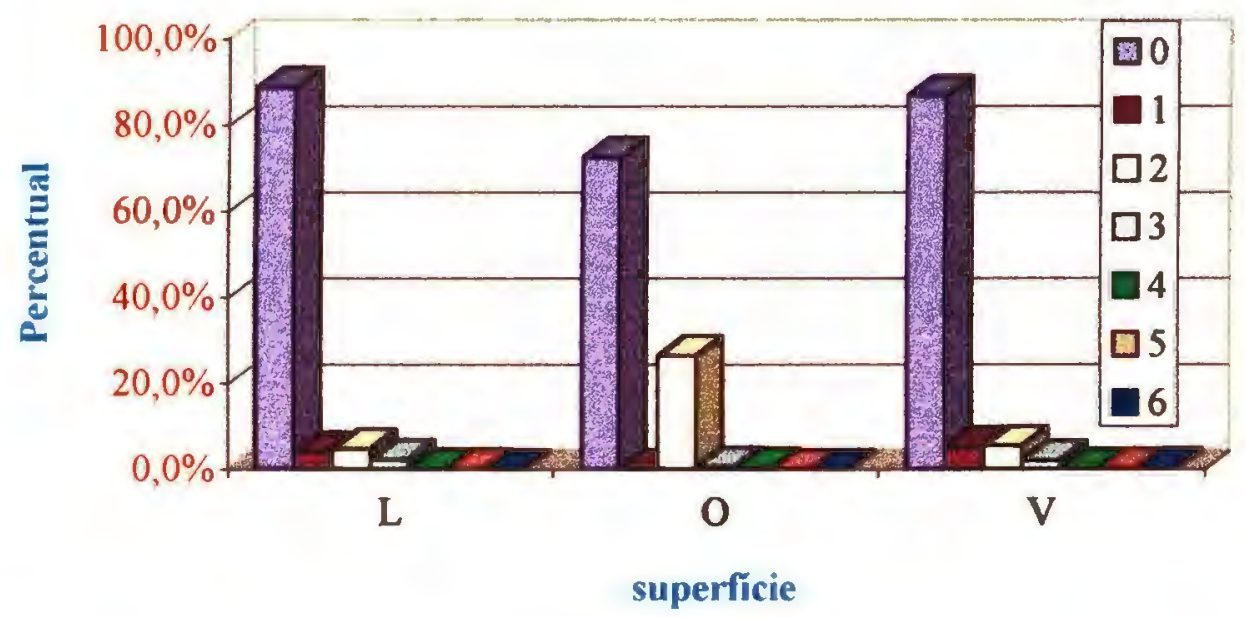


Tabela 12. Número e percentagem de superficies afetada por código, indice TSIF. em Cesário Lange.

\begin{tabular}{ccccccccccccccccc}
\hline \multicolumn{1}{c}{ Número de superficies } & \multicolumn{10}{c}{ Percentagem de superficies } \\
\hline Sup. & 0 & 1 & 2 & 3 & 4 & 5 & 6 & Total & 0 & 1 & 2 & 3 & 4 & 5 & 6 & Total \\
\hline L & 3635 & 298 & 101 & 49 & 0 & 1 & 0 & 4084 & $89,0 \%$ & $7,3 \%$ & $2,5 \%$ & $1,2 \%$ & $0,0 \%$ & $0,0 \%$ & $0,0 \%$ & $100,0 \%$ \\
0 & 1363 & 325 & 130 & 37 & 0 & 0 & 0 & 1855 & $73,5 \%$ & $17,5 \%$ & $7,0 \%$ & $2,0 \%$ & $0.0 \%$ & $0,0 \%$ & $0,0 \%$ & $100,0 \%$ \\
V & 3525 & 346 & 111 & 48 & 3 & 8 & 1 & 4042 & $87,2 \%$ & $8,6 \%$ & $2,7 \%$ & $1,2 \%$ & $0,1 \%$ & $0,2 \%$ & $0,0 \%$ & $100,0 \%$ \\
\hline Total & 8523 & 969 & 342 & 134 & 3 & 9 & 1 & 9981 & $85,4 \%$ & $9,7 \%$ & $3,4 \%$ & $1,3 \%$ & $0,0 \%$ & $0,1 \%$ & $0,0 \%$ & $100,0 \%$ \\
\hline
\end{tabular}

\section{Gráfico 3. Composição percentual dos códigos do TSIF, em Cesário Lange.}

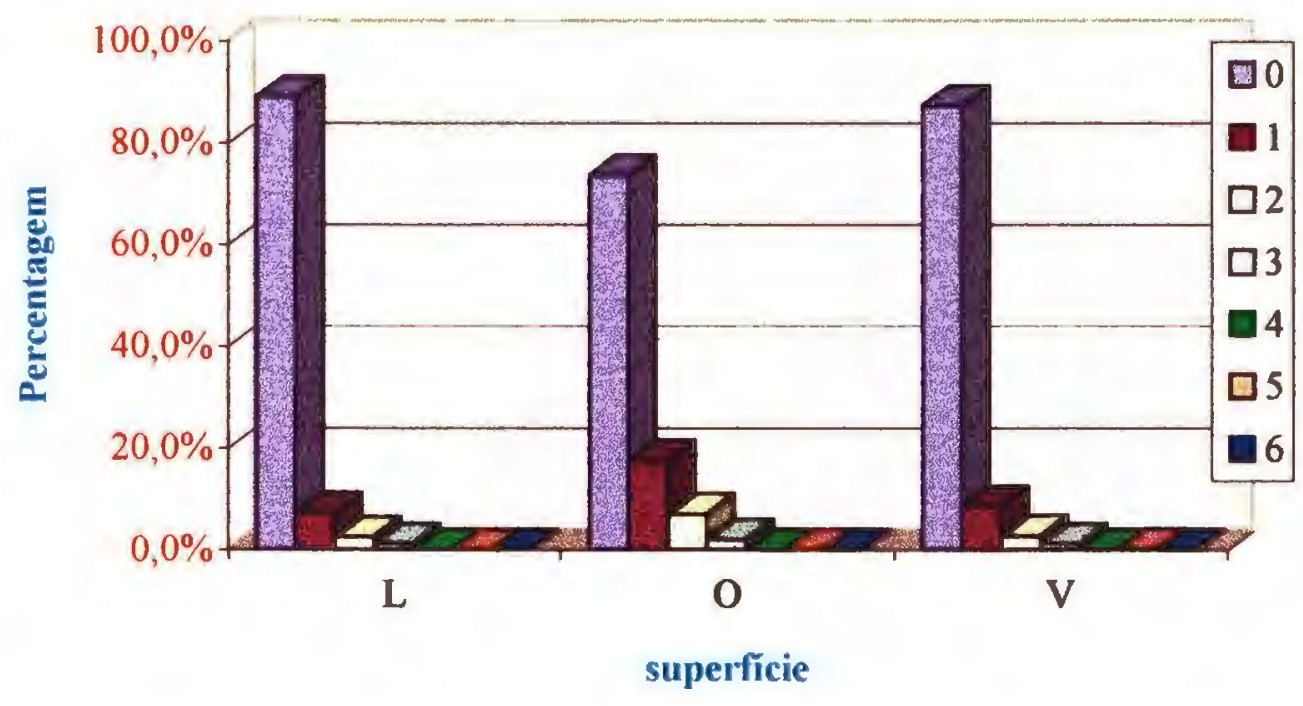


Tabela 13. Número e percentagem de superficies afetadas por código, indice de DEAN,em Piracicaba.

\begin{tabular}{lcccccccccccc}
\hline & \multicolumn{4}{c}{ Número de superficies } & \multicolumn{1}{c}{ Percentagem de superficies } \\
\hline Sup. & 0 & 1 & 2 & 3 & 4 & Total & 0 & 1 & 2 & 3 & 4 & Total \\
\hline L & 3551 & 187 & 48 & 13 & 0 & 3799 & $93,5 \%$ & $4,9 \%$ & $1,3 \%$ & $0,3 \%$ & $0,0 \%$ & $100,0 \%$ \\
O & 1600 & 178 & 49 & 13 & 0 & 1840 & $87,0 \%$ & $9,7 \%$ & $2,7 \%$ & $0,7 \%$ & $0,0 \%$ & $100,0 \%$ \\
V & 3499 & 214 & 45 & 13 & 4 & 3775 & $92,7 \%$ & $5,7 \%$ & $1,2 \%$ & $0,3 \%$ & $0,1 \%$ & $100,0 \%$ \\
\hline Total & 8650 & 579 & 142 & 39 & 4 & 9414 & $91,9 \%$ & $6,2 \%$ & $1,5 \%$ & $0,4 \%$ & $0,0 \%$ & $100,0 \%$ \\
\hline
\end{tabular}

Gráfico 4. Composição percentual dos códigos do indice de DEAN, por superficie, em Piracicaba.

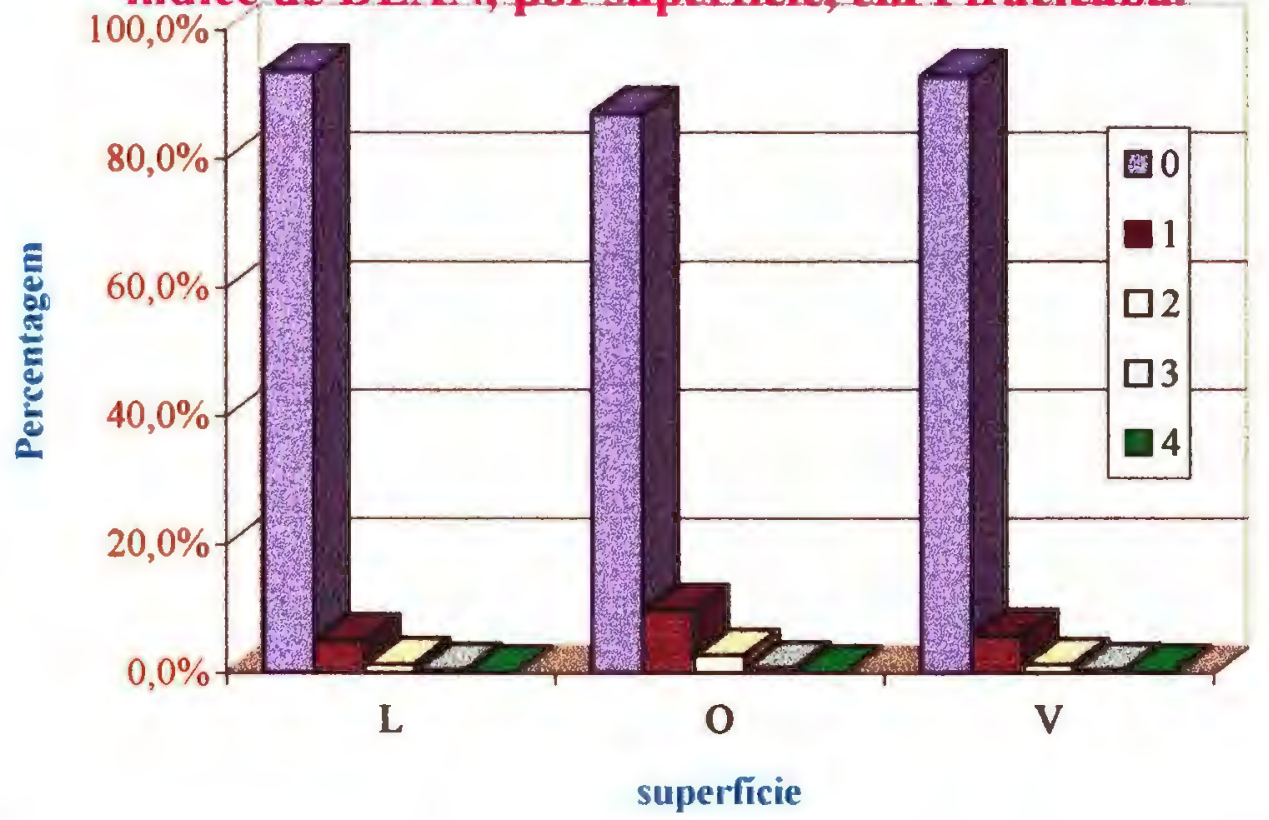


Tabela 14. Número e percentagem de superficies afetadas por código, índice T-F, em Piracicaba.

\begin{tabular}{ccccccccccccccc}
\hline \multicolumn{4}{c}{ Número de superficie } & \multicolumn{1}{c}{ Percentagem de superficie } \\
\hline Sup. & 0 & 1 & 2 & 3 & 4 & 5 & Total & 0 & 1 & 2 & 3 & 4 & 5 & Total \\
\hline $\mathrm{L}$ & 3543 & 74 & 140 & 41 & 1 & 0 & 3799 & $93,3 \%$ & $1,9 \%$ & $3,7 \%$ & $1,1 \%$ & $0,0 \%$ & $0,0 \%$ & $100,0 \%$ \\
$\mathrm{O}$ & 1591 & 0 & 207 & 41 & 1 & 0 & 1840 & $86,5 \%$ & $0,0 \%$ & $11,3 \%$ & $2,2 \%$ & $0,1 \%$ & $0,0 \%$ & $100,0 \%$ \\
$\mathrm{~V}$ & 3497 & 94 & 140 & 37 & 1 & 6 & 3775 & $92,6 \%$ & $2,5 \%$ & $3,7 \%$ & $1,0 \%$ & $0,0 \%$ & $0,2 \%$ & $100,0 \%$ \\
\hline Total & 8631 & 168 & 487 & 119 & 3 & 6 & 9414 & $91,7 \%$ & $1,8 \%$ & $5,2 \%$ & $1,3 \%$ & $0,0 \%$ & $0,1 \%$ & $100,0 \%$ \\
\hline
\end{tabular}

\section{Gráfico 5. Composição percentual dos códigos do índice T-F, em Piracicaba.}

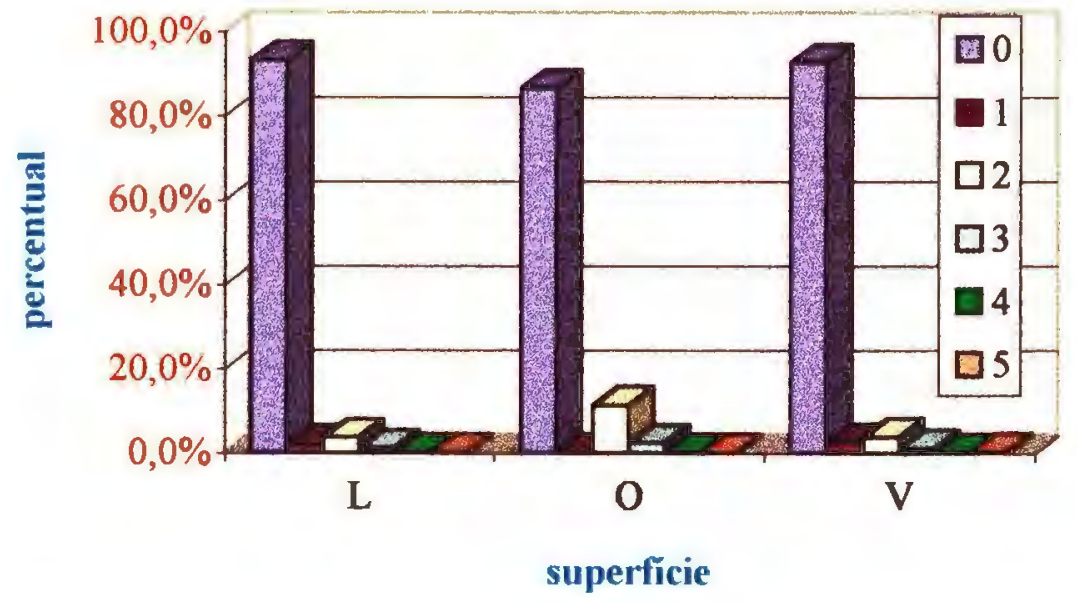


Tabela 15. Número e percentagem de superficies afetadas por código, TSIF, Piracicaba.

\begin{tabular}{lcccccccccccc}
\hline \multicolumn{1}{c}{ Número de superficies } & \multicolumn{1}{c}{ Percentagem de superficies } \\
\hline Sup. & 0 & 1 & 2 & 3 & 5 & Total & 0 & 1 & 2 & 3 & 5 & Total \\
\hline L & 3537 & 187 & 73 & 2 & 0 & 3799 & $93,1 \%$ & $4,9 \%$ & $1,9 \%$ & $0,1 \%$ & $0,0 \%$ & $100,0 \%$ \\
O & 1599 & 175 & 64 & 2 & 0 & 1840 & $86,9 \%$ & $9,5 \%$ & $3,5 \%$ & $0,1 \%$ & $0,0 \%$ & $100,0 \%$ \\
V & 3493 & 206 & 69 & 2 & 5 & 3775 & $92,5 \%$ & $5,5 \%$ & $1,8 \%$ & $0,1 \%$ & $0,1 \%$ & $100,0 \%$ \\
\hline Total & 8629 & 568 & 206 & 6 & 5 & 9414 & $91,7 \%$ & $6,0 \%$ & $2,2 \%$ & $0,1 \%$ & $0,0 \%$ & $100,0 \%$ \\
\hline
\end{tabular}

\section{Gráfico 6. Composição percentual dos códigos do} TSIF, por superfície, em Piracicaba.

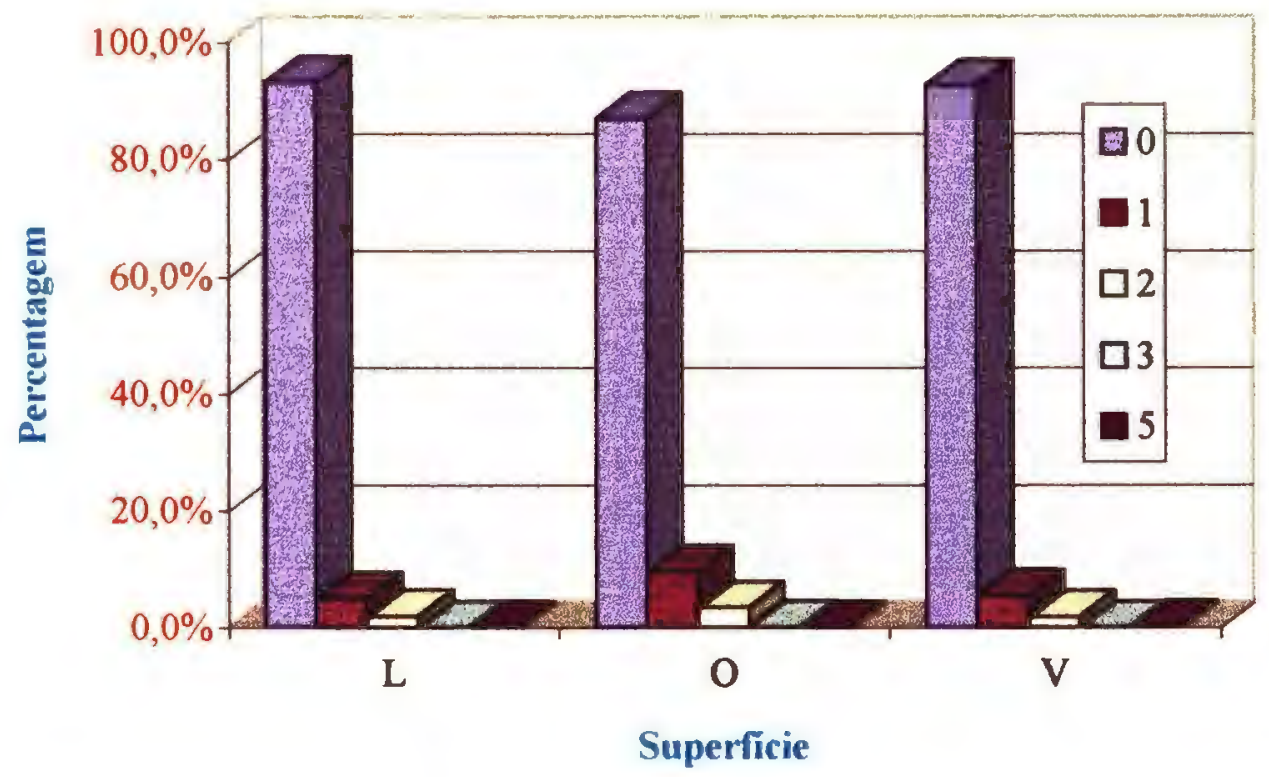


Tabela 16. Número e percentagem de superficies afetadas por código, índice de DEAN, em Iracemápolis.

\begin{tabular}{ccccccc}
\hline & \multicolumn{3}{c}{ Número de superficies } & \multicolumn{3}{c}{ Percentagem de superficies } \\
\hline Sup. & 0 & 1 & Total & 0 & 1 & Total \\
\hline L & 4405 & 34 & 4439 & $99,2 \%$ & $0,8 \%$ & $100,0 \%$ \\
O & 1559 & 61 & 1620 & $96,2 \%$ & $3,8 \%$ & $100,0 \%$ \\
V & 4342 & 34 & 4376 & $99,2 \%$ & $0,8 \%$ & $100,0 \%$ \\
\hline Total & 10306 & 129 & 10435 & $98,8 \%$ & $1,2 \%$ & $100,0 \%$ \\
\hline
\end{tabular}

\section{Gráfico 7. Composição percentual dos códigos}

do índice de DEAN, por superfície, em

Iracemápolis.

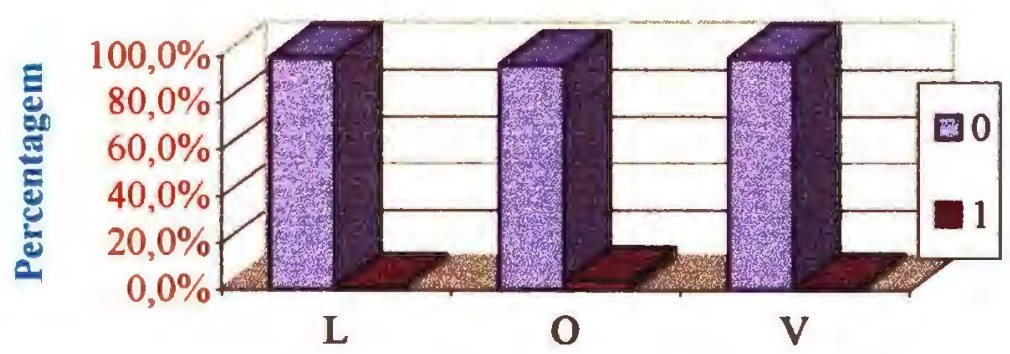

Superfície 
Tabela 17. Número e percentagem de superficies afetadas por código, indice T-F, em Iracemápolis. Número de superficies

\begin{tabular}{ccccccccc}
\hline Sup. & 0 & 1 & 2 & Total & 0 & 1 & 2 & Total \\
\hline L & 4401 & 14 & 24 & 4439 & $99,1 \%$ & $0,3 \%$ & $0,5 \%$ & $100,0 \%$ \\
O & 1552 & 0 & 68 & 1620 & $95,8 \%$ & $0,0 \%$ & $4,2 \%$ & $100,0 \%$ \\
V & 4338 & 14 & 24 & 4376 & $99,1 \%$ & $0,3 \%$ & $0,6 \%$ & $100,0 \%$ \\
\hline Total & 10291 & 28 & 116 & 10435 & $98,6 \%$ & $0,3 \%$ & $1,1 \%$ & $100,0 \%$ \\
\hline
\end{tabular}

Gráfico 8. Composição percentual dos códigos do indice T-F, por superfície, em Iracemápolis.

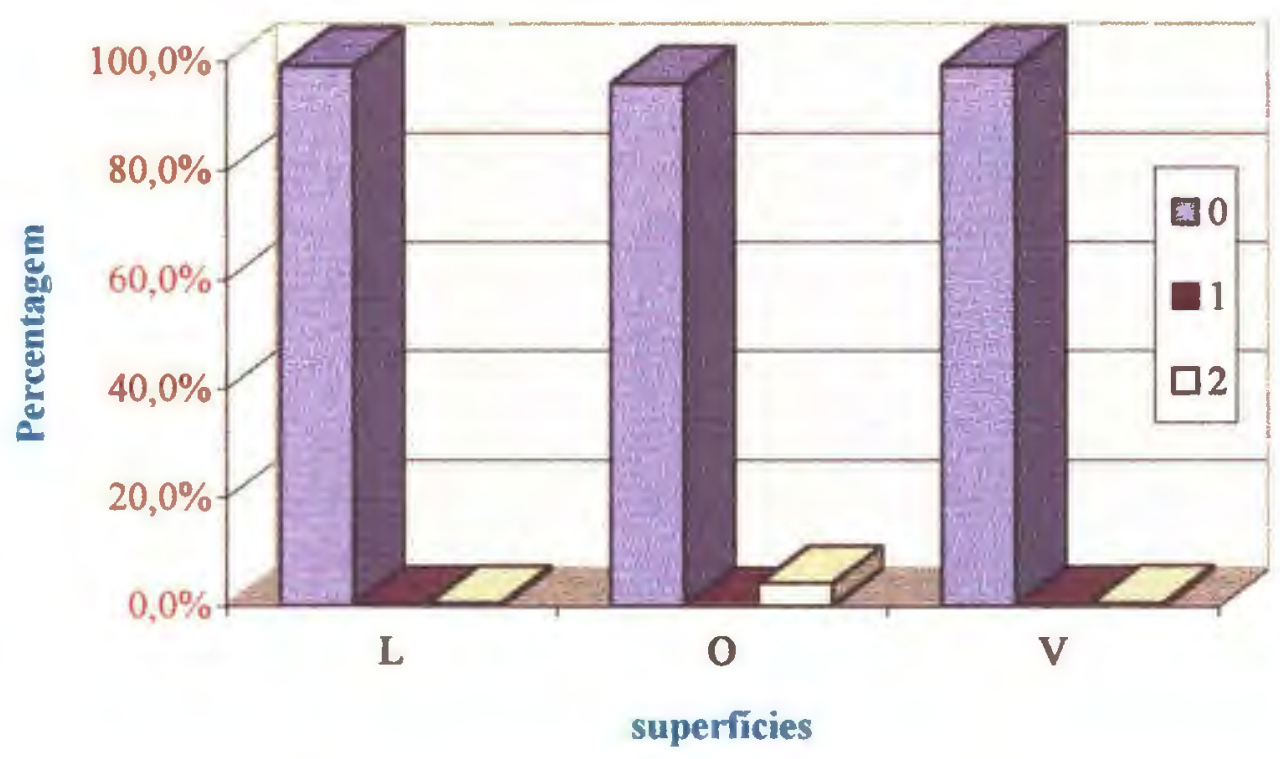


Tabela 18. Número e percentagem de superfícies afetadas por código, TSIF, em Iracemápolis.

\begin{tabular}{ccccccc}
\hline \multicolumn{3}{c}{ Número de superficies } & \multicolumn{3}{c}{ Percentagem de superficies } \\
\hline Sup. & 0 & 1 & Total & 0 & 1 & Total \\
\hline L & 4401 & 38 & 4439 & $99,1 \%$ & $0,9 \%$ & $100,0 \%$ \\
O & 1553 & 67 & 1620 & $95,9 \%$ & $4,1 \%$ & $100,0 \%$ \\
V & 4338 & 38 & 4376 & $99,1 \%$ & $0,9 \%$ & $100,0 \%$ \\
\hline Total & 10292 & 143 & 10435 & $98,6 \%$ & $1,4 \%$ & $100,0 \%$ \\
\hline
\end{tabular}

Gráfico 9. Composição percentual dos códigos do TSIF, por superfície, em Iracemápolis.

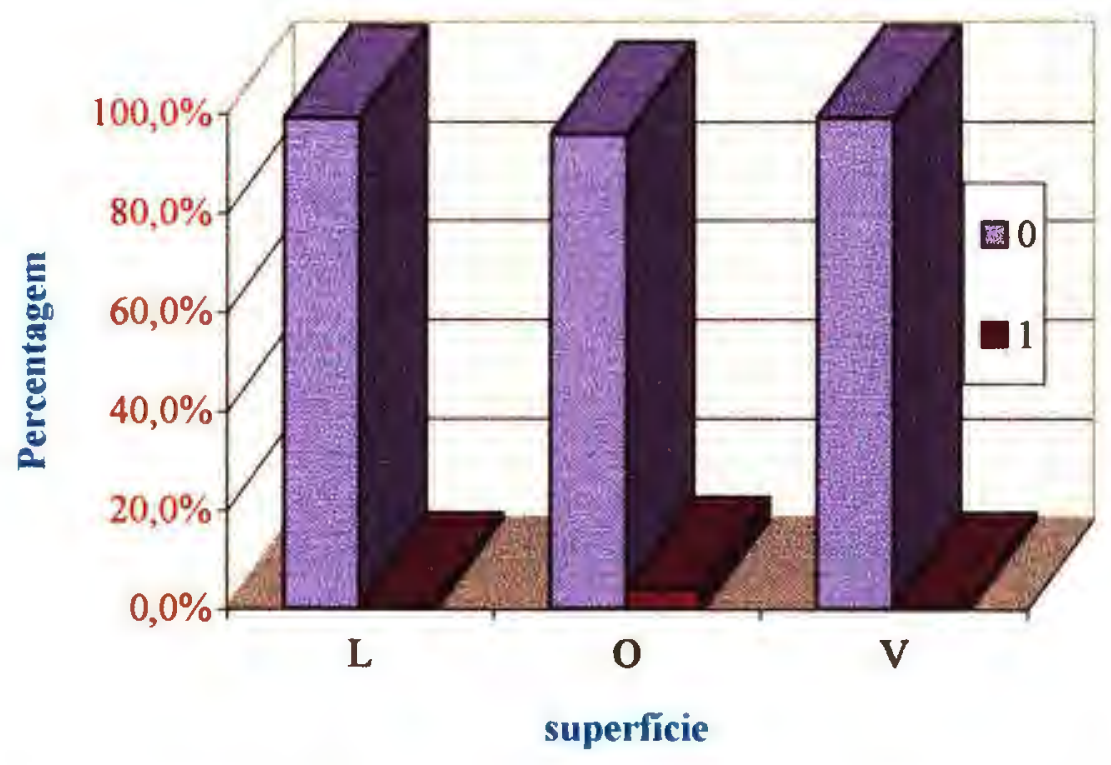



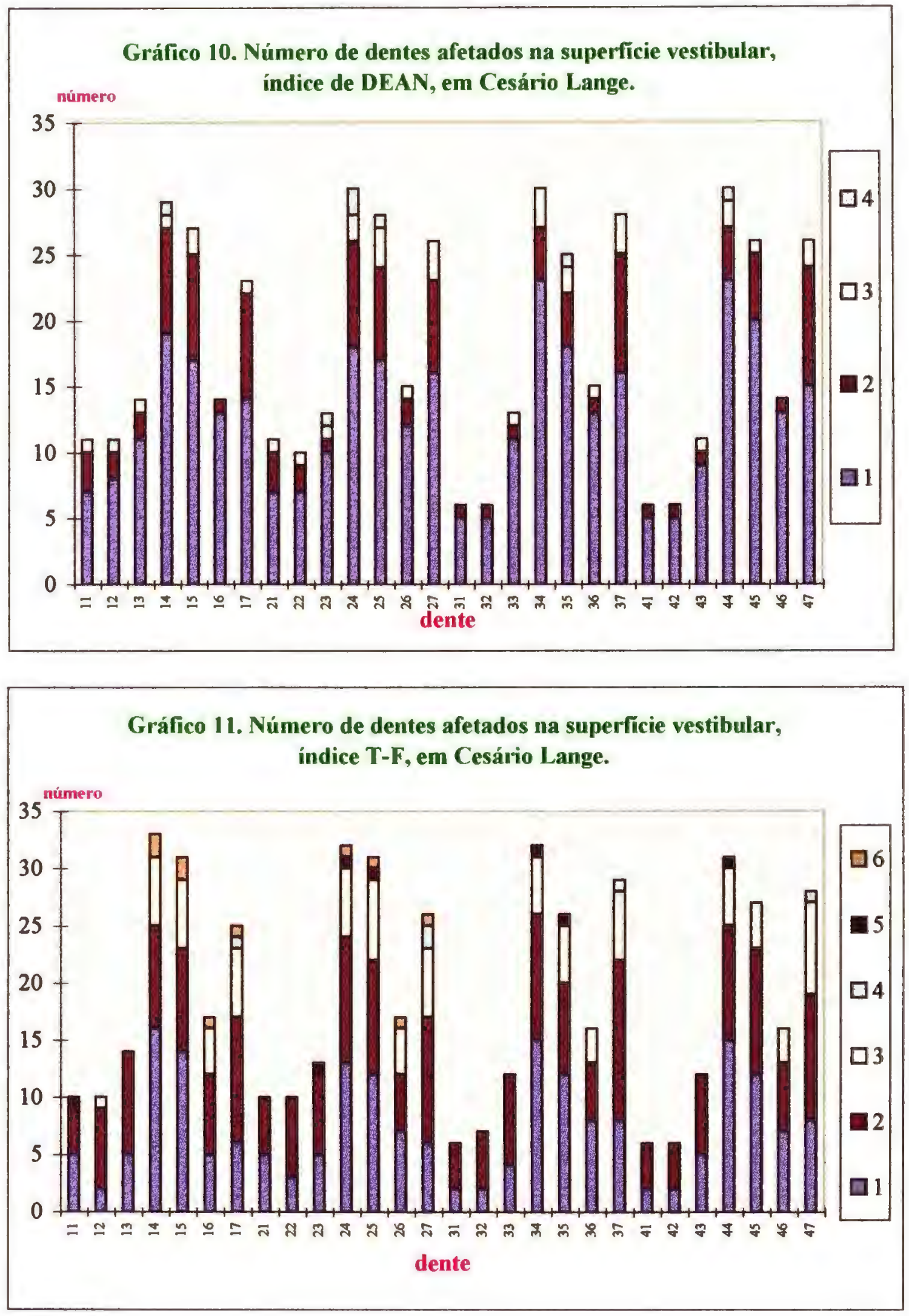

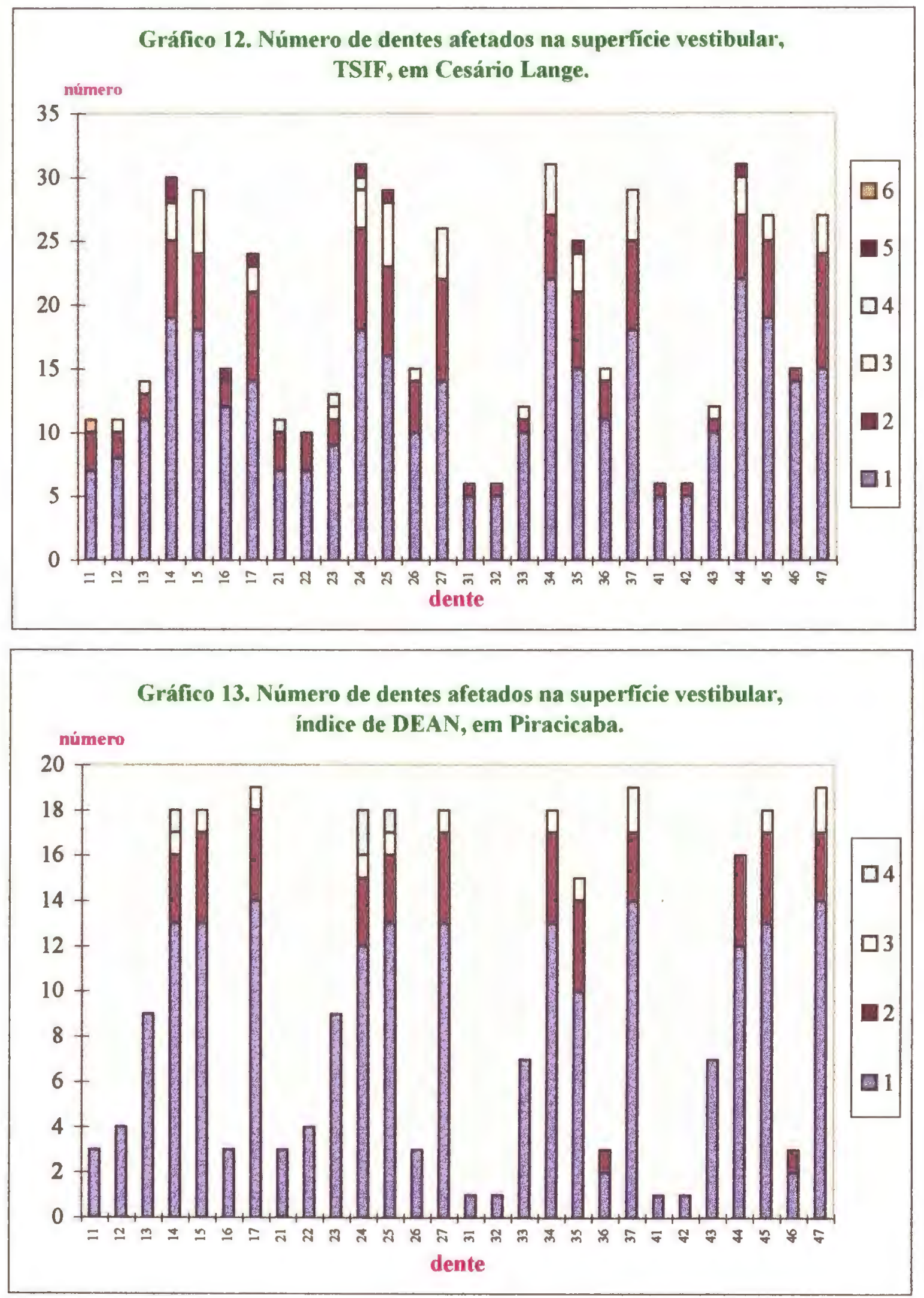

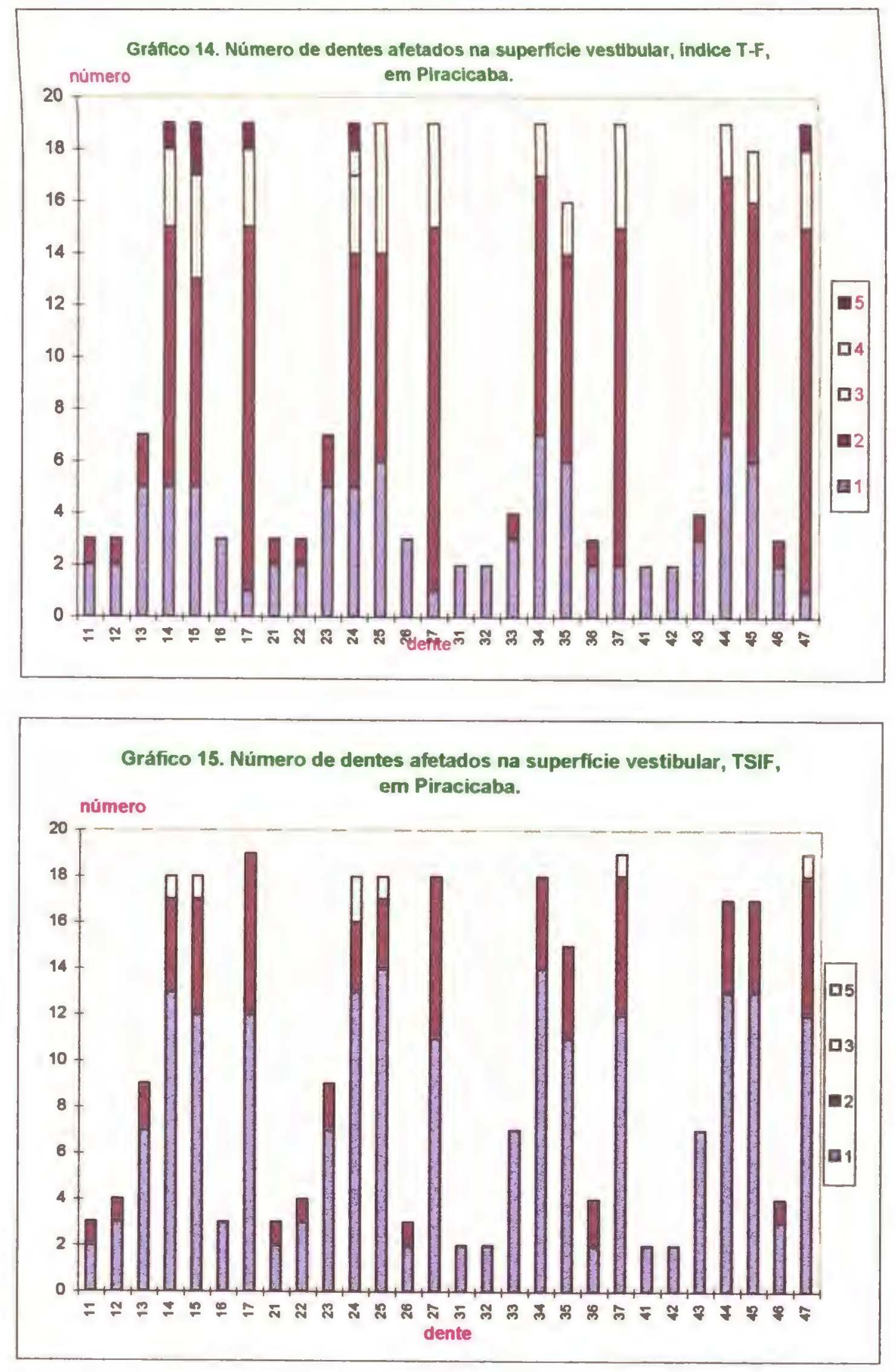
Grảfico 16. Número de dentes afetados na superfície vestibular, indice de DEAN, em Iracemápolis.

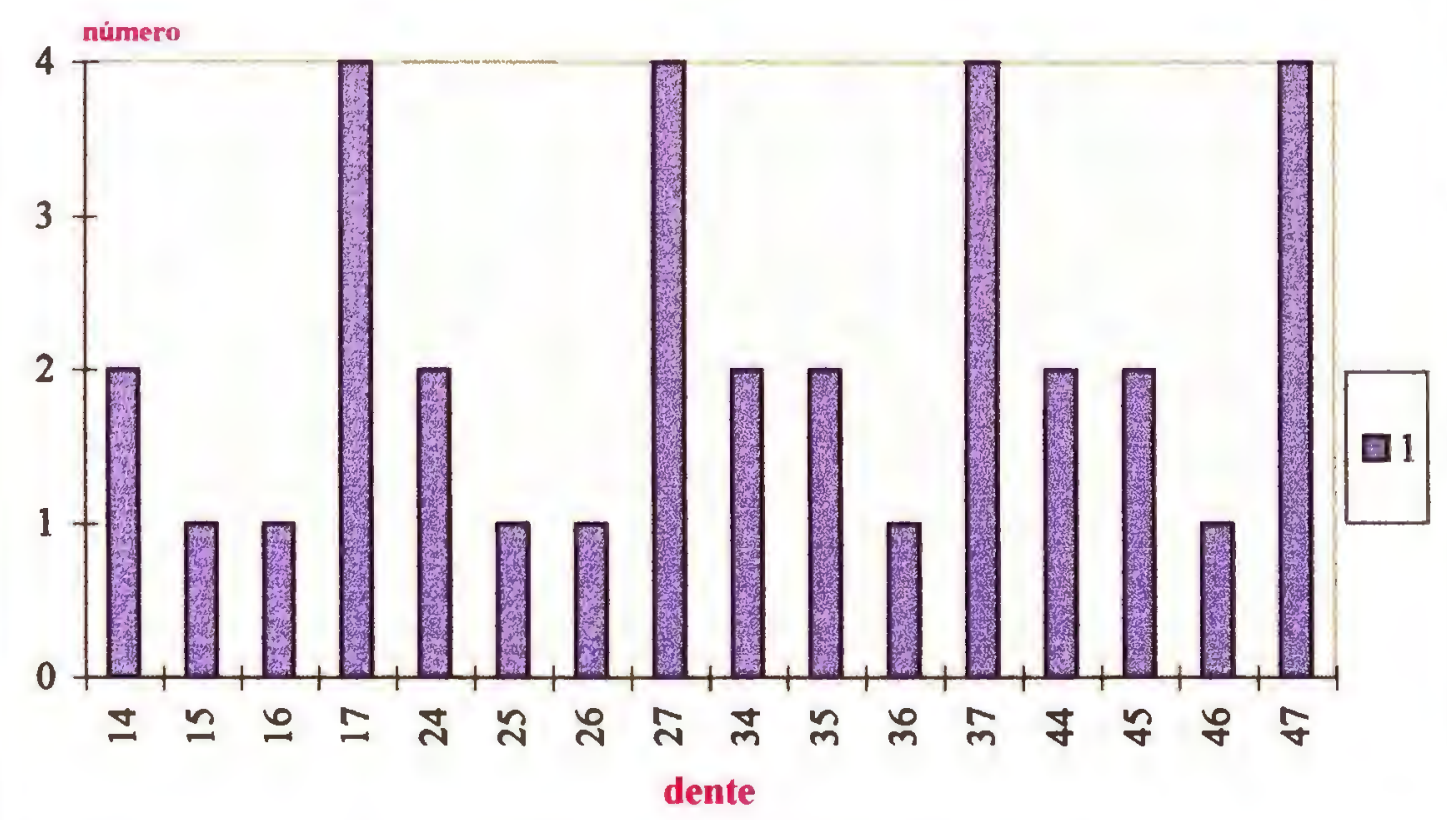

Gráfico 17. Número de dentes afetados na superficie vestibular, indice T-F, em Iracemápolis.

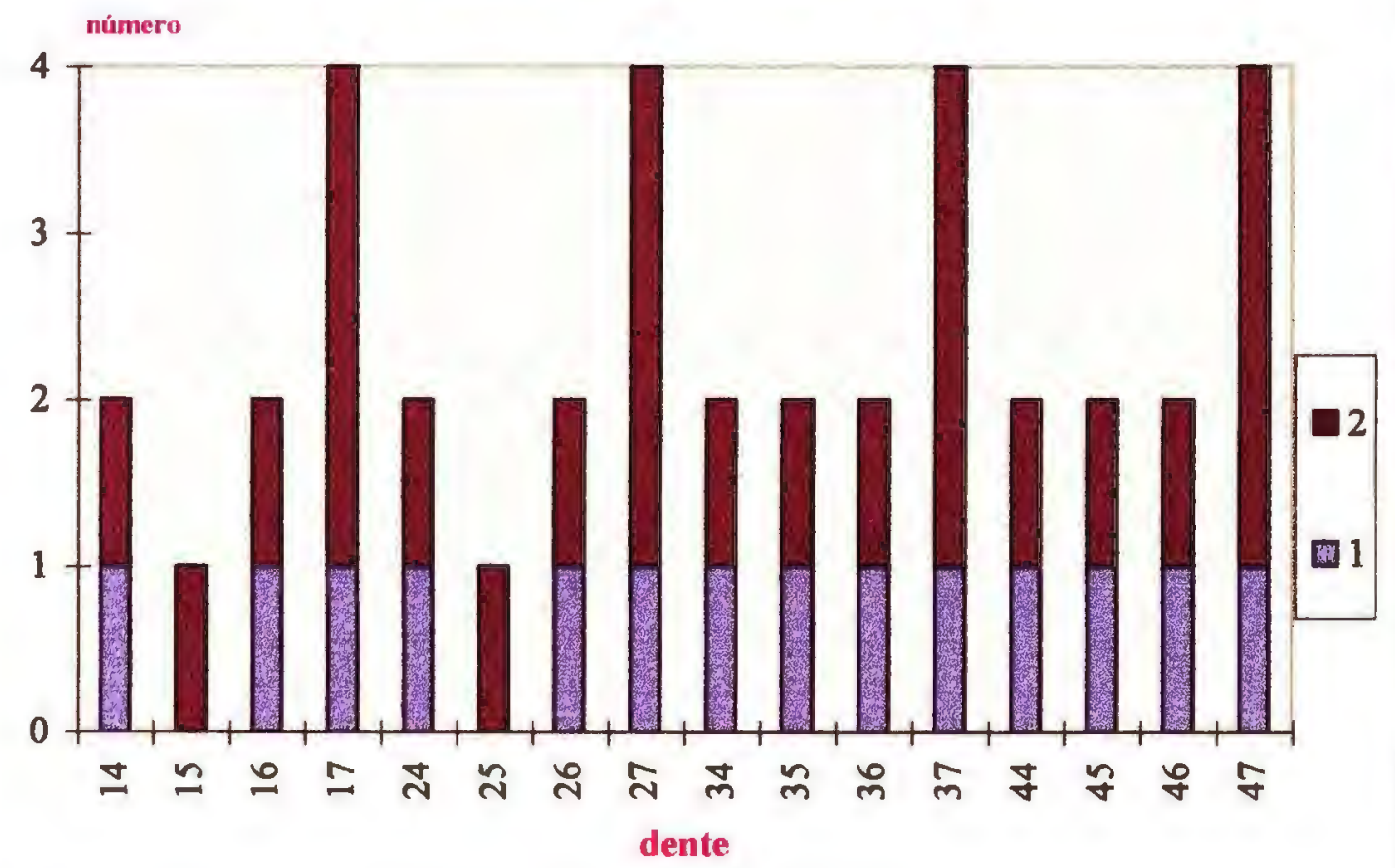


Gráfico 18. Número de dentes afetados na superfície vestibular, TSIF, em Iracemápolis.

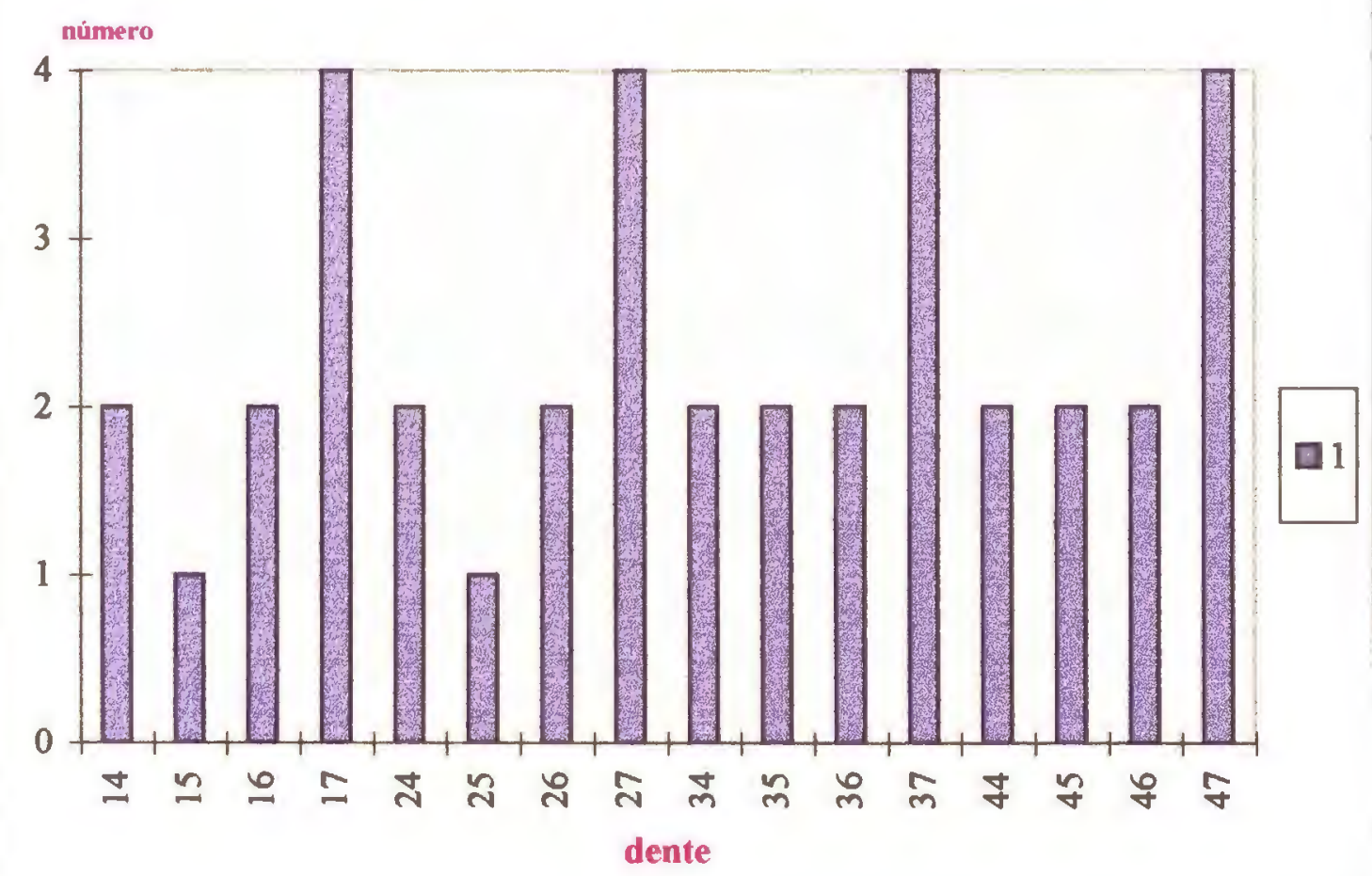


Tabela 19 . Prevalência de fluorose dentária, segundo a cidade e o indice utilizado.

\begin{tabular}{c|c|c|c|c|c|c}
\hline Índice & \multicolumn{2}{|c|}{ DEAN } & \multicolumn{2}{c|}{$\mathrm{T}-\mathrm{F}$} & \multicolumn{2}{c}{ TSIF } \\
\hline CIDADE & $\mathrm{N}^{*}$ & $\%$ & $\mathrm{~N}^{*}$ & $\%$ & $\mathrm{~N}^{*}$ & $\%$ \\
\hline Cesário & 50 & 32,7 & 51 & 33,7 & 50 & 32,7 \\
Piracicaba & 24 & 16,9 & 25 & 17,6 & 24 & 16,9 \\
Iracemápolis & 7 & 4,2 & 7 & 4,2 & 7 & 4,2 \\
\hline
\end{tabular}

* Número de crianças atingidas

Tabela 20. Tabela cruzada da distribuição percentual entre os indices de DEAN e T-F, em Cesário Lange.

\begin{tabular}{c|ccccccc|c}
\hline & \multicolumn{7}{|c|}{ T-F } & \\
\hline DEAN & 0 & 1 & 2 & 3 & 4 & 5 & 6 & Total \\
\hline 0 & $98,90 \%$ & $0,54 \%$ & $0,44 \%$ & $0,12 \%$ & $0,00 \%$ & $0,00 \%$ & $0,00 \%$ & $100,00 \%$ \\
1 & $1,65 \%$ & $31,89 \%$ & $63,99 \%$ & $1,96 \%$ & $0,00 \%$ & $0,00 \%$ & $0,51 \%$ & $100,00 \%$ \\
2 & $0,29 \%$ & $3,19 \%$ & $63,48 \%$ & $31,88 \%$ & $0,87 \%$ & $0,00 \%$ & $0,29 \%$ & $100,00 \%$ \\
3 & $0,00 \%$ & $2,04 \%$ & $30,61 \%$ & $47,96 \%$ & $13,27 \%$ & $4,08 \%$ & $2,04 \%$ & $100,00 \%$ \\
4 & $0,00 \%$ & $0,00 \%$ & $0,00 \%$ & $12,50 \%$ & $0,00 \%$ & $62,50 \%$ & $25,00 \%$ & $100,00 \%$ \\
\hline
\end{tabular}

Tabela 21. Tabela cruzada da distribuição percentual entre os índices de DEAN e T-F, em Piracicaba.

\begin{tabular}{c|cccccc|c}
\hline & \multicolumn{7}{|c|}{ TF } \\
\hline DEAN & 0 & 1 & 2 & 3 & 4 & 5 & Total \\
\hline 0 & $99,36 \%$ & $0,23 \%$ & $0,38 \%$ & $0,03 \%$ & $0,00 \%$ & $0,00 \%$ & $100,00 \%$ \\
1 & $6,22 \%$ & $25,22 \%$ & $65,45 \%$ & $2,94 \%$ & $0,00 \%$ & $0,17 \%$ & $100,00 \%$ \\
2 & $0,00 \%$ & $1,41 \%$ & $53,52 \%$ & $41,55 \%$ & $2,11 \%$ & $1,41 \%$ & $100,00 \%$ \\
3 & $0,00 \%$ & $0,00 \%$ & $0,00 \%$ & $97,44 \%$ & $0,00 \%$ & $2,56 \%$ & $100,00 \%$ \\
4 & $0,00 \%$ & $0,00 \%$ & $0,00 \%$ & $50,00 \%$ & $0,00 \%$ & $50,00 \%$ & $100,00 \%$ \\
\hline
\end{tabular}

Tabela 22. Tabela cruzada da distribuição percentual entre os índices de DEAN e T-F, em Iracemápolis.

\begin{tabular}{c|ccc|c}
\hline & \multicolumn{3}{|c|}{ TF } & \\
\hline DEAN & 0 & 1 & 2 & Total \\
\hline 0 & $99,85 \%$ & $0,08 \%$ & $0,07 \%$ & $100,00 \%$ \\
1 & $0,00 \%$ & $15,50 \%$ & $84,50 \%$ & $100,00 \%$ \\
\hline
\end{tabular}


Tabela 23. Tabela cruzada da distribuição percentual entre os índices de DEAN e TSIF, em Cesário Lange.

\begin{tabular}{c|ccccccc|c}
\hline & \multicolumn{7}{|c|}{ TSIF } & \\
\hline DEAN & 0 & 1 & 2 & 3 & 4 & 5 & 6 & Total \\
\hline 0 & $99,43 \%$ & $0,40 \%$ & $0,06 \%$ & $0,11 \%$ & $0,00 \%$ & $0,00 \%$ & $0,00 \%$ & $100,00 \%$ \\
1 & $1,34 \%$ & $89,81 \%$ & $7,82 \%$ & $0,82 \%$ & $0,00 \%$ & $0,21 \%$ & $0,00 \%$ & $100,00 \%$ \\
2 & $0,00 \%$ & $17,97 \%$ & $74,20 \%$ & $7,83 \%$ & $0,00 \%$ & $0,00 \%$ & $0,00 \%$ & $100,00 \%$ \\
3 & $0,00 \%$ & $0,00 \%$ & $5,10 \%$ & $90,82 \%$ & $1,02 \%$ & $2,04 \%$ & $1,02 \%$ & $100,00 \%$ \\
4 & $0,00 \%$ & $0,00 \%$ & $0,00 \%$ & $12,50 \%$ & $25,00 \%$ & $62,50 \%$ & $0,00 \%$ & $100,00 \%$ \\
\hline
\end{tabular}

Tabela 24. Tabela cruzada da distribuição percentual entre os índices de DEAN e TSIF, em Piracicaba.

\begin{tabular}{c|ccccc|c}
\hline & \multicolumn{5}{|c|}{ TSIF } & \\
\hline DEAN & 0 & 1 & 2 & 3 & 5 & Total \\
\hline 0 & $99,70 \%$ & $0,18 \%$ & $0,12 \%$ & $0,00 \%$ & $0,00 \%$ & $100,00 \%$ \\
1 & $0,86 \%$ & $89,64 \%$ & $9,33 \%$ & $0,00 \%$ & $0,17 \%$ & $100,00 \%$ \\
2 & $0,00 \%$ & $23,24 \%$ & $76,76 \%$ & $0,00 \%$ & $0,00 \%$ & $100,00 \%$ \\
3 & $0,00 \%$ & $0,00 \%$ & $84,62 \%$ & $15,38 \%$ & $0,00 \%$ & $100,00 \%$ \\
4 & $0,00 \%$ & $0,00 \%$ & $0,00 \%$ & $0,00 \%$ & $100,00 \%$ & $100,00 \%$ \\
\hline
\end{tabular}

Tabela 25. Tabela cruzada da distribuição percentual entre os índices de DEAN e TSIF, em Iracemápolis.

\begin{tabular}{|c|c|c|c|}
\hline & \multicolumn{2}{|c|}{ TSIF } & \\
\hline DEAN & 0 & 1 & Total \\
\hline 0 & $99,86 \%$ & 0,14 & $100,00 \%$ \\
\hline 1 & $0,00 \%$ & 0,00 & $100,00 \%$ \\
\hline
\end{tabular}


Tabela 26. Tabela cruzada da distribuição percentual entre os índices de T-F e TSIF, em Cesário Lange.

\begin{tabular}{c|ccccccc|c}
\hline & \multicolumn{7}{|c|}{ TSIF } & \\
\hline TF & 0 & 1 & 2 & 3 & 4 & 5 & 6 & Total \\
\hline 0 & $99,73 \%$ & $0,22 \%$ & $0,05 \%$ & $0,00 \%$ & $0,00 \%$ & $0,00 \%$ & $0,00 \%$ & $100,00 \%$ \\
1 & $11,65 \%$ & $82,66 \%$ & $5,69 \%$ & $0,00 \%$ & $0,00 \%$ & $0,00 \%$ & $0,00 \%$ & $100,00 \%$ \\
2 & $2,20 \%$ & $67,88 \%$ & $25,41 \%$ & $4,40 \%$ & $0,11 \%$ & $0,00 \%$ & $0,00 \%$ & $100,00 \%$ \\
3 & $1,07 \%$ & $14,97 \%$ & $43,32 \%$ & $40,64 \%$ & $0,00 \%$ & $0,00 \%$ & $0,00 \%$ & $100,00 \%$ \\
4 & $0,00 \%$ & $0,00 \%$ & $18,75 \%$ & $81,25 \%$ & $0,00 \%$ & $0,00 \%$ & $0,00 \%$ & $100,00 \%$ \\
5 & $0,00 \%$ & $0,00 \%$ & $0,00 \%$ & $22,22 \%$ & $22,22 \%$ & $44,45 \%$ & $11,11 \%$ & $100,00 \%$ \\
6 & $0,00 \%$ & $0,00 \%$ & $20,00 \%$ & $30,00 \%$ & $0,00 \%$ & $50,00 \%$ & $0,00 \%$ & $100,00 \%$ \\
\hline
\end{tabular}

Tabela 27. Tabela cruzada da distribuição percentual entre os índices de T-F e TSIF, em Piracicaba.

\begin{tabular}{c|ccccc|c}
\hline & \multicolumn{5}{|c|}{ TSIF } & \\
\hline TF & 0 & 1 & 2 & 3 & 5 & Total \\
\hline 0 & $99,42 \%$ & $0,44 \%$ & $0,14 \%$ & $0,00 \%$ & $0,00 \%$ & $100,00 \%$ \\
1 & $9,52 \%$ & $89,29 \%$ & $1,19 \%$ & $0,00 \%$ & $0,00 \%$ & $100,00 \%$ \\
2 & $6,57 \%$ & $75,56 \%$ & $17,87 \%$ & $0,00 \%$ & $0,00 \%$ & $100,00 \%$ \\
3 & $0,00 \%$ & $10,08 \%$ & $84,04 \%$ & $4,20 \%$ & $1,68 \%$ & $100,00 \%$ \\
4 & $0,00 \%$ & $0,00 \%$ & $100,00 \%$ & $0,00 \%$ & $0,00 \%$ & $100,00 \%$ \\
5 & $0,00 \%$ & $0,00 \%$ & $33,33 \%$ & $16,67 \%$ & $50,00 \%$ & $100,00 \%$ \\
\hline
\end{tabular}

Tabela 28. Tabela cruzada da distribuição percentual entre os índices de T-F e TSIF, em Iracemápolis.

\begin{tabular}{c|ccc|c}
\hline & & TSIF & \\
\hline TF & 0 & 1 & Total \\
\hline 0 & $100,00 \%$ & $0,00 \%$ & $100,00 \%$ \\
1 & $0,00 \%$ & $100,00 \%$ & $100,00 \%$ \\
2 & $0,86 \%$ & $99,14 \%$ & $100,00 \%$ \\
\hline
\end{tabular}


Tabela 29. Valores da estatística KAPPA, segundo o índice utilizado $(n=45)$.

\begin{tabular}{cccc}
\hline Índice & DEAN & T-F & TSIF \\
\hline valores K & 0,76 & 0,79 & 0,78 \\
\hline
\end{tabular}

Tabela 30. Coeficiente de correlação de Spearman, segundo o indice e a cidade

\begin{tabular}{c|c|c|c}
\hline & \multicolumn{3}{|c}{ índice } \\
\hline Cidade & DEAN x T-F & DEAN x TSIF & T-F x TSIF \\
\hline Cesário Lange & 0,956 & 0,974 & 0,966 \\
\hline Piracicaba & 0,937 & 0,977 & 0,932 \\
\hline Iracemápolis & 0,946 & 0,949 & 0,996 \\
\hline
\end{tabular}




\section{7-DISCUSSÃO}

Muitos estudos (HOROWITZ et al. "15; JACKSON, JAMES \& WOLFE" ${ }^{80}$; WILLIAMS \& ZWEMER ${ }^{184}$ ), utilizando diferentes índices, têm demonstrado que a prevalência e severidade da fluorose dentária aumentam conforme a concentração de flúor nas águas de abastecimento.

No presente estudo, com relação ao índice de $\mathrm{DEAN}$, a prevalência em superficies foi de 14,3\%, sendo 9,7 \% (código 1), 3,5\% (código 2), 1,0 \% (código 3) e $0,1 \%$ (código 4)(Tabela 10), em Cesário Lange (duas vezes a concentração ótima F). A prevalência em superficies verificada em Piracicaba foi de 8,1\%,sendo $6,2 \%$ (código 1), 1,5\%(código 2), 0,4\% (código 3), além de 4 superfícies atingidas e classificadas como código 4 (Tabela 13), próxima à verificada por LEVERETT ${ }^{97}$ com 7,0\% e KUMAR et al. ${ }^{88}$ com 9,0\%, porém distante dos dados obtidos por SEGRETO et al. ${ }^{156}$ na cidade de San Antonio(EUA) com 39,4 \%. Em Iracemápolis ( 0,3 vezes a concentração ótima $F)$ foi verificada uma prevalência de $1,2 \%$, todas essas superficies classificadas como código 1(Tabela 16), próxima aos dados de LEATHERWOOD et al. ${ }^{95}$ e CLARKSON \& O'MULLANE ${ }^{27}$ com 3,0 \% e 1,3\%, respectivamente, não sendo observada, nesta localidade, nenhuma superficie de dentes anteriores afetada pela fluorose dentária.

$\mathrm{O}$ índice T-F apresentou uma prevalência em superficies de $15,1 \%$, sendo 3,7\% (código 1), 9,1 \% (código 2), 1,9\% (código 3), 0,2 \% (código 4) , 0,1\% (código 5) e 0,1 (código 6)(Tabela 11),em Cesário Lange, enquanto WENZEL \& THYLSTRUP ${ }^{182}$ encontraram uma prevalência de superficies atingidas de $89,0 \%$. Observou-se , em Piracicaba, uma prevalência de 8,4\%, sendo 1,8 \% (código 1), $5,2 \%$ (código 2), $1,3 \%$ (código 3) e $0,1 \%$ (código 5), além de 3 superficies classificadas como código 4 (Tabela 14), próxima à encontrada por OSUJ et al. ${ }^{134} \mathrm{e}$ MABELYA , KONIG \& HELDERMAN ${ }^{107}$ com 12,9\% e 12,0\%, porém diferente da observada por RIORDAN \& BANKS ${ }^{147}$ e WENZEL \& THYLSTRUP ${ }^{182} \mathrm{com}$ $40,3 \%$ e $47,0 \%$. Na cidade de Iracemápolis, verificou-se uma prevalência de $1,4 \%$, sendo $0,3 \%$ (código 1) e 1,1\% (código 2) (Tabela 17), diferente da observada por PENDRYS et al. ${ }^{138}$, RIORDAN \& BANKS ${ }^{147}$ e LARSEN, RICHARDS \& FEJERSKOV ${ }^{91}$ com prevalências de $25,2 \%, 33,0 \%$ e $10,0 \%$, respectivamente, porém próxima à verificada por WENZEL \& THYLSTRUP ${ }^{182} \operatorname{com} 3,0 \%$. 
$\mathrm{O}$ índice $\mathrm{T}-\mathrm{F}$ apresentou somente uma diferença em relação aos indices de DEAN e TSIF, na distribuição percentual pelos códigos, onde o código 2 é mais prevalente que o código 1 , sendo isto explicado pelo diagnóstico da superficie oclusal que se inicia com este código.

O TSIF apresentou uma prevalência em todas as superficies de $14,6 \%$, sendo 9,7 \%(código 1), 3,4 \% (código 2), 1,3\% (código 3) e 0,1 \% (código 5), além de três superficies classificadas como código 4 e uma superficie classificada como código 6 (Tabela 12), na cidade de Cesário Lange(duas vezes o fator ótimo de flúor), diferente dos dados observados por HEIFETZ et al. ${ }^{70}$, nos anos de 1980 e 1985 , e HOROWITZ et al. ${ }^{25}$, os quais obtiveram prevalências de $38,3 \%, 66,5 \%$ e $69,2 \%$. Verificou-se em Piracicaba(concentração ótima de flúor), uma prevalência de $8,4 \%$ (Tabela 15), sendo 6,0 \% (código 1), 2,2 \%(código 2), 0,1\%(código 3) e 0,1\% (código 5), diferentes das prevalências obtidas por HEIFETZ et al. ${ }^{70}$ nos anos de 1980 e 1985, SZPUNAR \& BURT ${ }^{168}$, HOROWITZ et al. ${ }^{75}$, VIGNARAJAH ${ }^{180}$ e WILLIAMS \& ZWEMER ${ }^{184}$ que verificaram prevalências variando de 11,4 a $81,0 \%$ (Tabela 9). $\mathrm{Na}$ cidade de Iracemápolis ( 0,3 vezes o fator ótimo de flúor), obteve-se uma prevalência em superficies de $1,4 \%$, todas classificadas como código 1(Tabela 18), próxima dos dados de VIGNARAJAH ${ }^{180}$ com $4,8 \%$ e WOLFOLK, FAJA \& BAGRAMIAN ${ }^{185} \operatorname{com} 6,9 \%$, porém diferente dos dados de SZPUNAR \& BURT ${ }^{168}$ com $12,2 \%$ e HOROWITZ et al. ${ }^{7 s}$ com $56,0 \%$, não sendo observada nenhuma superficie, em dentes anteriores, afetada pela fluorose dentária.

Com relação à prevalência da fluorose por dente, verificou-se que os mais prevalentes são os pré molares, seguidos pelos segundos molares, nas cidades de Cesário Lange e Piracicaba (Gráficos 10 a 15), concorde com as conclusões de SMALL \& MURRAY ${ }^{161}$, WENZEL \& THYLSTRUP ${ }^{182}$, HOROWITZ et al. ${ }^{75}$, BURGER et al. ${ }^{18}$, LESAN ${ }^{\circ}$ e GASPAR, PEREIRA \& MOREIRA ${ }^{64}$, enquanto que outros estudos apontam os incisivos superiores como os mais afetados (MOLLER et al. ${ }^{122}$; POULSEN \& MOLLER ${ }^{139}$ ). Na cidade de Iracemápolis verificou-se que os segundos molares são os mais afetados (Gráficos 16 a 18).

A severidade da fluorose dentária afetando dentes individuais na dentição permanente é atribuída à duração de exposição ao flúor durante a formação de esmalte (MOLLER ${ }^{120}$ ), sendo os dentes normalmente mais afetados aqueles com tempo de mineralização maior. 
THYLSTRUP \& FEJERSKOV ${ }^{173}$ afirmaram que a severidade da fluorose dentária dentro de uma mesma dentição é determinada pela espessura da camada de esmalte, sendo os dentes posteriores mais afetados que os anteriores, explicando as maiores prevalências dos pré molares e molares, verificadas neste estudo.

Na distribuição por superficie (Tabelas 10 a 18 e Gráficos 1 a 9), observou-se um padrão constante de maior prevalência nas superficies oclusais nos três índices estudados, justificado pelo fato do diagnóstico de formas iniciais de fluorose ser caracterizado por se apresentar com aspecto branco-giz (cume de neve) em ponta de cúspides. Porém, sendo estas superficies examinadas somente em dentes posteriores, acredita-se que a estética fica preservada, embora nas localidades examinadas neste estudo fossem verificadas poucas superficies comprometidas pela estética, podendo citar duas superficies vestibulares de dentes anteriores em Cesário Lange (códigos D4, T-F5 e TSIF4), não havendo nas cidades de Piracicaba e Iracemápolis superficies vestibulares com estética afetada.

Com relação à prevalência por criança (Tabela 19 ), notou-se um aumento progressivo de pessoas atingidas, conforme se eleva a concentração de flúor nas águas de abastecimento. Neste estudo, as prevalências diminuem, respectivamente em Cesário Lange, Piracicaba e Iracemápolis, sem contudo haver diferenças significativas entre os índices, verificando-se somente que o índice T-F apresentou uma prevalência ligeiramente superior que os índices de DEAN e TSIF, nas cidades de Cesário Lange e Piracicaba, podendo isto ser explicado pela diferença no diagnóstico intra-examinador, visto que alguns trabalhos (THYLSTRUP \& FEJERSKOV ${ }^{173}$; WENZEL \& THYLSTRUP ${ }^{182}$; GRANATH, WIDENHEIN \& BIRKHED ${ }^{\circ 6}$; BURGER et al. ${ }^{18}$ ) constataram diferenças pequenas ou despreziveis nas prevalências entre os índices.

A padronização dos dados de diferentes estudos, em área fluoretadas e não fluoretadas, foi pesquisada por CLARK ${ }^{24}$ baseado em estudos dos anos 80, afirmando que, em áreas não fluoretadas ou com flúor em concentrações baixas, as prevalências variavam de $4,4 \%$ a $55,0 \%$, com cinco dos oito estudos demonstrando prevalências acima de $20 \%$. Neste estudo, na cidade de Iracemápolis foi observada 
uma prevalência de $4,2 \%$, abaixo da estimativa proposta por PENDRYS \& STAMM ${ }^{137}$ de $10,0 \%$ e próxima à estimativa sugerida pelo Serviço Americano de Saúde Pública ,USPH ${ }^{17}$, em torno de $6,0 \%$, porém estas estimativas foram consideradas por CLARK ${ }^{24}$ como bastante conservadoras.

Com relação às áreas fluoretadas, as prevalências variavam de $11,4 \%$ a $80,9 \%$, sendo que 7 dos 11 estudos apresentavam percentagens acima de 25,0\% (CLARK ${ }^{24}$ ), enquanto PENDRYS \& STAMM ${ }^{137}$ e o Serviço Americano de Saúde Pública,USPH ${ }^{17 n}$, calcularam estimativas de prevalências em torno de $23,0 \%$ e $22,0 \%$, respectivamente, acima da observada, neste estudo, com prevalência de $17,0 \%$ em Piracicaba, porém muito próxima à observada por GASPAR, PEREIRA \& MOREIRA ${ }^{64}$ com $20,4 \%$, examinando crianças da mesma localidade.

Mediante os dados da Tabela 2, notou-se que as prevalências verificadas neste estudo estão próximas às dos estudos de DEAN,nas décadas de 30 e 40, e menores que as prevalências da década de 80 (Tabelas 3 e 4). Essas diferenças poderiam ser atribuidas à larga utilização de flúor, desde as idades iniciais, por métodos tópicos aplicados em massa, universalização do uso de dentifrícios fluoretados, além dos bochechos, vernizes,etc., verificada nos EUA e outros países desenvolvidos, que elevariam as percentagens de prevalência. No Brasil e, em especial, nas cidades deste estudo, se observam somente iniciativas de programas preventivos sem supervisão, principalmente após a criação dos Procedimentos Preventivos financiados pelo SUS, incluindo principalmente escovação e bochechos fluoretados, sendo realizados após o ingresso da criança na escola(idade acima de 6 anos), diminuindo a probabilidade do aparecimento da fluorose dentária, pois segundo DEN BESTEN \& THARIANI ${ }^{42}$, LIMEBACK ${ }^{105}$ RICHARDS et al. ${ }^{144}$, ISHII \& SUCKLING ${ }^{n}$ e DEN BESTEN \& CRENSHAW ${ }^{41}$ a fase de maturação do esmalte é a responsável pelo aparecimento dos sinais de fluorose.

Portanto, a diferenciação das prevalências, entre as três cidades deste estudo, foi única e exclusivamente devido às concentrações de flúor nas águas de abastecimento.

As diferenças de prevalências entre os diferentes estudos,utilizando os diversos índices de fluorose, podem ser explicadas por:

a) definição de "caso";

b) métodos de mensuração; 
c) erro intra e inter examinadores;

d) indice utilizado.

O problema da definição de "caso" esbarra em alguns aspectos metodológicos utilizados especificamente em cada estudo. KINGMAN ${ }^{86}$ afirma que cada escala de um indice pode ser dicotomizada para refletir uma definição de fluorose, sendo que a presença de fluorose pode ser apresentada por diferentes modos (dente, superficie, local da superficie ou, o que é mais comum, por grupo examinado), sendo recomendado de forma diferente para cada índice.

Isto pode ser melhor entendido se verificar que o índice de DEAN ${ }^{34}$ utilizava, para definição de "caso", os dois dentes mais severamente afetados pela fluorose, sendo portanto definido por KINGMAN ${ }^{84}$ como DI 2, diferente das classificações utilizadas pelos índices T-F e TSIF, que utilizavam como padrão para se medir a prevalência, qualquer valor diferente de $0(\mathrm{~T}-\mathrm{F}$ e $\mathrm{TSIF}>$ ou $=1)$, sendo definidos como T-F 1 e TSIF 1.

Porém, devido ao caráter bilateral da fluorose dentária, normalmente o DI 1 é igual ou muito próximo a DI 2 , sendo que neste estudo, para tentar eliminar possíveis diferenças entre DI 1 e DI 2 e diferenciar o critério para definição de "caso" entre os diferentes índices, optou-se pela escolha de DI 1, T-F 1 e TSIF 1.

Outro problema relacionado à determinação da prevalência da fluorose dentária são os métodos utilizados para os exames clínicos (Tabela 31 ). 
Tabela 31. Métodos utilizados em estudos de fluorose dentária por índice, 1980-1992.

\begin{tabular}{c|c|c|c|c}
\hline MÉTODO & CATEGORIA & DEAN(N=26) & T-F(N=18) & TSIF(N=7) \\
\hline Secagem & gaze/rolo algodão & - & 5 & - \\
& Ar comprimido & - & 6 & - \\
& Não & 6 & - & 1 \\
& Não reportado & 20 & 7 & 6 \\
Limpeza & Escovação & 3 & - & - \\
& Placa removida & 3 & - & - \\
& quando necessário & & & - \\
& gaze & - & 5 & - \\
& profilaxia & - & 1 & 7 \\
\multirow{4}{*}{ Luz } & não reportado & 20 & 12 & \\
& Artificial & 10 & 4 & 5 \\
& Natural & 10 & 6 & - \\
& Não reportado & 6 & 8 & 2 \\
\hline
\end{tabular}

Fonte: ROZIER ${ }^{149}$.

A determinação epidemiológica das condições clínicas para estimativa da prevalência de fluorose dentária pode estar sujeita à variabilidade devido à utilização de diferentes métodos. Originalmente, 0 indice de DEAN ${ }^{34}$ utilizava luz natural $\mathrm{e}$ os dentes eram examinados úmidos, enquanto $\mathrm{o}$ indice $\mathrm{T}-\mathrm{F}{ }^{173}$ realizava profilaxia prévia, sendo o exame efetuado com luz artificicial e secagem dos dentes por 1 minuto, além do TSIF ${ }^{75}$ que, em seu protocolo, utilizava luz artificial, examinando os dentes úmidos.

Neste estudo, para padronização dos métodos, optou-se pela utilização da escovação prévia, pois a profilaxia preconizada por THYLSTRUP \& FEJERSKOV ${ }^{173}$ demandaria muito tempo. Adicionalmente utilizou-se a secagem dos dentes e iluminação artificial. 
Tabela 32. Estimativas dos erros intra e inter examinadores reportadas em estudos de fluorose dentária, segundo o índice utilizado.

\begin{tabular}{|c|c|c|c|c|c|c|c|}
\hline \multirow[b]{2}{*}{ ESTUDO } & \multirow{2}{*}{\multicolumn{2}{|c|}{$\begin{array}{l}\text { No } \\
\text { ex. }\end{array}$}} & \multirow[b]{2}{*}{$\begin{array}{l}\text { Unidade } \\
\text { de medida }\end{array}$} & \multicolumn{2}{|c|}{ \% Concordância } & \multicolumn{2}{|c|}{ Estatística KAPPA } \\
\hline & & & & Intra & Inter & Intra & Inter \\
\hline \multicolumn{8}{|l|}{ Índice de DEAN } \\
\hline BOHATY et al. ${ }^{16}$ & & 1 & $\mathrm{NE}^{*}$ & 96 & & & \\
\hline $\begin{array}{l}\text { CLARKSON } \\
\text { O'MULLANE }{ }^{27}\end{array}$ & $\&$ & 4 & Pessoa & & $>95$ & & \\
\hline DRISCOLL et al. ${ }^{43}$ & & 1 & Pessoa & 82 & & & \\
\hline EKLUND et al. ${ }^{47}$ & & 1 & dente & 77 & & & \\
\hline EVANS 31 & & 2 & dente & & & $\begin{array}{l}\mathbf{0 , 7 6} \\
\mathbf{0 , 8 3}\end{array}$ & 0,61 \\
\hline EVANS \& STAMM $^{52}$ & & 1 & dente & & & $\begin{array}{l}0,92 \\
0,86\end{array}$ & \\
\hline LEWIS et al. ${ }^{104}$ & & 1 & $\mathrm{NE}$ & $>95$ & & & \\
\hline MANN et al. ${ }^{112}$ & & 1 & Pessoa & 98 & & & \\
\hline MANN et al. ${ }^{113}$ & & 1 & Pessoa & 92 & & & \\
\hline SONGPAISAN \& DAVIES ${ }^{1}$ & 163 & 1 & Pessoa & & 79 & & 0,35 \\
\hline $\begin{array}{l}\text { WARNAKULASURIYA } \\
\text { al. }{ }^{181}\end{array}$ & et & 1 & Pessoa & 66 & & & \\
\hline $\begin{array}{l}\text { MABELYA, KONIG } \\
\text { HELDERMAN }\end{array}$ & $\&$ & 2 & dente & & & 0,83 & \\
\hline \multicolumn{8}{|l|}{ Índice $\mathbf{T}-\mathbf{F}$} \\
\hline BAELUM et al. ${ }^{10}$ & & 3 & $\begin{array}{l}\text { Superf. } \\
\text { Vestib. }\end{array}$ & & $65,66,66$ & & \\
\hline HOLT et al. ${ }^{73}$ & & 1 & $\begin{array}{l}\text { Superf. } \\
\text { Vest. } \\
\text { Incisivos }\end{array}$ & 87 & & 0,67 & \\
\hline MANJ et al. ${ }^{110}$ & & 1 & $\begin{array}{l}\text { Superf. } \\
\text { Vestib. }\end{array}$ & $64-100^{* *}$ & & 0,67 & \\
\hline OSUJ et al. ${ }^{134}$ & & 1 & NS & & & 0,93 & \\
\hline RIORDAN\& BANKS ${ }^{147}$ & & 1 & $\begin{array}{l}\text { Todas } \\
\text { Superf. }\end{array}$ & & & 0,78 & \\
\hline $\begin{array}{l}\text { MABELYA, KONIG } \\
\text { HELDERMAN }\end{array}$ & $\&$ & 2 & dente & & & 0,87 & \\
\hline \multicolumn{8}{|l|}{ Indice TSIF } \\
\hline DRISCOLL et al. ${ }^{44}$ & & 2 & $\begin{array}{l}\text { Todas } \\
\text { Superf. }\end{array}$ & & & & $0,48,0,65$ \\
\hline HEIFETZ et al. ${ }^{70}$ & & 2 & $\begin{array}{l}\text { Todas } \\
\text { Superf. }\end{array}$ & & & & $0,51,0,61$ \\
\hline ISMAIL et al. ${ }^{79}$ & & 3 & Pessoa & & & & $0,51-0,70^{* * *}$ \\
\hline SZPUNAR \& BURT ${ }^{169}$ & & 1 & Pessoa & 92 & & 0,85 & \\
\hline
\end{tabular}

Fonte : ROZIER, ${ }^{149}$. * Não Especificado ** Concordância dos valores do índice T-F

*** Variação para a confiança do erro intra e inter examinadores 
Com relação ao erro intra examinador, verificaram-se, neste estudo (Tabela 29), valores da estatística de KAPPA de 0,76 para o índice de DEAN, muito próximo ao verificado por EVANS ${ }^{31}$ com 0,76 e 0,83 ,enquanto para o índice $T-F$, calculou-se 0,79 , próximo ao verificado por RIORDAN \& BANKS ${ }^{147} \mathrm{com} 0,78 \mathrm{e}$ um valor de 0,78 para o TSIF, próximo ao verificado por SZPUNAR \& BURT ${ }^{169}$ com 0,85 (Tabela 32).

Segundo MABELYA, KONIG \& HELDERMAN ${ }^{107}$, deveria esperar-se que um índice onde haja discriminações mais detalhadas (maior número de classificações), resultasse em um valor da estatística KAPPA menor, porém este princípio não se aplica ao indice $\mathrm{T}-\mathrm{F}$, pois foi construído de forma coerente, sendo cada valor da classificação precisamente descrito, caracterizando a evolução biológica do aparecimento dos sinais da fluorose dentária, desde os estágios iniciais com pequenas linhas esbranquiçadas cortando a superficie do esmalte dentário, até os estágios mais severos com perda de anatomia.

Porém, como todos os indices tiveram a mesma metodologia e houve um período grande de calibração, os valores da estatística KAPPA foram bastante satisfatórios, não comprometendo a confiança dos dados referentes aos três índices (Tabela 29).

Os valores de KAPPA, observados neste estudo, classificam-se como "substanciais" $(p<0,01)$ segundo a classificação de LANDIS \& $\mathrm{KOCH}^{9}$.

Nove estudos têm comparado os indices de DEAN, T-F e TSIF em várias combinações(THYLSTRUP \& FEJERSKOV ${ }^{173}$; WENZEL \& THYLSTRUP ${ }^{182}$; HOROWITZ et al. ${ }^{75}$; GRANATH, WIDENHEIN \& BIRKHED ${ }^{6 \%}$; DRISCOLL et al.4; BURGER et al. ${ }^{18}$; CLEATON-JONES \& HARGREAVES ${ }^{28}$; MABELYA, KONIG \& HELDERMAN ${ }^{107}$; GASPAR , PEREIRA \& MOREIRA ${ }^{64}$ ). As estimativas de prevalência são mostradas na Tabela 33 . 
Tabela 33 .Prevalências de fluorose dental verificadas em estudos comparando os indices de DEAN, T-F e TSIF.

\begin{tabular}{|c|c|c|c|c|}
\hline \multirow[t]{2}{*}{ Estudo } & \multirow[t]{2}{*}{ F ppm (Água) } & \multicolumn{3}{|c|}{ Percentagem afetada } \\
\hline & & DI & T-F & TSIF \\
\hline $\begin{array}{l}\text { THYLSTRUP \& } \\
\text { FEJERSKOV } 173\end{array}$ & 3,$5 ; 6,0 ; 21,0$ & 100 & 100 & \\
\hline $\begin{array}{l}\text { WENZEL \& } \\
\text { THYLSTRUP } \\
182\end{array}$ & $<0, \overline{2}$ & 5 & 5 & \\
\hline HOROWITZ et al. & 0,2 & 520 & $\overline{24}$ & \\
\hline $\begin{array}{l}\text { GRANATH,WIDENHEN } \\
\text { \& BIRKHED }^{66}\end{array}$ & $1, \overline{6}$ & $15^{*}$ & $15^{*}$ & \\
\hline $\begin{array}{l}\text { GASPAR, PEREIRA } \\
\text { \&ORERA }\end{array}$ & ótima & $\begin{array}{l}4,0 \\
20,8\end{array}$ & $\begin{array}{l}2,0 \\
20,4\end{array}$ & \\
\hline DRISCOLL et al & Ótima & 44 & & $60^{*-4}$ \\
\hline BURGER et al. ${ }^{18}$ & $\begin{array}{l}2 \mathrm{x} \text { ótimo } \\
3 \mathrm{x} \text { ótimo } \\
4 \mathrm{x} \text { ótimo }\end{array}$ & $\begin{array}{l}82 \\
77 \\
87\end{array}$ & & $\begin{array}{l}88 \\
91 \\
97\end{array}$ \\
\hline $\begin{array}{l}\text { CLEATON-JONES } \\
\text { HARGREAVES }{ }^{28}\end{array}$ & 1,56 & 67 & $51^{* \bar{*}}$ & $45^{* * *}$ \\
\hline
\end{tabular}

*Percentagem de dentes afetados

** Máximo valor de TSIF *** Percentagem de superficies afetadas

Seis estudos(THYLSTRUP \& FEJERSKOV 173; WENZEL \& THYLSTRUP ${ }^{182}$; HOROWITZ et al. ${ }^{75}$; GRANATH, WIDENHEIN \& BIRKHED ${ }^{66}$; MABELYA, KONIG \& HELDERMAN ${ }^{107}$; GASPAR, PEREIRA \& MOREIRA ${ }^{64}$ ) compararam resultados obtidos com os indices de DEAN e T-F. Poucas diferenças foram encontradas na estimativa das prevalências derivadas do uso dos dois índices, excetuando-se o estudo de MABELYA, KONIG \& HELDERMAN 107 que compararam os índices em áreas com alta, moderada e baixa prevalências de fluorose, verificando diferenças estatisticamente significantes nas duas primeiras áreas, devido às diferenças na metodologia entre os índices, principalmente a utilização da secagem dos dentes. Em nosso estudo verificaram-se prevalências bastante semelhantes, nos três indices utilizados(Tabela 19).

Todos os seis estudos indicavam o indice T-F como o mais apropriado para se estudar os efeitos biológicos do flúor. 
GRANATH, WIDENHEIN \& BIRKHED ${ }^{66}$ propuseram modificação na classificação para facilitar a comparação dos dois índices, sugerindo que o código "1" no indice T-F fosse considerada como normal (código "0"), e a categoria questionável do índice de DEAN fosse considerado como presença definitiva de fluorose (código "1"). Adicionalmente os autores consideravam o índice T-F mais sensível, sendo mais apropriado em trabalhos clínicos com amostra limitada.

Em termos de severidade, THYLSTRUP \& FEJERSKOV ${ }^{173}$ observaram que $o$ índice T-F era apto para identificar uma diferença no efeito do flúor entre as duas comunidades de alta concentração de flúor, enquanto o índice de DEAN não o era. Nas três áreas estudadas, expostas a níveis de flúor acima de 3 ppm F, o TF era capaz de diferenciar as formas mais severas de fluorose , códigos de "5 a 9", na qual $o$ indice de DEAN diagnosticava somente com código " 4 ".

Neste estudo, a comparação entre a distribuição percentual dos índices de DEAN e T-F(Tabelas 20 a 22), apresentou um padrão claro no que se refere à associação entre o código 1 de DEAN e o código $2 \mathrm{~T}-\mathrm{F}$, sendo que na classificação de DEAN o dente apresenta menos que $25 \%$ da superficie afetada e no índice T-F, o código 2 diagnostica que há linhas pronunciadas de opacidades que ocasionalmente se unem a linhas adjacentes formando bandas, característica de estágios iniciais. Portanto, as duas classificações são bastante semelhantes. Além disso, a associação entre o código 4 de DEAN e 5 T-F é explicada pelo fato da superficie estar totalmente afetada, porém com aparecimento de erosões, o que não é diferenciado no indice de DEAN que se limita a estabelecer no código 4 todas as possíveis situações de severidade .

Os indices de DEAN e TSIF foram comparados em 2 estudos. Prevalências mais altas eram verificadas pelo índice TSIF (DRISCOLL et al. ${ }^{44}$ ), sendo mais apto a identificar significantes diferenças entre aqueles expostos a duas e três vezes a concentração ótima de flúor na água de consumo, enquanto o índice de DEAN não o era. Razões para essas diferenças foram atribuídas pelos autores à maneira como cada índice classificava um "caso" (TSIF>ou=1 e DEAN>ou=2) e às diferenças metodológicas entre os dois índices (secagem dos dentes). Porém, em nosso estudo não foram observadas diferenças entre os dois indices, devido à padronização da metodologia usada nos índices (DEAN $>$ ou $=1$ e TSIF $>0 u=1$ ), secagem dos dentes nos dois índices, além da semelhança da classificação dos indices entre os códigos " 0 " e " 3 ", predominantes nas comunidades examinadas. 
Verificou-se nas Tabelas 23 a 25 a distribuição percentual entre os indices de DEAN e o TSIF, havendo alta proporção de concordância entre os códigos 1,2 e 3 dos dois índices, concorde com FEJERSKOV, MANJI \& BAELUM ${ }^{54}$, excetuando-se a relação entre o código 4 de DEAN e 5 do TSIF, na cidade de Cesário Lange, onde foram observadas 5 superficies com discretas cavitações (código 5 de TSIF), as quais não eram diferenciadas pelo indice de DEAN em termos de severidade (código 4 DEAN). Verificou-se que as únicas diferenciações entre os códigos dos índices de DEAN e TSIF se concentraram nas características de maior severidade $(5,6,7$ TSIF e 4 DEAN).

Nas tabelas 26 a 28 são apresentados os dados referentes a distribuição percentual entre os índices T-F e TSIF. Pode-se observar um notável cruzamento entre os códigos 0 e 1 .

Importante ressaltar que neste estudo, os três índices apresentaram altos coeficientes de correlação de Spearman, SAS ${ }^{165}$, (Tabela 30), estatisticamente significantes $(\mathrm{p}<0,01)$, quando se comparava os índices 2 a 2 .

No estudo final, CLEATON-JONES \& HARGREAVES ${ }^{2}$ utilizaram os três índices, verificando que os índices de T-F e TSIF eram diretamente comparáveis, com $92 \%$ de concordância em todas as categorias. Os autores concluíram que os três índices eram usados sem dificuldades em campo, mas o tempo utilizado pelo indice T-F era maior devido à necessidade de secagem. Neste estudo, observou-se boa concordância entre os índices, considerando-se as três cidades, além de não se verificar nenhuma dificuldade para utilização, em campo, de qualquer um deles.

Algumas limitações na utilização destes índices vêm sendo citadas . $O$ indice de DEAN apresenta alguns incovenientes:

a) atribui um único valor ao individuo de acordo com os dois dentes mais severamente afetados, não levando em conta se houver somente um dente afetando o indivíduo;

b) não diferencia as prevalências entre as superficies;

c) a categoria "questionável"é de dificil definição e interpretação precisa (FEJERSKOV et al. ${ }^{58}$ ), sendo excluída em alguns estudos (LEVERETT " GASPAR, PEREIRA \& MOREIRA ${ }^{64}$ ); 
d) o diagnóstico apresenta-se impreciso nos casos mais graves, pois possui apenas uma categoria englobando estes sinais (código 4);

e) o peso estatístico proposto por DEAN é arbitrário, sendo que uma criança classificada com código 4(manchas severas) conta com o mesmo peso que quatro casos de categoria muito leve (código 1), e este último caso não implicaria nenhum tratamento, enquanto em casos mais graves o indivíduo pode necessitar de extensivo tratamento restaurador por razões estéticas (SMALL \& MURRAY ${ }^{161}$ ).

FEJERSKOV, MANJI \& BAELUM ${ }^{\text {s4 }}$, com relação ao índice TSIF, comentaram que o mesmo engloba os princípios básicos de outros índices (DEAN e T-F) e suas classificações 1,2 e 3 são idênticas às categorias "muito leve", "leve" e "moderada"do índice de DEAN, concordes com este estudo.

Isto poderia ser considerado contraditório, pois HOROWITZ et al. ${ }^{75}$ tentando aperfeiçar o índice de DEAN, cometeram o mesmo erro, ou seja, na imprecisão de diagnóstico das categorias mais leves de fluorose. Porém a mais importante limitação do índice TSIF seria a proposição que manchas escurecidas nas superficies de esmalte deveriam ter um critério diagnóstico, o que na luz do conhecimento atual sobre fluorose dentária seria incorreto, pois as manchas que se apresentam no esmalte, nas situações mais severas, são resultados de mudanças póseruptivas.

A classificação original do índice T-F poderia apresentar somente um incoveniente que seria o tempo de exame aumentado devido à profilaxia preconizada pelos autores (THYLSTRUP \& FEJERSKOV ${ }^{173}$ ).

Para diminuir limitações apresentadas em cada índice, a fim de compará-los, optou-se por apresentar os dados através da distribuição por dente e superficie, padronizar a definição de "caso"(DEAN 1, T-F 1 e TSIF 1), eliminar a categria 0,5 do índice de DEAN, além de realizar somente uma escovação prévia, o que diminui o tempo em comparação ao preconizado por THYLSTRUP \& FEJERSKOV ${ }^{173}$, ou seja, uma profilaxia.

As indicações mais apropriadas de cada índice poderiam ser as seguintes:

-Índice de DEAN- estudos comparativos entre as prevalências atuais e as verificadas nas décadas de 30 e 40 . 
-Índice T-F = estudos clínicos ou estudos epidemiológicos analíticos;

-Índice TSIF= estudos nos quais se desejasse uma base estética para definição de "caso"e poderia ser usado onde se identificassem fatores de risco ou quando os dentes não poderiam ser limpos e secos, embora nosso estudo tenha demonstrado que, quando há secagem e escovação prévia, as diferenças entre os índices são mínimas ou insignificantes;

Muitos comentários podem ser feitas concernentes ao uso dos três índices.

1) todos têm sido e continuam sendo usados com sucesso por grande número de investigadores com diferentes propósitos, tipos de estudos e diferentes populações;

2) passos da metodologia utilizada na condução do exame clínico não são reportados, sendo esta omissão particularmente importante com respeito à secagem e limpeza dos dentes, desde que o efeito potencial na estimativa da fluorose possa ser variável;

3) a confiança dos examinadores (erro inter e intra-examinador) está dentro de uma variação aceitável na maioria dos estudos reportados, inclusive neste estudo o erro intra-examinador foi "substancial" segundo LANDIS \& $\mathrm{KOCH}$ ". Entretanto, muitos estudos não citam estas estimativas de erro, o que dificulta a confiança dos dados apresentados;

4) a definição de "caso" de fluorose é muito importante e difere entre as pesquisas, sendo indispensável que se estabeleça no estudo;

Finalmente, todos os estudos relacionados à fluorose deveriam citar sua prevalência e severidade, facilitando a compreensão sobre o assunto. 


\section{8-CONCLUSÕES}

Mediante o apresentado neste estudo é lícito concluir que:

a) as percentagens de superficies afetadas foram de $14,3 \%, 8,1 \%$ e $1,2 \%$ para o índice de DEAN, enquanto para o índice T-F foram de $15,1 \%, 8,4 \%$ e $1,4 \%$ e para o TSIF foram de $13,6 \%, 8,4 \%$ e $1,4 \%$, respectivamente para as cidades de Cesário Lange, Piracicaba e Iracemápolis.

b) os dentes mais severamente afetados foram os pré molares e $2 \underline{0 s}$ molares em ambas as arcadas, nas cidades de Cesário Lange e Piracicaba, enquanto na cidade de Iracemápolis os segundos molares foram os mais atingidos.

c) as percentagens de crianças afetadas nas três cidades foram de $32,9 \%$, $16,9 \%$ e 4,2\%, para o índice de Dean; enquanto para o índice T-F as prevalências foram de $33,5 \%, 17,6 \%$ e $4,2 \%$ e para o TSIF foram de $32,8 \%, 16,9 \%$ e 4,2 \%, respectivamente para Cesário Lange, Piracicaba e Iracemápolis.

d) os três índices utilizados apresentaram um coeficiente de correlação de Spearman alto, principalmente quando se comparavam os índices de DEAN e TSIF. 


\section{9-SUMMARY}

The studies refering to dental fluorosis has been the objective of many researches in various countries of the world. The objective of this paper was to compare dental fluorosis indexes of DEAN, T-F and TSIF in relation to prevalences for surfaces, teeth and region, besides verifying the statistical correlation between the same. The sample consisted of 461 school children, between the age of 12 to 14 years-old, born or resident from two years of age, being 153 from Cesario Lange with fluoride concentration in water supply of 1,4 parts $/ 10^{\circ} \mathrm{F}, 142$ from Piracicaba $(0,7$ parts $/ 10^{6} \mathrm{~F}$ )and 166 from Iracemápolis $\left(<0,3\right.$ parts $\left./ 10^{6} \mathrm{~F}\right)$. The clinical examination was done after teeth brushing and was carried out using plane mirror, a probe , artificial light and teeth drying. The results showed that the teth more severily afected were the pre molars and second molars, while oclusal surfaces were the most afected. The conclusion of the three indexes showed similar prevalences of fluorosis in the population, or better still, the percentages of children afected in the three towns were of $32,7 \%, 16,9 \%$ and $4,2 \%$, respectively for the DEAN's index, while for the T-F's index the prevalences were $33,3 \%, 17,6 \%$ and $4,2 \%$ and for the TSIF were estimated percentages of $32,7 \%, 16,9 \%$ and $4,2 \%$, repectively. There were no difficulties for the use of the three indexes in the field trials, then it can be sugested the use of anyone of them in regions with fluoride similar concentrations of this research. 


\section{0- REFERÊNCIA BIBLIOGRÁFICA}

1 -AASENDEN, R., PEEBLES, T.C. Effects of fluoride supplementation from birth on human deciduos and permanent teeth. Archs oral Biol., Oxford, v.19, n.4, p.321-326, 1974.

2 Effects of fluoride supplementation from birth on dental caries and fluorosis in teenaged children. Archs oral Biol., Oxford, v. 23, n. 2, p. 111-115, 1978.

$3-$ . et al. An in vivo study on enamel fluoride in children living in a fluoridated and in non-fluoridated area. Archs oral Biol., Oxford, v.16, n.12, p.1399-1411, 1971.

4 -AINAMO, J. et al. An Epidemiological index of developmental defects of enamel (DDE index). Int. dent. J., Bristol, v.32, n.2, p.159-167, 1982.

5 -AINSWORTH, N.J. Mottled teeth. Br. dent. J., London, v.55, n.3, p.233$250,1933$.

6 -AL ALOUSI, W. et al. Enamel mottling in a fluoride and in a non fluoride community. Br. dent. J., London, v.138, n.1, p.9-15, 1975.

7. -ALCAIDE, A.L., VERONEZI, O. Prevalência de fluorose dental na cidade de Icém. Rev. Ass. Paul. Cir. Dent., São Paulo, v.33, n.1, p.90-95, 1979.

8 -ANDERSON, R., GRAHNEN, H. Fluoride tablets in pre school age-effect on primary and permanent teeth. Sven Tandlak Tidskr, Stockholm, v.69, n.5, p.137-143, 1976.

9 -ANDO, T. Estudo comparativo da prevalência de cárie, em dentes permanentes de escolares residentes em regiões com alto e baixo teor de flúor. Rev. Fac. Odont. S. Paulo, São Paulo, v.13, n.2, p.261266, 1975.

Referências Bibliográficas de acordo com a Associação Brasileira de Normas Técnicas (ABNT),, NBR-6023 (agosto de 89). Abreviaturas dos Periódicos seguem as normas do "World List of Scientific Periodicas". 
10 -BAELUM, V. et al.Posteruptive tooth age and severity of dental fluorosis in Kenya.Scand. J. dent. Res.,Copenhagen,v.94,n.5,p.405-410, 1986.

11 -BELL, R.A. et al. Fluoride retention in children using self-applied topical fluoride products. Clin. prev. Dent., Philadelphia, v.7, n.3, p.22-27, 1985.

12 -BINDER, K. Caries frequency and mottled enamel in Austrian regions with high natural $\mathrm{F}$ content in the drinking water. Caries Res., Basel, v.1, n.1, p. 18-19, 1971.

13 - _ Comparison of the effects of fluoride drinking water on caries frequency and mottled enamel in three similar regions of Austria over a 10-year period. Caries Res., Basel, v.7, n.2, p.179-183, 1973.

14 -BISHOFF, J.I. et al. Relationship between fluoride concentration in enamel, DMFT index, and degree of fluorosis in a community residing in a area with a high level of fluoride. J. dent. Res., Washington, v.55, n.1, p.37-42, 1976.

15 -BLACK, G.V. Mottled teeth. Dent. Cosmos, Philadelphia, v. 58, n.2, p. 129-156, 1916.

16 -BOHATY, B.S. et al. The prevalence of fluorosis-like lesions associated with topical and systemic fluoride usage in an area of optimal water fluoridation. Pediatric Dent., Iowa, v.11, n.2, p.125-128, 1989.

17 -BRUNELLE, J.A., CARLOS, J.P. Recent trends in dental caries in US children and the effect of water fluoridation. J. dent. Res., Washington, v.69, p. 723-727, 1990. [ Special Issue]

18 -BURGER, $\mathrm{P}$. et al. Comparison of two fluorosis indices in the primary dentition of Tswana children. Community Dent. oral Epidemiol., Copenhagen, v.15, n.2, p.95-97, 1987.

19 -BUTLER, W.J., SEGRETO, V., COLLINS, E. Prevalence of dental mottling in school-age lifetime residents of 16 Texas communities. Am. J. publ. Hlth, New York, v.75, n.12, p.1408-1412, 1985.

20 -CAPELLA, L.F. et al. Ocorrência de fluorose dentária endêmica. RGO, Porto Alegre, v.37, n.5, p. 371-375, 1989.

21 -CARLOS, J.P. Fluoride mouth rinses. In: WEY, S. Clinical uses of fluoride. Philadelphia: Lea \& Febiger, 1985. cap.6, p. 75-82.

22 -CHURCHILL, H.V. Ocurrence of fluorides in some waters of United States. Ind. Engng. Chem. ind. , Easton, v.23, p.996-998, 1931. Apud: USPHS. op. cit. Ref. 177. 
23 -CLARK, D.C. 1991. Apud: CLARK, D.C. et al. Influence of exposure to various fluoride techonologies on the prevalence of dental fluorosis. Community Dent. oral Epidemiol., Copenhagen, v.22, n.6, p.461464, 1994.

24 - _ Trends in prevalence of dental fluorosis in North America. Community Dent. oral Epidemiol., Copenhagen, v.22, n.3, p.148$152,1994$.

25 - . et al. Influence of exposure to various fluoride techonologies on the prevalence of dental fluorosis. Community Dent. oral Epidemiol., Copenhagen, v.22, n.6, p.461-464, 1994.

26 -CLARKSON, J., O'MULLANE, D. A modified DDE index for use in Epidemiological studies of enamel defects. J. dent. Res., Washington, v.68, n.3, p.445-450, 1989.

27 - _ Prevalence of enamel defects/fluorosis in fluoridated and non-fluoridated areas in Ireland. Community Dent. oral Epidemiol., Copenhagen, v.20, n.4, p.196-199, 1992.

28 -CLEATON-JONES, P., HARGREAVES, J.A. Comparison of three fluorosis indices in a namibian community with twice optimum fluoride in the drinking water. J. dent. Ass. S. Afr., Cape Town, v.45, n.5, p.173-175, 1990.

29 -CONATSER, K. Excell 5 for Windows. Rio de Janeiro:Berkeley, 1994. 395p.

30 -CUTRESS, T.W., SUCKLING, G.W. Differential diagnosis of dental fluorosis. J. dent. Res., Washington, v.69, p. 714-720, 1990. [Special Issue]

31 -DABEKA, R.W. et al. Determination of fluoride in Canadian infant foods and calculation of fluoride intakes by infants. Can. J. publ. Hith, Toronto, v.73, n. 3, p.188-191, 1982.

32 -DEAN, H.T. Distribution of mottled enamel in United States. J. Am. dent. Ass., Chicago, v.20, n.3, p. 319-33, 1933.

33 - _ Classification of mottled enamel diagnosis. J. Am. dent. Ass., Chicago, v.21, n.8, p.1421-1426, 1934.

34 - The investigation of physiological effects by the Epidemiological method. 1942. Apud: MOULTON, F. R. Fluorine and dental health. Washington: American Association for the Advancement

of

Science

,1946. 
35 -DEAN, H.T. , ARNOLD, F. H. Endemic dental fluorosis or mottled teeth. J. Am. dent. Ass., Chicago, v.30, n.16, p.1278-1284, 1943.

$36-$ ., ELVOVE, E. Domestic water and dental caries, V, additional studies of the relation of fluoride domestic waters to dental caries experience in 4,425 white children aged 12-14 years of 13 cities in 4 states. Publ. Hlth Rep., Washington, v. 57, p.1155-1179, 1942.

37 ., ELVOVE, E. Some Epidemiological aspects of chronic endemic dental fluorosis. Am. J. publ. Hlth, New York, v.26, n.6, p.567-575, 1936.

$38-$ , DIXON, R.M. \& COHEN, C. Mottled enamel in Texas. Publ. Hith Rep., Washington, v.50, p.424-442, 1935.

39 , McKAY, F. S. Production of mottled enamel halted by a chance in common water supply.Am. J. publ. Hith, New York, v. 29 , n.6, p. 590-596, 1939.

40 - _ et al. Domestic water and the dental caries including certain Epidemioliological aspects of oral L. acidophilus. Publ. Hlth Rep., Washington, v.54, p.862-888, 1939.

41 -DEN BESTEN, P.K., CRENSHAW, M.A. Studies on the changes in developing enamel caused by ingestion of high levels of fluoride in the rat. Adv. dent. Res., Washington, v.1, n.2, p.176-180, 1987.

42 , THARIANI, $\mathrm{H}$. Biological mechanisms of fluorosis and level and timing of systemic exposure to fluorides with respect to fluorosis. J. dent. Res., Washington, v.71, n.5, p.1238-1243, 1992.

43 -DRISCOLL, W.S. et al. Prevalence of dental caries and dental fluorosis in areas with optimal and above optimal water fluoride concentrations. J. Am. dent. Ass., Chicago, v.107, n.1, p.42-47, 1983.

44 . et al. Prevalence of dental caries and dental fluorosis in areas with negligible, optimal, and above optimal fluoride concentrations in drinking water. J. Am. dent. Ass., Chicago, v.113, n.1, p.29-33, 1986.

45 -DUCKWORTH, S.C., DUCKWORTH, R. The ingestion of fluoride in tea. Br. dent. J., London, v.145, n.12, p.368-370, 1978.

46 -EAGER, J.M. Chiaie teeth. Dent. Cosmos, Philadelphia, v.44, n.3, p.300-301, 1902. [Abstract]

47 -EKLUND, S.A. et al. High fluoride drinking water, fluorosis, and dental caries in adults. J. Am. dent. Ass., Chicago, v.114, n.3 , p.324-328, 1987. 
48 -EKSTRAND, J., FEJERSKOV, O., SILVERSTONE, L.M. Fluoride in dentistry. Copenhagem: Munskgaard, 1988. cap. 9, 294p.

49 -ELLWOOD, R.P., O'MULLANE, D.M. The demographic and social variation in the prevalence of dental enamel opacities in water wales. Commmunity dent. Hlth, London, v.11, n.4, p.192-196, 1994.

50 -ERICSSON, Y., HAMMARSTRöM, L. Mouse placental transfer of F18, in comparison with Ca45. Acta odont. scand., Oslo, v.22, n.5, p.523-528, 1964.

51 -EVANS, R.W. Changes in dental fluorosis following an adjustment to the fluoride concentration of Hong Kong's water supplies. Adv. dent. Res., Washington, v.3, n.2, p.154-160, 1989.

52 -__ STAMM, J.W. Dental fluorosis following downward adjustment of fluoride in drinking water. J. publ. Hlth. Dent., Richmond, v.51, n.2, p.91-98, 1991.

53 -FEJERSKOV, O., JOHNSON, N.W., SILVERSTONE, L.M. The ultrastructure of fluorosed human dental enamel. Scand. J. dent. Res., Copenhagen, v. 82, n.5, p.357-372, 1974.

54 -_ MANJ, F. , BAELUM, V. The nature and mechanisms of dental fluorosis in man. J. dent. Res., Washington, v.69, p. 692-700, 1990. [Special Issue]

$55-$ , THYLSTRUP, A., LARSEN, M.J. Clinical and structural features and possible pathogenic mechanisms of dental fluorosis. Scand. J. dent. Res.,Copenhagen,v.85,n.7,p.510-539,1977.

56 Rational use of fluorides in caries prevention. Acta odont. Scand., Oslo, v.39, n.4, p.241-249, 1981.

57 - _ et al. Histological features of fluorosed human dental enamel. Caries Res., Basel, v.9, n.3, p.190-210, 1975.

$58-$ . et al. Dental fluorosis: a handbook for health workers. Copenhagem: Munksgard, 1988. 145p.

59 -FORREST, J.R. Caries incidence and enamel defects in areas with different levels of fluoride in the drinking water. Br. dent. J., London,v. 100, n.8, p. 195-200, 1956.

60 - _ _ J JAMES, P.M.C. A blind study of enamel opacities and dental caries prevalence after eight years of fluoridation of water, Br. dent. J., London, v.119, n.7, p.319-322, 1965.

61 -FORSMAN, B. Dental fluorosis and caries in high-fluoride districts in sweden. Community Dent. oral Epidemiol., Copenhagen, v.2, n.3, p.132-148, 1974. 
62 -GALAGAN, D.J., LAMSON, G.G. Climate and endemic dental fluorosis. Publ. Hlth Rep., Washington, v.68, n.5, p.497-508, 1953.

63 ., VERMILLION, J.R. Determining optimum fluoride concentrations. Publ. Hlth Rep., Washington, v.72, n.6, p.491-493, 1957.

64 -GASPAR, M:R., PEREIRA, A.C., MOREIRA, B.H.W. Opacidades de esmalte de origem não fluorótica e fluorose dentária em áreas com baixa $(0,2 \mathrm{ppm} \mathrm{F})$ e ótima $(0,7 \mathrm{ppm} F)$ concentrações de flúor nas águas de abastecimento público. Revta bras. Odontol., Rio de Janeiro, v.52, n.2, p.13-18, 1995.

65 -GOWARD, P.E. Enamel mottling in a non-fluoride community in England. Community Dent. oral Epidemiol., Copenhagen, v.4, n.3, p.111114, 1976.

66 -GRANATH, L., WIDENHEIN, J., BIRKHED, D. Diagnosis of mild enamel fluorosis in permanent maxillary incisors using two scoring systems. Community Dent. oral Epidemiol., Copenhagen, v.13, n.5, p.273-276, 1985.

67 -GROBLER, S.R., van WYK, C.W. , KOTZE, D. Relationship between enamel fluoride levels, degree of fluorosis and caries experience in communities with a nearly optimal and a high fluoride level in the drinking water . Caries Res., Basel, v.20, n.3, p.284-288, 1986.

68 -GUSTAFSON, A.G. The histology of fluorosed teeth. Archs oral Biol., Oxford, v.4, n.1 , p.67-69, 1961.

69 -HARGREAVES, J.A. et al. Commencement date of fluoride supplementation related to fluorosis. J. dent. Res. , Washington, v.67, p.231, 1988. [Abstract ,948].

70 -HEIFETZ, S.B. et al. Prevalence of dental caries and dental fluorosis in areas with optimal and above optimal water fluoride concentrations: a 5 year follow-up survey. J. Am. dent. Ass., Chicago, v.116, n.4, p. $490-495,1988$.

71 -HODGE, H.C. The concentration of fluorides in the drinking water to give the period of minimun caries water maximun safety. . J. Am. dent. Ass., Chicago, v. 40, n.4, p.436-439, 1950.

72 -HOLM, A. K., ANDERSSON, R. Enamel mineralization disturbances in 12-year-old children with known early exposure to fluorides. Community Dent. oral Epidemiol., Copenhagen, v.10, n.6, p.335$339,1982$. 
73 -HOLT, R.D. et aL. Enamel opacities in children whose mothers took part in a dental health education scheme. Community Dent. oral Epidemiol., v.18, n.2, p.74-76,1990.

74 -HOROWITZ, H.S. Fluoride and enamel defects. Adv. dent. Res., Washington, v.3, n.2, p.143-146, 1989.

75 - _ . et al. A new method for assessing the prevalence of dental fluorosis - the Tooth Surface Index of Fluorosis. J. Am. dent. Ass., Chicago, v.109, n.1, p.37-41, 1984.

76 -HOUWINK, B. , WAGG, B. J. Effect of fluoride dentrifice usage during infancy upon enamel mottling of the permanent teeth. Caries Res., Basel, v.13, n.4, p.231-237, 1979.

77 -ISHII, T. , SUCKLING, G. The severity of dental fluorosis in children exposed to water with a high fluoride content for various periods of time. J. dent. Res., Washington, v.70, n.6, p.952-956, 1991.

78 -ISMAIL, A.I. Fluoride supplements: current effectiveness, side effects, and recomendations. Community Dent. oral Epidemiol., Copenhagen, v.22, n. 3, p. 164-172, 1994.

79 - _ et al. Prevalence of dental caries and dental fluorosis in students, 11-17 years of age, in fluoridated and non-fluoridated cities in Quebec. Caries Res., Basel, v. 24, n. 4, p. 290-297, 1990.

80 -JACKSON, D., JAMES, P.M.C., WOLFE, W.B. Fluoridation in Anglesey, a clinical study. Br. dent. J., London, v.138, n.5, p.165$171,1975$.

81 -JOHNSTON, D.W. Current status of professionaly applied topical fluorides. Community Dent. oral Epidemiol., Copenhagen, v. 22, n. 3, p. 159-163, 1994.

82 -KAMINSKY, L.S. et al. Fluoride : benefits and risks of exposure. Crit. Rev. Oral Biol. Med., Boca Raton, v.1, n.4, p. 261-281, 1990.

83 -KAWAHARA, H., KAWAHARA, K. The new method of classifying mottled teeth based on fluorine content in drinking water. Shikoku Acta med., Tokushima, v. 5, p.120, 1954.

84 -KEMPF, G.A., McKAY, F.S. Mottled enamel in a segregated population. Publ. Hlth Rep., Washington, v.45, p.2923-2940, 1930.

85 -KIDD, E.A.M. et al. Influence of fluoride in surface enamel and degree of dental fluorosis on caries development in vitro. Caries Res., Basel, v. 14, n.4, p.196-201, 1980.

86 -KINGMAN, A. Current techniques for measuring dental fluorosis: issues in data analyses. Adv. dent. Res., Washington, v.8, n.1, p.56-65, 1994. 
87 -KUHNS, C. Dt. Mschr. Zahnheilk, Berlim, v.6, p.446, 1888. Apud: MOLLER, I.J. op cit. Ref. 120.

88 -KUMAR, J.V. et al. Trends in dental fluorosis and dental caries prevalences in Newburgh and Kingston, N.Y. Am. J. publ. Hlth, New York, v.79, n.5, p.565-569, 1989.

89 -LALUMANDIER, J.A. The prevelence and risk factors of fluorosis among children in a pediatric practice in Asheville, North Carolina. J. publ. Hith Dent., Richmond, v.52, n.3, p.188, 1992.

90 -LANDIS, J.R., KOCH, G.G. The measurement of observer agreement for categorial data. Biometrics, Washington, v.33, n.1 , p.159-174, 1977.

91 -LARSEN, M.J., RICHARDS, A., FEJERSKOV,O. Development of dental fluorosis according to age at start of fluoride administration. Caries Res., Basel, v.19, n.6, p.519-527, 1985.

92 -___ . et al. Prevalence of dental fluorosis after fluoride gel treatments in a low-fluoride area. J. dent. Res., Washington, v.64, n.8, p.10761079, 1985.

93 - __ et al. Enamel fluoride, dental fluorosis and dental caries among immigrants to and permanent residents of five danish fluoride areas. Caries Res., Basel, v.20, n.4, p.349-355, 1986.

94 - _ et al. Dental fluorosis in the primary and the permanent dentition in fluoridated areas with consumption of either powdered milk or natural cow's milk. J. dent. Res., Washington, v.67, n.5, p.822-825, 1988.

95 -LEATHERWOOD, E.C. et al. Dental caries and dental fluorosis in Thailand. Am. J. publ. Hlth, New York, v.55, n.11, p.1792-1799, 1965.

96 -LESAN, W.R. Dental fluorosis, a review of literature with comments on tropical characteristics. E. Afr. med. J., Nairobi, v.64, n.7, p.493498, 1987.

97 -LEVERETT, D. Fluoride and the changing prevalence of dental caries. Science, Washington, v.217, n.4554, p.26-30, 1982.

98 - _ Prevalence of dental fluorosis in fluoridated and non fluoridated comunities: a preliminary investigation. J. publ. Hlth Dent., Richmond, v.46, n.4, p.184-187, 1986.

99 -LEVINE, R.S., BEAL, J.F. , FLEMING, C.M. A photographically recorded assessment of enamel hypoplasia in fluoridated and nonfluoridated areas in England. Br. dent. J., London, v.166, n.7, p.249-252, 1989. 
100-LEVY, S.M. Review of fluoride exposures and ingestion. Community Dent. oral Epidemiol., Copenhagen, v.22, n.3, p.173-180, 1994.

101-_ , ROZIER, R.G. Use of systemic fluoride supplement by North Carolina dentists. J. Am. dent. Ass., Chicago, v.114, n.3, p.347-350, 1987.

102-___ _ _ ZAREI, M.Z. Evaluation of fluoride exposures in children. J. Dent. Child., Chicago, v.58, n.6, p.467-473, 1991.

103-LEWIS, D.W. , BANTING, D.W. Water fluoridation: current effectiveness and dental fluorosis. Community Dent. oral Epidemiol., Copenhagen, v.22, n.3, p.153-158, 1994.

104-LEWIS, H.A. et al. Fluorosis and dental caries in schoolchildren from rural areas with about 9 and $1 \mathrm{ppm} F$ in the water supplies. Community Dent. oral Epidemiol., Copenhagen, v.20, n.1, p.5354, 1992.

105-LIMEBACK, H. Enamel formation and the effects of fluoride. Community Dent. oral Epidemiol., Copenhagen, v.22, n.3, p.144$147,1994$.

106-MABELYA, L., KÖNIG, K.G. , van PALENSTEIN HELDERMAN, W.H. Dental fluorosis, altitude, and associated dietary factors. Caries Res., Basel, v.26, n.1, p.65-67, 1992.

107. Comparison of two indices of dental fluorosis in low, moderate and high fluorosis Tanzanian populations. Community Dent. oral Epidemiol., Copenhagen, v.22, n.6, p. 415420, 1994.

108-MALTZ, M. , FARIAS, C. Prevalência de fluorose dentária em cidades com nivel ótimo de flúor na água de abastecimento. Anais da Soc. Bras. de Pesq. Odont., São Paulo, p.38, 1989.

109-MANJ, F., BAELUM, M.V., FEJERSKOV, O. Dental fluorosis in an area of Kenya with $2 \mathrm{ppm}$ fluoride in the drinking water. J. dent. Res., Washington, v.65, n.5, p. 659-662, 1986.

110-__ et al. Enamel changes in two low-fluoride areas of Kenya. Caries Res., Basel, v.20, n.4, p.371-380, 1986 a.

111-__ et al . Fluoride, altitude and dental fluorosis. Caries Res., Basel, v.20, n.5, p.473-480, 1986 b. 
112-MANN, J. et al. Tea drinking, caries prevalence, and fluorosis among northern Israeli Arab Youth . Clin. prev. Dent., Philadelphia, v.7, n.6, p.23-26, 1985.

113-___ et al. Fluorosis and dental caries in 6-8 year-old children in a 5 ppm fluoride area. Community Dent. oral Epidemiol., Copenhagen, v.18, n.2, p.77-79, 1990.

114-MASSLER, M., SHOUR, I. Relation of endemic fluorosis to malnutrition. J. Am. dent. Ass., Chicago, v. 44, n. 2, p. 156-165, 1952.

115-McCLURE, F.J. Fluorine in foods, survey of recent data. Publ. Hlth Rep., Washington, v.64, p.1061, 1949.

116-McCOLLUM, E.V. et al. The effect of addition of fluoride to the diet of rats on the quality of the teeth. J. biol. Chem., Baltimore, v.63, p.553-558, 1925.

117-McKAY, F.S. An investigation of mottled teeth (I). Dent. Cosmos, Philadelphia, v.58, n.5, p.477-484, 1916

118-McKNIGHT-HANES, M. C. et al. Fluoride content of infant formulas, Soy-based formulas as a potencial factor in dental fluorosis. Pediatric Dent., Iowa, v.10, n.3, p.189-194, 1988.

119-MOLLER, I.J. Dental fluorose og caries undersogelse over litteraturen sant nogle Epidemioliologiske undersogelser af daniske born. Kobenhaun: Rhodos, 1965. 287 p.

120 _ _ Fluorides and dental fluorosis. Int. dent. J., Bristol, v.32, n.2, p.135-147, 1982.

121-___ _ POULSEN, S. A study of dental mottling in children in Khouribga, Morocco. Archs oral Biol., Oxford, v.20, n.9, p.601$607,1975$.

122-___ et al. The prevalence of dental fluorosis in the people of Uganda. Archs oral Biol., Oxford, v.15, n.3, p.213-225, 1970.

123-MYERS, H.M. Fluorides and dental fluorosis. Basel: S. Karger, 1978.

124-MURRAY, I.J., SHAW, L. Classification and prevalence of enamel opacities in the human deciduos and permanent dentitions. Archs oral Biol., Oxford, v.24, n.1, p.7-13, 1979.

125-NANDA, R.S. et al. Factors affecting the prevalence of dental fluorosis in Lucknow, India. Archs oral Biol., Oxford, v.19, n.9, p.781-792, 1974. 
126-NEVITT,G.A., FRANKEL, J.M. , WITTER, D.M. Ocurrence of nonfluoride opacities and nonfluoride hypoplasias of enamel in 58 children ages 9 to 14 years. J. Am. dent. Ass., Chicago, v.66, n.1, p.65-69, 1963.

127-NEWBRUN, E. Effectiveness of water fluoridation. J. publ. Hlth Dent., Richmond, v. 49, n.5, p.279-289, 1989.

128-NUNN, J. H. et al. Assessment of enamel opacities in children in Sri Lanka and England using a photographic method. Community dent. Hith, London, v.10, n.3, p.175-188, 1993.

129-OLSEN, T. , JOHANSEN, E. Fluoride content of human fluorosed enamel. J. dent. Res., Washington, v. 57, p.281 , 1978. [Abstract ,828].

130-OLSSON, B. Dental findings in high-fluoride areas in Ethiopia. Community Dent. oral Epidemiol., Copenhagen, v.7, n.1, p.51-56, 1979.

131-ORGANIZAÇÃO MUNDIAL DA SAÚDE (OMS). Levantamento epidemiológico básico de saúde bucal. São Paulo: Editora Santos, 1991.

132-OPINYA, R. Fluorosis of deciduos teeth and first permanent molars in a rural Kenyan community. Acta odont. scand., Oslo, v.49, n.4, p.197-202, 1991.

133-OSUJ, O.O., NIKIFORUK, G., LEAKE, J.L. A review of differential diagnosis of dental fluorosis and non-fluoride enamel defects. $\mathbf{J}$. Can. dent. Ass., Montreal, v.54, n.10, p.743-747, 1988.

134-__. et al. Risk factors for dental fluorosis in a fluoridated community. J. dent. Res., Washington, v.67, n.12, p.1488-1492, 1988.

135-PENDRYS, D.G. The fluorosis risk index, a method for investigating risk factors. J. publ. Hlth Dent., Richmond, v.50, n.5 , p.291-298, 1990.

136-__ _ KATZ, R.V. Fluoride supplements and enamel fluorosis. J. dent. Res., Washington, v.67, p. 230, 1988. [Abstract ,937]

137-_ _ STAMM, J. W. Relationship of total fluoride intake to beneficial effects and enamel fluorosis. J. dent. Res., Washington, $v$. 69, p.529-538, 1990. [Special Issue]

138-___ et al. Prevalence of fluorosis in children served by a nonfluoridated water supply. J. dent. Res., Washington, v.65, p. 198, 1986. [Abstract, 256]. 
139-PUULSEN, S., MULLER, 1.J. Gingivitis and dental plaque in relation to dental fluorosis in man in Morocco. Archs oral Biol., Oxford, v.19, n.10, p.951-954, 1974.

140-PU, M.Y., LILIENTHAL, B. Dental caries and mottled enamel among Formosan children. Archs oral Biol., Oxford, v.5, n.2, p.125-136, 1961.

141-PURCZINSKY, D. et al . Ionic fluoride content of foods distributed in the Dallas area. J. dent. Res., Washington, v.69, p.180, 1990. [Abstract, 571].

142-RENSON, C. E. Changing patterns of dental caries, a survey of 20 countries. Ann. Acad. Med. Singapore, Singapore, v.15, n.3, p.284-298, 1986.

143-RICHARDS, A., FEJERSKOV, O. , BAELUM, V. Enamel fluoride in relation to severity of human dental fluorosis. Adv. dent. Res., Washington, v.3, n.2, p.147-153, 1989.

144-___ et al. Dental fluorosis developed in post-secretory enamel. J. dent. Res., Washington, v.65, n. 12, p. 1406-1409, 1986.

145-RICHARDS, L. F. et al. Determining optimun fluoride levels for community water supplies in relation to temperature. J. Am. dent. Ass., Chicago, v.74, n.3, p.389-397, 1967a.

146-__ et al. Non-fluoride enamel hypoplasia in varying fluoride temperature zones. J. Am. dent. Ass., Chicago, v.75, n.6, p. 1412$1418,1967 b$.

147-RIORDAN, P.J. , BANKS, J.A. Dental fluorosis and fluoride exposure in western Australia. J. dent. Res., Washington, v.70, n.7, p.1022$1028,1991$.

148-RIPA, L.W. A critique of topical fluoride methods (dentifrices, mouthrinses, operator and self-applied gels) in an area of decreased caries and increased fluorosis prevalence. J. publ. Hlth Dent., Richmond, v.51, n.1, p. 23-41, 1991.

149-ROZIER, R.G. Epidemiologic indices for measuring the clinical manifestations of dental fluorosis: overview and critique . Adv. dent.Res., Washington, v.8, n.1, p.39-55, 1994.

150 ___ DUDNEY, G.G. Dental fluorosis in children exposed to multiple sources of fluoride,implications for school fluoridation programs. Publ. Hlth Rep., Richmond, v.96, n.6, p.542-546, 1981.

151-RUSSEL, A.L. The diferential diagnosis of fluoride and non-fluoride enamel opacities. J. publ. Hlth Dent., Richmond, v. 21, n.3, p.143146, 1961. 
152-SAMPAIO, F.C. Prevalência de cárie e fluorose dental em cidades com fluoretação natural no Estado da Paraíba. Tese de Mestrado: Universidade Federal Fluminense, 1992.

153-SAVARA, B.S., NOYES, H.J., SUHER, T. Effects of air-borne fluorides on children living on Sauvie Island.J. Am. dent. Ass., Chicago, v.49, n.1, p.39-45, 1954.

154-SCHAMSCHULA, R.G. et al. The fluoride content of human tooth enamel in relation to environmental exposure to fluoride. Aust. dent. J., St. Leonards, v. 27, n. 4, p. 243-247, 1982.

155-SEBRELL, W.H. et al. Change in the teeth of white rats given water from a mottled enamel area compared to those produced by water containing sodium fluoride. Publ. Hlth Rep., Washington, v.48, p.437-440, 1933.

156-SEGRETO, V.A. et al. A current study of mottled enamel in Texas. J. Am. dent. Ass., Chicago, v.108, n.1, p.56-59, 1984.

157-SHCHORI, D. et al. Fluoride uptake in rats given tea with milk. J. dent. Res., Washington, v.55, n.5, p.916, 1976.

158-SILNESS,J. , GUSTAVSEN, F. Some observations on the fine structure of fluorosed dental enamel. Acta odont. scand., Oslo, v.28, n.5, p.701-720, 1970.

159-SINGER, L., OPHANG, R., HARLAND, B.F. Total fluoride intake of infants. Pediatr., Springfield, v. 63, n.3, p.460-466, 1979.

160-SKOTOWSKY, M.L. et al. Risk factors for dental fluorosis in pediatric patients. Iowa: University of Iowa, 1991.

161-SMALL, B.W., MURRAY, J.J. Enamel opacities: prevalence, classifications and aetiological considerations. J. Dent., Bristol, v.6, n.1, p.33-42, 1978.

162-SMTTH, D.A., HARRIS, H.A., KIRK, R. Fluorosis in the Butana, Sudam. J. trop. Med. Hyg., London, v.56, n.3, p.57-58, 1953.

163-SONGPAISAN, Y., DAVIES, G.N. Dental caries experience in the Changmai/Lamphum provinces of Thailand. Community Dent. oral Epidemiol., Copenhagen, v.17, n.3, p. 131-135, 1989.

164-STAMM, J.W. , KUO, H.D. Fluoride concentration in prepared infant foods. J. dent. Res., Washington, v.56 , p.209, 1977. [Abstract ,628].

165-SAS Institute. SAS/ STAT Guide for personal computers. Cary:SAS Institute Inc., 1987. 1028p. 
166-STOOKEY, G.K. Review of fluorosis risk of self-applied topical fluorides,dentifrices, mouthrinses and gels. Community Dent. oral Epidemiol., Copenhagen, v. 22, n.3, p.181-186, 1994.

167-SUCKLING, G.W. , PEARCE, E.I.F. Developmental defects of enamel in a group of New Zealand children, their prevalence and some associated etiological factors. Community Dent. oral Epidemiol., Copenhagen, v.12, n.3, p.177-184, 1984.

168-SZPUNAR , S. M. , BURT, B. A. Trends in the prevalence of dental fluorosis in the United States: A review. J. publ. Hlth Dent., Richmond, v.47, n.2, p.71-79, 1987.

$169-$ Dental caries, fluorosis and fluoride exposure in Michigan Schoolchildren. J. dent. Res.; Washington, v.67, n.5, p.802-806, 1988.

$170-$ .Evaluation of appropriate use of dietary fluoride supplements in the U.S. Community Dent. oral Epidemiol., Copenhagen, v.20, n.3, p.148-154, 1992.

171-THYLSTRUP, A. Distribution of dental fluorosis in the primary dentition. Community Dent. oral Epidemiol., Copenhagen, v.6, n.6, p.329-337, 1978.

172-__ A scanning electron microscopical study of normal and fluorotic enamel demineralized by EDTA. Acta odont. scand., Oslo, v.37, n.2, p.127-135, 1979.

173-___ FEJERSKOV, O. Clinical appearance of dental fluorosis in permanent teeth in relation to histologic changes. Community Dent. oral Epidemiol., Copenhagen, v.6, n.6, p.315-328, 1978.

$174-$

A scanning electron microscopic and microradiographic study of pits in fluorosed human enamel. Scand. J. dent. Res., Copenhagen, v.87, n.2 , p.105-114, 1979.

$175-$ . et al. Enamel changes and dental caries in 7-year-old children given fluoride tablets from shortly after birth. Caries Res., Basel, v.13, n.5, p.265-276, 1979.

176-UCHOA, H.W. , SALIBA, N.A. Prevalência de fluorose na cidade de Pereira Barreto. Bol. Serv. Odont. Sanit., São Paulo, v.6, n.3, p.11$16,1970$.

177-USPHS(UNITED STATES PUBLIC HEALTH SERVICE). Report on fluoride benefits and risks. Review of fluoride benefits and risks. Report of the Ad Hoc Subcommittee on fluoride. 1991. 
178-VAN DER MERWE, E.H.M. et al. Relationships between fluoride in enamel, DMFT index and fluorosis in high and low-fluoride areas in south Africa. Community Dent. oral Epidemiol., Copenhagen, v.5, n.1, p.61-64, 1977.

179-VENKATESWARLY, R., RAO, D.N., RAO, K.R. Studies in endemics fluorosis visakhapatnam and sururban area. Fluorine, mottled enamel and dental caries. Indian J. med. Res., Calcutta v.40, p. 535, 1952.

180-VIGNARAJAH, S. Dental caries experience and enamel opacities in children on Antigua with different levels of natural fluoride in drinking water. Community dent. Hlth, London, v.10, n.3, p.159$166,1993$.

181-WARNAKULASURIYA, K.A.A.S. et al. Determining optimal levels of fluoride in drinking water for hot, dry climates: a case study in Sry Lanka. Community Dent. oral Epidemiol., Copenhagen, v.20, n.6, p.364-367, 1992.

182-WENZEL, A., THYLSTRUP, A. Dental fluorosis and localized enamel opacities in fluoride and non-fluoride danish communities. Caries Res., Basel, v.16, n.4, p.340-348, 1982.

183-WILLIAMS, J.L. Mottled enamel, and other studies of normal and pathological conditions of this tissue. J. dent. Res., Washington, v.5, n.1, p. 117-195, 1923.

184-WILLIAMS, J.E., ZWEMER, J.D. Community water fluoride levels, preschool dietary patterns, and the occurrence of fluoride enamel opacities. J. publ. Hlth Dent., Richmond, v.50, n.4, p. 276-281, 1990.

185-WOLFOLK, M.W., FAJA, B.W., BAGRAMIAN, R.A. Relation of sources of systemic fluoride to prevalence of dental fluorosis. J. publ. Hlth Dent., Richmond, v.49, n.2, p.78-82, 1989.

186-WOLGENS, J.H.M., ETTY, E.J., NIEUWLAND, W.M.D. Prevalence of mottled enamel in permanent dentition of children participating in a fluoride programme at the Amsterdam dental school. J. Biol. Buccale, Paris, v.17, n.1 , p.15-20, 1989.

187-WORLD. HEALTH ORGANIZATION. Fluorides and human health. Geneva: WHO, 1970. (Monograph Series n. 59).

188-YOUNG, M.A. An Epidemiological study of enamel opacities in temperature and subtropical climates. Thesis (PHD), University of London, 1973. Apud: SMALL, B.W., MURRAY, J.J. op cit Ref. 161 . 
189-ZIMMERMAN, E.R. Fluoride and nonfluoride enamel opacities. Publ. Hlth Rep., Washington, v.69, n.11, p. 1115-1120, 1954. 
11- ANEXOS 


\begin{tabular}{|c|c|c|c|c|c|c|c|c|c|c|c|c|c|}
\hline DENTE & Sup. & 0 & 1 & $\overline{2}$ & 3 & 4 & Total & 0 & 1 & 2 & $\overline{3}$ & 4 & Total \\
\hline \multirow[t]{2}{*}{$\pi$} & L & 146 & 4 & 0 & $T$ & 0 & T5T & $96,7 \%$ & $2,6 \%$ & $0,0 \%$ & $0,7 \%$ & $0,0 \%$ & $100,0 \%$ \\
\hline & V & 139 & 7 & 3 & 1 & 0 & 150 & $92,7 \%$ & $4,7 \%$ & $2,0 \%$ & $0,7 \%$ & $0,0 \%$ & $100,0 \%$ \\
\hline \multirow[t]{2}{*}{12} & L & 145 & 4 & 1 & 1 & 0 & 151 & $96,0 \%$ & $2,6 \%$ & $0,7 \%$ & $0,7 \%$ & $0,0 \%$ & $100,0 \%$ \\
\hline & V & 138 & 8 & 2 & 0 & 1 & 149 & $92,6 \%$ & $5,4 \%$ & $1,3 \%$ & $0,0 \%$ & $0,7 \%$ & $100,0 \%$ \\
\hline \multirow[t]{2}{*}{13} & L & 139 & 4 & 2 & 1 & 0 & 146 & $95,2 \%$ & $2,7 \%$ & $1,4 \%$ & $0,7 \%$ & $0,0 \%$ & $100,0 \%$ \\
\hline & V & 132 & 11 & 2 & 1 & 0 & 146 & $90,4 \%$ & $7,5 \%$ & $1,4 \%$ & $0,7 \%$ & $0,0 \%$ & $100,0 \%$ \\
\hline \multirow[t]{3}{*}{14} & L & 123 & 18 & 8 & 2 & 0 & 151 & $81,5 \%$ & $11,9 \%$ & $5,3 \%$ & $1,3 \%$ & $0,0 \%$ & $100,0 \%$ \\
\hline & 0 & 102 & 26 & 11 & 1 & 0 & 140 & $72,9 \%$ & $18,6 \%$ & $7,9 \%$ & $0,7 \%$ & $0,0 \%$ & $100,0 \%$ \\
\hline & V & 122 & 19 & 8 & 1 & 1 & 151 & $80,8 \%$ & $12,6 \%$ & $5,3 \%$ & $0,7 \%$ & $0,7 \%$ & $100,0 \%$ \\
\hline \multirow[t]{3}{*}{15} & L & 120 & 16 & 8 & 2 & 0 & 146 & $82,2 \%$ & $11,0 \%$ & $5,5 \%$ & $1,4 \%$ & $0,0 \%$ & $100,0 \%$ \\
\hline & 0 & 97 & 25 & 11 & 1 & 0 & 134 & $72,4 \%$ & $18,7 \%$ & $8,2 \%$ & $0,7 \%$ & $0,0 \%$ & $100,0 \%$ \\
\hline & V & 119 & 17 & 8 & 2 & 0 & 146 & $81,5 \%$ & $11,6 \%$ & $5,5 \%$ & $1,4 \%$ & $0,0 \%$ & $100,0 \%$ \\
\hline 16 & L & 134 & 13 & 1 & 0 & 0 & 148 & $90,5 \%$ & $8,8 \%$ & $0,7 \%$ & $0,0 \%$ & $0,0 \%$ & $100,0 \%$ \\
\hline & O & 52 & 14 & 3 & 0 & 0 & 69 & $75,4 \%$ & $20,3 \%$ & $4,3 \%$ & $0,0 \%$ & $0,0 \%$ & $100,0 \%$ \\
\hline & V & 132 & 13 & 1 & 0 & 0 & 146 & $90,4 \%$ & $8,9 \%$ & $0,7 \%$ & $0,0 \%$ & $0,0 \%$ & $100,0 \%$ \\
\hline 17 & L & 114 & 13 & 8 & 1 & 0 & 136 & $83,8 \%$ & $9,6 \%$ & $5,9 \%$ & $0,7 \%$ & $0,0 \%$ & $100,0 \%$ \\
\hline & 0 & 92 & 13 & 15 & 1 & 0 & 121 & $76,0 \%$ & $10,7 \%$ & $12,4 \%$ & $0,8 \%$ & $0,0 \%$ & $100,0 \%$ \\
\hline & V & 113 & 14 & 8 & 1 & 0 & 136 & $83,1 \%$ & $10,3 \%$ & $5,9 \%$ & $0,7 \%$ & $0,0 \%$ & $100,0 \%$ \\
\hline 21 & L & 146 & 4 & 0 & 1 & 0 & 151 & $96,7 \%$ & $2,6 \%$ & $0,0 \%$ & $0,7 \%$ & $0,0 \%$ & $100,0 \%$ \\
\hline & V & 139 & 7 & 3 & 1 & 0 & 150 & $92,7 \%$ & $4,7 \%$ & $2,0 \%$ & $0,7 \%$ & $0,0 \%$ & $100,0 \%$ \\
\hline 22 & L & 145 & 5 & 0 & 1 & 0 & 151 & $96,0 \%$ & $3,3 \%$ & $0,0 \%$ & $0,7 \%$ & $0,0 \%$ & $100,0 \%$ \\
\hline & V & 141 & 7 & 2 & 1 & 0 & 151 & $93,4 \%$ & $4,6 \%$ & $1,3 \%$ & $0,7 \%$ & $0,0 \%$ & $100,0 \%$ \\
\hline 23 & L & 140 & 3 & 1 & 1 & 0 & 145 & $96,6 \%$ & $2,1 \%$ & $0,7 \%$ & $0,7 \%$ & $0,0 \%$ & $100,0 \%$ \\
\hline & V & 131 & 10 & 1 & 1 & 1 & 144 & $91,0 \%$ & $6,9 \%$ & $0,7 \%$ & $0,7 \%$ & $0,7 \%$ & $100,0 \%$ \\
\hline 24 & L & 122 & 17 & 9 & 3 & 0 & 151 & $80,8 \%$ & $11,3 \%$ & $6,0 \%$ & $2,0 \%$ & $0,0 \%$ & $100,0 \%$ \\
\hline & O & 98 & 26 & 12 & 3 & 0 & 139 & $70,5 \%$ & $18,7 \%$ & $8,6 \%$ & $2,2 \%$ & $0,0 \%$ & $100,0 \%$ \\
\hline & V & 121 & 18 & 8 & 2 & 2 & 151 & $80,1 \%$ & $11,9 \%$ & $5,3 \%$ & $1,3 \%$ & $1,3 \%$ & $100,0 \%$ \\
\hline 25 & L & 120 & 16 & 8 & 3 & 0 & 147 & $81,6 \%$ & $10,9 \%$ & $5,4 \%$ & $2,0 \%$ & $0,0 \%$ & $100,0 \%$ \\
\hline & O & 97 & 25 & 12 & 3 & 0 & 137 & $70,8 \%$ & $18,2 \%$ & $8,8 \%$ & $2,2 \%$ & $0,0 \%$ & $100,0 \%$ \\
\hline & V & 119 & 17 & 7 & 3 & 1 & 147 & $81,0 \%$ & $11,6 \%$ & $4,8 \%$ & $2,0 \%$ & $0,7 \%$ & $100,0 \%$ \\
\hline 26 & L & 130 & 12 & 2 & 1 & 0 & 145 & $89,7 \%$ & $8,3 \%$ & $1,4 \%$ & $0,7 \%$ & $0,0 \%$ & $100,0 \%$ \\
\hline & o & 56. & 13 & 5 & 0 & 0 & 74 & $75,7 \%$ & $17,6 \%$ & $6,8 \%$ & $0,0 \%$ & $0,0 \%$ & $100,0 \%$ \\
\hline & V & 127 & 12 & 2 & 1 & 0 & 142 & $89,4 \%$ & $8,5 \%$ & $1,4 \%$ & $0,7 \%$ & $0,0 \%$ & $100,0 \%$ \\
\hline 27 & L & 107 & 14 & 7 & 3 & 0 & 131 & $81,7 \%$ & $10,7 \%$ & $5,3 \%$ & $2,3 \%$ & $0,0 \%$ & $100,0 \%$ \\
\hline & O & 91 & 13 & 13 & 3 & 0 & 120 & $75,8 \%$ & $10,8 \%$ & $10,8 \%$ & $2,5 \%$ & $0,0 \%$ & $100,0 \%$ \\
\hline & V & 105 & 16 & 7 & 3 & 0 & 131 & $80,2 \%$ & $12,2 \%$ & $5,3 \%$ & $2,3 \%$ & $0,0 \%$ & $100,0 \%$ \\
\hline 31 & L & 147 & 4 & 0 & 0 & 0 & 151 & $97,4 \%$ & $2,6 \%$ & $0,0 \%$ & $0,0 \%$ & $0,0 \%$ & $100,0 \%$ \\
\hline & V & 145 & 5 & 1 & 0 & 0 & 151 & $96,0 \%$ & $3,3 \%$ & $0,7 \%$ & $0,0 \%$ & $0,0 \%$ & $100,0 \%$ \\
\hline 32 & L & 147 & 4 & 0 & 0 & 0 & 151 & $97,4 \%$ & $2,6 \%$ & $0,0 \%$ & $0,0 \%$ & $0,0 \%$ & $100,0 \%$ \\
\hline & V & 145 & 5 & 1 & 0 & 0 & 151 & $96,0 \%$ & $3,3 \%$ & $0,7 \%$ & $0,0 \%$ & $0,0 \%$ & $100,0 \%$ \\
\hline 33 & L & 143 & 6 & 0 & 1 & 0 & 150 & $95,3 \%$ & $4,0 \%$ & $0,0 \%$ & $0,7 \%$ & $0,0 \%$ & $100,0 \%$ \\
\hline & V & 137 & 11 & 1 & 1 & 0 & 150 & $91,3 \%$ & $7,3 \%$ & $0,7 \%$ & $0,7 \%$ & $0,0 \%$ & $100,0 \%$ \\
\hline 34 & L & 124 & 19 & 5 & 3 & 0 & 151 & $82,1 \%$ & $12,6 \%$ & $3,3 \%$ & $2,0 \%$ & $0,0 \%$ & $100,0 \%$ \\
\hline & O & 103 & 29 & 9 & 3 & 0 & 144 & $71,5 \%$ & $20,1 \%$ & $6,3 \%$ & $2,1 \%$ & $0,0 \%$ & $100,0 \%$ \\
\hline & V & 121 & 23 & 4 & 3 & 0 & 151 & $80,1 \%$ & $15,2 \%$ & $2,6 \%$ & $2,0 \%$ & $0,0 \%$ & $100,0 \%$ \\
\hline 35 & L & 125 & 15 & 5 & 2 & 0 & 147 & $85,0 \%$ & $10,2 \%$ & $3,4 \%$ & $1,4 \%$ & $0,0 \%$ & $100,0 \%$ \\
\hline & O & 100 & 23 & 8 & 2 & 0 & 133 & $75,2 \%$ & $17,3 \%$ & $6,0 \%$ & $1,5 \%$ & $0,0 \%$ & $100,0 \%$ \\
\hline & V & 122 & 18 & 4 & 2 & 1 & 147 & $83,0 \%$ & $12,2 \%$ & $2,7 \%$ & $1,4 \%$ & $0,7 \%$ & $100,0 \%$ \\
\hline 36 & L & 112 & 13 & 1 & 1 & 0 & 127 & $88,2 \%$ & $10,2 \%$ & $0,8 \%$ & $0,8 \%$ & $0,0 \%$ & $100,0 \%$ \\
\hline & O & 50 & 9 & 3 & 0 & 0 & 62 & $80,6 \%$ & $14,5 \%$ & $4,8 \%$ & $0,0 \%$ & $0,0 \%$ & $100,0 \%$ \\
\hline & V & 94 & 13 & 1 & 1 & 0 & 109 & $86,2 \%$ & $11,9 \%$ & $0,9 \%$ & $0,9 \%$ & $0,0 \%$ & $100,0 \%$ \\
\hline 37 & L & 116 & 15 & 9 & 3 & 0 & 143 & $81,1 \%$ & $10,5 \%$ & $6,3 \%$ & $2,1 \%$ & $0,0 \%$ & $100,0 \%$ \\
\hline & O & 87 & 18 & 13 & 3 & 0 & 121 & $71,9 \%$ & $14,9 \%$ & $10,7 \%$ & $2,5 \%$ & $0,0 \%$ & $100,0 \%$ \\
\hline & V & 114 & 16 & 9 & 3 & 0 & 142 & $80,3 \%$ & $11,3 \%$ & $6,3 \%$ & $2,1 \%$ & $0,0 \%$ & $100,0 \%$ \\
\hline 41 & L & 147 & 4 & 0 & 0 & 0 & 151 & $97,4 \%$ & $2,6 \%$ & $0,0 \%$ & $0,0 \%$ & $0,0 \%$ & $100,0 \%$ \\
\hline & V & 145 & 5 & 1 & 0 & 0 & 151 & $96,0 \%$ & $3,3 \%$ & $0,7 \%$ & $0,0 \%$ & $0,0 \%$ & $100,0 \%$ \\
\hline 42 & L & 147 & 4 & 0 & 0 & 0 & 151 & $97,4 \%$ & $2,6 \%$ & $0,0 \%$ & $0,0 \%$ & $0,0 \%$ & $100,0 \%$ \\
\hline & V & 145 & 5 & 1 & 0 & 0 & 151 & $96,0 \%$ & $3,3 \%$ & $0,7 \%$ & $0,0 \%$ & $0,0 \%$ & $100,0 \%$ \\
\hline 43 & L & 145 & 5 & 0 & 1 & 0 & 151 & $96,0 \%$ & $3,3 \%$ & $0,0 \%$ & $0,7 \%$ & $0,0 \%$ & $100,0 \%$ \\
\hline & V & 140 & 9 & 1 & 1 & 0 & 151 & $92,7 \%$ & $6,0 \%$ & $0,7 \%$ & $0,7 \%$ & $0,0 \%$ & $100,0 \%$ \\
\hline 44 & L & 124 & 19 & 5 & 3 & 0 & 151 & $82,1 \%$ & $12,6 \%$ & $3,3 \%$ & $2,0 \%$ & $0,0 \%$ & $100,0 \%$ \\
\hline & 0 & 102 & 29 & 9 & 3 & 0 & 143 & $71,3 \%$ & $20,3 \%$ & $6,3 \%$ & $2,1 \%$ & $0,0 \%$ & $100,0 \%$ \\
\hline & V & 120 & 23 & 4 & 2 & 1 & 150 & $80,0 \%$ & $15,3 \%$ & $2,7 \%$ & $1,3 \%$ & $0,7 \%$ & $100,0 \%$ \\
\hline 45 & L & 125 & 17 & 5 & 1 & 0 & 148 & $84,5 \%$ & $11,5 \%$ & $3,4 \%$ & $0,7 \%$ & $0,0 \%$ & $100,0 \%$ \\
\hline & 0 & 100 & 25 & 9 & 1 & 0 & 135 & $74,1 \%$ & $18,5 \%$ & $6,7 \%$ & $0,7 \%$ & $0,0 \%$ & $100,0 \%$ \\
\hline & V & 121 & 20 & 5 & 1 & 0 & 147 & $82,3 \%$ & $13,6 \%$ & $3,4 \%$ & $0,7 \%$ & $0,0 \%$ & $100,0 \%$ \\
\hline 46 & L & 109 & 13 & 1 & 0 & 0 & 123 & $88,6 \%$ & $10,6 \%$ & $0,8 \%$ & $0,0 \%$ & $0,0 \%$ & $100,0 \%$ \\
\hline & 0 & 50 & 12 & 2 & 0 & 0 & 64 & $78,1 \%$ & $18,8 \%$ & $3,1 \%$ & $0,0 \%$ & $0,0 \%$ & $100,0 \%$ \\
\hline & V & 98 & 13 & 1 & 0 & 0 & 112 & $87,5 \%$ & $11,6 \%$ & $0,9 \%$ & $0,0 \%$ & $0,0 \%$ & $100,0 \%$ \\
\hline 47 & L & 114 & 14 & 9 & 2 & 0 & 139 & $82,0 \%$ & $10,1 \%$ & $6,5 \%$ & $1,4 \%$ & $0,0 \%$ & $100,0 \%$ \\
\hline & 0 & 87 & 20 & 10 & 2 & 0 & 119 & $73,1 \%$ & $16,8 \%$ & $8,4 \%$ & $1,7 \%$ & $0,0 \%$ & $100,0 \%$ \\
\hline & V & 113 & 15 & 9 & 2 & 0 & 139 & $81,3 \%$ & $10,8 \%$ & $6,5 \%$ & $1,4 \%$ & $0,0 \%$ & $100,0 \%$ \\
\hline Tots & & 8558 & 972 & 345 & 98 & 8 & 9981 & $85,7 \%$ & $9,7 \%$ & $3,5 \%$ & $1,0 \%$ & $0,1 \%$ & $100,0 \%$ \\
\hline
\end{tabular}




\begin{tabular}{|c|c|c|c|c|c|c|c|c|c|c|c|c|c|c|c|c|c|}
\hline DENIE & Sup. & 0 & $T$ & 2 & 3 & 4 & 5 & 6 & Tota & 0 & $T$ & 2 & 3 & 4 & 5 & 6 & Tota \\
\hline \multirow[t]{2}{*}{$\Pi$} & $\mathrm{L}$ & 145 & 2 & 3 & $T$ & 0 & 0 & 0 & T5T & $96,0 \%$ & $1,3 \%$ & $2,0 \%$ & $0,7 \%$ & $0,0 \%$ & $0,0 \%$ & $0,0 \%$ & $700,0 \%$ \\
\hline & V & 140 & 5 & 4 & 0 & 0 & 1 & 0 & 150 & $93,3 \%$ & $3,3 \%$ & $2,7 \%$ & $0,0 \%$ & $0,0 \%$ & $0,7 \%$ & $0,0 \%$ & $100,0 \%$ \\
\hline \multirow[t]{2}{*}{12} & $\mathrm{~L}$ & 144 & 1 & 5 & 1 & 0 & 0 & 0 & 151 & $95,4 \%$ & $0,7 \%$ & $3,3 \%$ & $0,7 \%$ & $0,0 \%$ & $0,0 \%$ & $0,0 \%$ & $100,0 \%$ \\
\hline & V & 139 & 2 & 7 & 1 & 0 & 0 & 0 & 149 & $93,3 \%$ & $1,3 \%$ & $4,7 \%$ & $0,7 \%$ & $0,0 \%$ & $0,0 \%$ & $0,0 \%$ & $100,0 \%$ \\
\hline \multirow[t]{2}{*}{13} & L. & 138 & 4 & 4 & 0 & 0 & 0 & 0 & 146 & $94,5 \%$ & $2,7 \%$ & $2,7 \%$ & $0,0 \%$ & $0,0 \%$ & $0,0 \%$ & $0,0 \%$ & $100,0 \%$ \\
\hline & V & 132 & 5 & 9 & 0 & 0 & 0 & 0 & 146 & $90,4 \%$ & $3,4 \%$ & $6,2 \%$ & $0,0 \%$ & $0,0 \%$ & $0,0 \%$ & $0,0 \%$ & $100,0 \%$ \\
\hline 14 & $\mathbf{L}$ & 121 & 14 & 9 & 7 & 0 & 0 & 0 & 151 & $80,1 \%$ & $9,3 \%$ & $6,0 \%$ & $4,6 \%$ & $0,0 \%$ & $0,0 \%$ & $0,0 \%$ & $100,0 \%$ \\
\hline & O & 100 & 0 & 40 & 0 & 0 & 0 & 0 & 140 & $71,4 \%$ & $0,0 \%$ & $28,6 \%$ & $0,0 \%$ & $0,0 \%$ & $0,0 \%$ & $0,0 \%$ & $100,0 \%$ \\
\hline & V & 118 & 16 & 9 & 6 & 0 & 0 & 2 & 151 & $78,1 \%$ & $10,6 \%$ & $6,0 \%$ & $4,0 \%$ & $0,0 \%$ & $0,0 \%$ & $1,3 \%$ & $100,0 \%$ \\
\hline 15 & L & 117 & 13 & 8 & 7 & 1 & 0 & 0 & 146 & $80,1 \%$ & $8,9 \%$ & $5,5 \%$ & $4,8 \%$ & $0,7 \%$ & $0,0 \%$ & $0,0 \%$ & $100,0 \%$ \\
\hline & $\mathrm{O}$ & 95 & 0 & 38 & 1 & 0 & 0 & 0 & 134 & $70,9 \%$ & $0,0 \%$ & $28,4 \%$ & $0,7 \%$ & $0,0 \%$ & $0,0 \%$ & $0,0 \%$ & $100,0 \%$ \\
\hline & V & 115 & 14 & 9 & 6 & 0 & 0 & 2 & 146 & $78,8 \%$ & $9,6 \%$ & $6,2 \%$ & $4,1 \%$ & $0,0 \%$ & $0,0 \%$ & $1,4 \%$ & $100,0 \%$ \\
\hline 16 & L & 132 & 4 & 8 & 4 & 0 & 0 & 0 & 148 & $89,2 \%$ & $2,7 \%$ & $5,4 \%$ & $2,7 \%$ & $0,0 \%$ & $0,0 \%$ & $0,0 \%$ & $100,0 \%$ \\
\hline & $\mathrm{O}$ & 50 & 0 & 19 & 0 & 0 & 0 & 0 & 69 & $72,5 \%$ & $0,0 \%$ & $27,5 \%$ & $0,0 \%$ & $0,0 \%$ & $0,0 \%$ & $0,0 \%$ & $100,0 \%$ \\
\hline & V & 129 & 5 & 7 & 4 & 0 & 0 & 1 & 146 & $88,4 \%$ & $3,4 \%$ & $4,8 \%$ & $2,7 \%$ & $0,0 \%$ & $0,0 \%$ & $0,7 \%$ & $100,0 \%$ \\
\hline 17 & L & 112 & 6 & 10 & 6 & 1 & 1 & 0 & 136 & $82,4 \%$ & $4,4 \%$ & $7,4 \%$ & $4,4 \%$ & $0,7 \%$ & $0,7 \%$ & $0,0 \%$ & $100,0 \%$ \\
\hline & $\mathrm{O}$ & 91 & 0 & 26 & 2 & 2 & 0 & 0 & 121 & $75,2 \%$ & $0,0 \%$ & $21,5 \%$ & $1,7 \%$ & $1,7 \%$ & $0,0 \%$ & $0,0 \%$ & $100,0 \%$ \\
\hline & V & 111 & 6 & 11 & 6 & 1 & 0 & 1 & 136 & $81,6 \%$ & $4,4 \%$ & $8,1 \%$ & $4,4 \%$ & $0,7 \%$ & $0,0 \%$ & $0,7 \%$ & $100,0 \%$ \\
\hline 21 & L & 145 & 2 & 4 & 0 & 0 & 0 & 0 & 151 & $96,0 \%$ & $1,3 \%$ & $2,6 \%$ & $0,0 \%$ & $0,0 \%$ & $0,0 \%$ & $0,0 \%$ & $100,0 \%$ \\
\hline & V & 140 & 5 & 5 & 0 & 0 & 0 & 0 & 150 & $93,3 \%$ & $3,3 \%$ & $3,3 \%$ & $0,0 \%$ & $0,0 \%$ & $0,0 \%$ & $0,0 \%$ & $100,0 \%$ \\
\hline 22 & $\mathbf{L}$ & 144 & 2 & 5 & 0 & 0 & 0 & 0 & 151 & $95,4 \%$ & $1,3 \%$ & $3,3 \%$ & $0,0 \%$ & $0,0 \%$ & $0,0 \%$ & $0,0 \%$ & $0 \%$ \\
\hline & V & 141 & 3 & 7 & 0 & 0 & 0 & 0 & 151 & $93,4 \%$ & $2,0 \%$ & $4,6 \%$ & $0,0 \%$ & $0,0 \%$ & $0,0 \%$ & $0,0 \%$ & $100,0 \%$ \\
\hline 23 & L & 139 & 2 & 4 & 0 & 0 & 0 & 0 & 145 & $95,9 \%$ & $1,4 \%$ & $2,8 \%$ & $0,0 \%$ & $0,0 \%$ & $0,0 \%$ & $0,0 \%$ & $0 \%$ \\
\hline & V & 131 & 5 & 7 & 0 & 0 & 1 & 0 & 144 & $91,0 \%$ & $3,5 \%$ & $4,9 \%$ & $0,0 \%$ & $0,0 \%$ & $0,7 \%$ & $0,0 \%$ & $100,0 \%$ \\
\hline 24 & L & 121 & 12 & 11 & 7 & 0 & 0 & 0 & 151 & $80,1 \%$ & $7,9 \%$ & $7,3 \%$ & $4,6 \%$ & $0,0 \%$ & $0,0 \%$ & $0,0 \%$ & $100,0 \%$ \\
\hline & $\mathrm{O}$ & 98 & 0 & 41 & 0 & 0 & 0 & 0 . & 139 & $70,5 \%$ & $0,0 \%$ & $29,5 \%$ & $0,0 \%$ & $0,0 \%$ & $0,0 \%$ & $0,0 \%$ & $100,0 \%$ \\
\hline & V & 119 & 13 & 11 & 6 & 0 & 1 & 1 & 151 & $78,8 \%$ & $8,6 \%$ & $7,3 \%$ & $4,0 \%$ & $0,0 \%$ & $0,7 \%$ & $0,7 \%$ & $100,0 \%$ \\
\hline 25 & L & 118 & 12 & 10 & 7 & 0 & 0 & 0 & 147 & $80,3 \%$ & $8,2 \%$ & $6,8 \%$ & $4,8 \%$ & $0,0 \%$ & $0,0 \%$ & $0,0 \%$ &, $0 \%$ \\
\hline & O & 96 & 0 & 41 & 0 & 0 & 0 & 0 & 137 & $70,1 \%$ & $0,0 \%$ & $29,9 \%$ & $0,0 \%$ & $0,0 \%$ & $0,0 \%$ & $0,0 \%$ & $100,0 \%$ \\
\hline & V & 116 & 12 & 10 & 7 & 0 & 1 & 1 & 147 & $78,9 \%$ & $8,2 \%$ & $6,8 \%$ & $4,8 \%$ & $0,0 \%$ & $0,7 \%$ & $0,7 \%$ & $100,0 \%$ \\
\hline 26 & $\mathrm{~L}$ & 129 & 6 & 6 & 4 & 0 & 0 & 0 & 145 & $89,0 \%$ & $4,1 \%$ & $4,1 \%$ & $2,8 \%$ & $0,0 \%$ & $0,0 \%$ & $0,0 \%$ & $100,0 \%$ \\
\hline & $\mathrm{O}$ & 55 & 0 & 19 & 0 & 0 & 0 & 0 & 74 & $74,3 \%$ & $0,0 \%$ & $25,7 \%$ & $0,0 \%$ & $0,0 \%$ & $0,0 \%$ & $0,0 \%$ & $0 \%$ \\
\hline & V & 125 & 7 & 5 & 4 & 0 & 0 & 1 & 142 & $88,0 \%$ & $4,9 \%$ & $3,5 \%$ & $2,8 \%$ & $0,0 \%$ & $0,0 \%$ & $0,7 \%$ & $100,0 \%$ \\
\hline 27 & $\mathrm{~L}$ & 106 & 6 & 11 & 6 & 1 & 1 & 0 & 131 & $80,9 \%$ & $4,6 \%$ & $8,4 \%$ & $4,6 \%$ & $0,8 \%$ & $0,8 \%$ & $0,0 \%$ & $100,0 \%$ \\
\hline & $\mathrm{O}$ & 89 & 0 & 26 & 3 & 2 & 0 & 0 & 120 & $74,2 \%$ & $0,0 \%$ & $21,7 \%$ & $2,5 \%$ & $1,7 \%$ & $0,0 \%$ & $0,0 \%$ & $100,0 \%$ \\
\hline & V & 105 & 6 & 11 & 6 & 2 & 0 & 1 & 131 & $80,2 \%$ & $4,6 \%$ & $8,4 \%$ & $4,6 \%$ & $1,5 \%$ & $0,0 \%$ & $0,8 \%$ & $100,0 \%$ \\
\hline 31 & $L$ & 146 & 1 & 4 & 0 & 0 & 0 & 0 & 151 & $96,7 \%$ & $0,7 \%$ & $2,6 \%$ & $0,0 \%$ & $0,0 \%$ & $0,0 \%$ & $0,0 \%$ & $0 \%$ \\
\hline & V & 145 & 2 & 4 & 0 & 0 & 0 & 0 & 151 & $96,0 \%$ & $1,3 \%$ & $2,6 \%$ & $0,0 \%$ & $0,0 \%$ & $0,0 \%$ & $0,0 \%$ & $100,0 \%$ \\
\hline 32 & L & 146 & 1 & 4 & 0 & 0 & 0 & 0 & 151 & $96,7 \%$ & $0,7 \%$ & $2,6 \%$ & $0,0 \%$ & $0,0 \%$ & $0,0 \%$ & $0,0 \%$ & $100,0 \%$ \\
\hline & V & 144 & 2 & 5 & 0 & 0 & 0 & 0 & 151 & $95,4 \%$ & $1,3 \%$ & $3,3 \%$ & $0,0 \%$ & $0,0 \%$ & $0,0 \%$ & $0,0 \%$ & $0 \%$ \\
\hline 33 & L & 144 & 0 & 6 & 0 & 0 & 0 & 0 & 150 & $96,0 \%$ & $0,0 \%$ & $4,0 \%$ & $0,0 \%$ & $0,0 \%$ & $0,0 \%$ & $0,0 \%$ & $100,0 \%$ \\
\hline & V & 138 & 4 & 8 & 0 & 0 & 0 & 0 & 150 & & $2,7 \%$ & $5,3 \%$ & $0,0 \%$ & $0,0 \%$ & $0,0 \%$ & $0,0 \%$ &, $0 \%$ \\
\hline 34 & L & 123 & 12 & 10 & 6 & 0 & 0 & 0 & 151 & $81,5 \%$ & $7,9 \%$ & $6,6 \%$ & $4,0 \%$ & $0,0 \%$ & $0,0 \%$ & $0,0 \%$ & $100,0 \%$ \\
\hline & $\mathrm{O}$ & 101 & 0 & 43 & 0 & 0 & 0 & 0 & 144 & $70,1 \%$ & $0,0 \%$ & $29,9 \%$ & $0,0 \%$ & $0,0 \%$ & $0,0 \%$ & $0,0 \%$ & $0 \%$ \\
\hline & V & 119 & 15 & 11 & 5 & 0 & 1 & 0 & 151 & $78,8 \%$ & $9,9 \%$ & $7,3 \%$ & $3,3 \%$ & $0,0 \%$ & $0,7 \%$ & $0,0 \%$ & $100,0 \%$ \\
\hline 35 & $\mathrm{~L}$ & 124 & 10 & 8 & 5 & 0 & 0 & 0 & 147 & $84,4 \%$ & $6,8 \%$ & $5,4 \%$ & $3,4 \%$ & $0,0 \%$ & $0,0 \%$ & $0,0 \%$ & $100,0 \%$ \\
\hline & $\mathrm{O}$ & 98 & 0 & 35 & 0 & 0 & 0 & 0 & 133 & $73,7 \%$ & $0,0 \%$ & $26,3 \%$ & $0,0 \%$ & $0,0 \%$ & $0,0 \%$ & $0,0 \%$ & $100,0 \%$ \\
\hline & V & 121 & 12 & 8 & 5 & 0 & 1 & 0 & 147 & $82,3 \%$ & $8,2 \%$ & $5,4 \%$ & $3,4 \%$ & $0,0 \%$ & $0,7 \%$ & $0,0 \%$ &, $0 \%$ \\
\hline 36 & $L$ & 112 & 7 & 5 & 3 & 0 & 0 & 0 & 127 & $2 \%$ & $5,5 \%$ & $\%$ & & $\%$ & $0 \%$ & $0,0 \%$ & $0 \%$ \\
\hline & $\mathrm{O}$ & 50 & 0 & 12 & 0 & 0 & 0 & 0 & 62 & $80,6 \%$ & $0,0 \%$ & $19,4 \%$ & $0,0 \%$ & $0,0 \%$ & $0,0 \%$ & $0,0 \%$ & $100,0 \%$ \\
\hline & V & 93 & 8 & 5 & 3 & 0 & 0 & 0 & 109 & $85,3 \%$ & $7,3 \%$ & $4,6 \%$ & $2,8 \%$ & $0,0 \%$ & $0,0^{\circ} \%$ & $0,0 \%$ & $100,0 \%$ \\
\hline 37 & $\mathrm{~L}$ & 115 & 8 & 13 & 6 & 1 & 0 & 0 & 143 & $80,4 \%$ & $5,6 \%$ & $9,1 \%$ & $4,2 \%$ & $0,7 \%$ & $0,0 \%$ & $0,0 \%$ & $100,0 \%$ \\
\hline & $\mathrm{O}$ & 86 & 0 & 33 & 1 & 1 & 0 & 0 & 121 & $71,1 \%$ & $0,0 \%$ & $27,3 \%$ & $0,8 \%$ & $0,8 \%$ & $0,0 \%$ & $0,0 \%$ & $100,0 \%$ \\
\hline & V & 113 & 8 & 14 & 6 & 1 & 0 & 0 & 142 & $79,6 \%$ & $5,6 \%$ & $9,9 \%$ & $2 \%$ & $0,7 \%$ & $0,0 \%$ & $0,0 \%$ & $.0 \%$ \\
\hline 41 & $\mathrm{~L}$ & 146 & 1 & 4 & 0 & 0 & 0 & 0 & 151 & $96,7 \%$ & $0,7 \%$ & $2,6 \%$ & $0,0 \%$ & $0,0 \%$ & $0,0 \%$ & $0,0 \%$ & $0 \%$ \\
\hline & V & 145 & 2 & 4 & 0 & 0 & 0 & 0 & 151 & $96,0 \%$ & $1,3 \%$ & $2,6 \%$ & $\%$ & $0,0 \%$ & $0,0 \%$ & $0,0 \%$ & $0 \%$ \\
\hline 42 & L & 146 & 1 & 4 & 0 & 0 & 0 & 0 & 151 & $96,7 \%$ & $0,7 \%$ & $2,6 \%$ & $0,0 \%$ & $0,0 \%$ & $0,0 \%$ & $0,0 \%$ &, $0 \%$ \\
\hline & V & 145 & 2 & 4 & 0 & 0 & 0 & 0 & 151 & $96,0 \%$ & $1,3 \%$ & $2,6 \%$ & $0,0 \%$ & $0,0 \%$ & $0,0 \%$ & $0,0 \%$ & $100,0 \%$ \\
\hline 43 & L & 145 & 1 & 5 & 0 & 0 & 0 & 0 & 151 & $96,0 \%$ & $0,7 \%$ & $3,3 \%$ & $0,0 \%$ & $0,0 \%$ & $0,0 \%$ & $0,0 \%$ &, $0 \%$ \\
\hline & V & 139 & 5 & 7 & 0 & 0 & 0 & 0 & 151 & $92,1 \%$ & $3,3 \%$ & $4,6 \%$ & $0,0 \%$ & $0,0 \%$ & $0,0 \%$ & $0,0 \%$ & $.0 \%$ \\
\hline 44 & $L$ & 124 & 12 & 9 & 6 & 0 & 0 & 0 & 15 & & $7,9 \%$ & $6,0 \%$ & $\%$ & $0,0 \%$ & $0,0 \%$ & $0,0 \%$ & $0 \%$ \\
\hline & $\mathbf{O}$ & 101 & 0 & 42 & 0 & 0 & 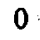 & 0 & 143 & $70,6 \%$ & $0,0 \%$ & $29,4 \%$ & $0,0 \%$ & $0,0 \%$ & $0,0 \%$ & $0,0 \%$ & $100,0 \%$ \\
\hline & V & 119 & 15 & 10 & 5 & 0 & 1 & 0 & 150 & $79,3 \%$ & $10,0 \%$ & $6,7 \%$ & & $0,0 \%$ & $0,7 \%$ & $0,0 \%$ & $100,0 \%$ \\
\hline 45 & L & 125 & 9 & 10 & 4 & 0 & 0 & 0 & 148 & $84,5 \%$ & $6,1 \%$ & $6,8 \%$ & $2,7 \%$ & $0,0 \%$ & $0,0 \%$ & $0,0 \%$ & $100,0 \%$ \\
\hline & $\mathrm{O}$ & 99 & 0 & 36 & 0 & 0 & 0 & 0 & 135 & $73,3 \%$ & $0,0 \%$ & $26,7 \%$ & $0,0 \%$ & $0,0 \%$ & $0,0 \%$ & $0,0 \%$ & $100,0 \%$ \\
\hline & V & 120 & 12 & 11 & 4 & 0 & 0 & 0 & 147 & $81,6 \%$ & $8,2 \%$ & $7,5 \%$ & $2,7 \%$ & $0,0 \%$ & $0,0 \%$ & $0,0 \%$ & $100,0 \%$ \\
\hline 46 & L & 108 & 6 & 6 & 3 & 0 & 0 & 0 & 123 & $87,8 \%$ & $4,9 \%$ & $4,9 \%$ & $2,4 \%$ & $0,0 \%$ & $0,0 \%$ & $0,0 \%$ & $100,0 \%$ \\
\hline & O & 50 & 0 & 14 & 0 & 0 & 0 & 0 & 64 & $78,1 \%$ & $0,0 \%$ & $21,9 \%$ & $0,0 \%$ & $0,0 \%$ & $0,0 \%$ & $0,0 \%$ & $100,0 \%$ \\
\hline & V & 96 & 7 & 6 & 3 & 0 & 8 & 0 & 112 & $85,7 \%$ & $6,3 \%$ & $5,4 \%$ & $2,7 \%$ & $0,0 \%$ & $0,0 \%$ & $0,0 \%$ & $100,0 \%$ \\
\hline 47 & L & 112 & 8 & 10 & 8 & 1 & 0 & 0 & 139 & $80,6 \%$ & $5,8 \%$ & $7,2 \%$ & $5,8 \%$ & $0,7 \%$ & $0,0 \%$ & $0,0 \%$ & $100,0 \%$ \\
\hline & 0 & 86 & 0 & 28 & 4 & 1 & 0 & 0 & 119 & $72,3 \%$ & $0,0 \%$ & $23,5 \%$ & $3,4 \%$ & $0,8 \%$ & $0,0 \%$ & $0,0 \%$ & $100,0 \%$ \\
\hline & V & 111 & 8 & 11 & 8 & 1 & 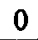 & 0 & 139 & $79,9 \%$ & $5,8 \%$ & $7,9 \%$ & $5,8 \%$ & $0,7 \%$ & $0,0 \%$ & $0,0 \%$ & $100,0 \%$ \\
\hline otal & & 8481 & 369 & 909 & 787 & 16 & 9 & 10 & 9981 & $85,0 \%$ & $3,7 \%$ & $9,1 \%$ & $1,9 \%$ & $0,2 \%$ & $0,1 \%$ & $0,1 \%$ & $100,0 \%$ \\
\hline
\end{tabular}


Anexo 3: TSIF por dente e superficie, Cesário Lange.

\begin{tabular}{|c|c|c|c|c|c|c|c|c|c|c|c|c|c|c|c|c|c|}
\hline \multirow[b]{2}{*}{ DENTE } & \multicolumn{7}{|c|}{ Numero de superticies } & \multicolumn{10}{|c|}{ Percentagern de supenticies } \\
\hline & Sup. & 0 & $\mathrm{~T}$ & 2 & 3 & 4 & 5 & 6 & Tota & 0 & $\mathrm{~T}$ & 2 & 3 & 4 & 5 & 6 & Total \\
\hline$\Pi$ & $\mathrm{L}$ & 745 & 4 & 2 & \% & 0 & 0 & 0 & TाT & $96,0 \%$ & $2,6 \%$ & $1,3 \%$ & $0,0 \%$ & $0,0 \%$ & $0,0 \%$ & $0,0 \%$ & $100,0 \%$ \\
\hline & V & 139 & 7 & 3 & 0 & 0 & $\mathbf{0}$ & 1 & 150 & $92,7 \%$ & $4,7 \%$ & $2,0 \%$ & $0,0 \%$ & $0,0 \%$ & $0,0 \%$ & $0,7 \%$ & $100,0 \%$ \\
\hline 12 & L & 144 & 6 & 1 & 0 & 0 & $\mathbf{0}$ & 0 & 151 & $95,4 \%$ & $4,0 \%$ & $0,7 \%$ & $0,0 \%$ & $0,0 \%$ & $0,0 \%$ & $0,0 \%$ & $100,0 \%$ \\
\hline & $\mathrm{V}$ & 138 & 8 & 2 & 1 & 0 & $\mathbf{0}$ & 0 & 149 & $92,6 \%$ & $5,4 \%$ & $1,3 \%$ & $0,7 \%$ & $0,0 \%$ & $0,0 \%$ & $0,0 \%$ & $100,0 \%$ \\
\hline 13 & $\mathrm{~L}$ & 138 & 7 & $\mathbf{0}$ & 1 & 0 & $\mathbf{0}$ & 0 & 146 & $94,5 \%$ & $4,8 \%$ & $0,0 \%$ & $0,7 \%$ & $0,0 \%$ & $0,0 \%$ & $0,0 \%$ & $100,0 \%$ \\
\hline & V & 132 & 11 & 2 & 1 & 0 & 0 & 0 & 146 & $90,4 \%$ & $7,5 \%$ & $1,4 \%$ & $0,7 \%$ & $0,0 \%$ & $0,0 \%$ & $0,0 \%$ & $100,0 \%$ \\
\hline 14 & L & 122 & 18. & 7 & 4 & 0 & 0 & 0 & 151 & $80,8 \%$ & $11,9 \%$ & $4,6 \%$ & $2,6 \%$ & $0,0 \%$ & $0,0 \%$ & $0,0 \%$ & $100,0 \%$ \\
\hline & 0 & 102 & 28 & 8 & 2 & 0 & 0 & 0 & 140 & $72,9 \%$ & $20,0 \%$ & $5,7 \%$ & $1,4 \%$ & $0,0 \%$ & $0,0 \%$ & $0,0 \%$ & $100,0 \%$ \\
\hline & V & 121 & 19 & 6 & 3 & 0 & 2 & 0 & 151 & $80,1 \%$ & $12,6 \%$ & $4,0 \%$ & $2,0 \%$ & $0,0 \%$ & $1,3 \%$ & $0,0 \%$ & $100,0 \%$ \\
\hline 15 & L & 118 & 17 & 6 & 5 & 0 & 0 & 0 & 146 & $80,8 \%$ & $11,6 \%$ & $4,1 \%$ & $3,4 \%$ & $0,0 \%$ & $0,0 \%$ & $0,0 \%$ & $100,0 \%$ \\
\hline & O & 96 & 26 & 8 & 4 & 0 & 0 & 0 & 134 & $71,6 \%$ & $19,4 \%$ & $6,0 \%$ & $3,0 \%$ & $0,0 \%$ & $0,0 \%$ & $0,0 \%$ & $100,0 \%$ \\
\hline & V & 117 & 18 & 6 & 5 & 0 & 0 & 0 & 146 & $80,1 \%$ & $12,3 \%$ & $4,1 \%$ & $3,4 \%$ & $0,0 \%$ & $0,0 \%$ & $0.0 \%$ & $100,0 \%$ \\
\hline 16 & L & 133 & 13 & 2 & 0 & 0 & 0 & 0 & 148 & $89,9 \%$ & $8,8 \%$ & $1,4 \%$ & $0,0 \%$ & $0,0 \%$ & $0,0 \%$ & $0,0 \%$ & $100,0 \%$ \\
\hline & 0 & 51 & 15 & 3 & 0 & 0 & 0 & 0 & 69 & $73,9 \%$ & $21,7 \%$ & $4,3 \%$ & $0,0 \%$ & $0,0 \%$ & $0,0 \%$ & $0,0 \%$ & $100,0 \%$ \\
\hline & V & 131 & 12 & 2 & 0 & 0 & 1 & 0 & 146 & $89,7 \%$ & $8,2 \%$ & $1,4 \%$ & $0,0 \%$ & $0,0 \%$ & $0,7 \%$ & $0,0 \%$ & $100,0 \%$ \\
\hline 17 & L & 113 & 12 & 8 & 3 & 0 & 0 & 0 & 136 & $83,1 \%$ & $\mathbf{8 , 8 \%}$ & $5,9 \%$ & $2,2 \%$ & $0,0 \%$ & $0,0 \%$ & $0,0 \%$ & $100,0 \%$ \\
\hline & 0 & 91 & 16 & 11 & 3 & 0 & 0 & 0 & 121 & $75,2 \%$ & $13,2 \%$ & $9,1 \%$ & $2,5 \%$ & $0,0 \%$ & $0,0 \%$ & $0,0 \%$ & $100,0 \%$ \\
\hline & V & 112 & 14 & 7 & 2 & 0 & 1 & 0 & 136 & $82,4 \%$ & $10,3 \%$ & $5,1 \%$ & $1,5 \%$ & $0,0 \%$ & $0,7 \%$ & $0,0 \%$ & $100,0 \%$ \\
\hline 21 & L & 145 & 4 & 2 & 0 & 0 & 0 & 0 & 151 & $96,0 \%$ & $2,6 \%$ & $1,3 \%$ & $0,0 \%$ & $0,0 \%$ & $0,0 \%$ & $0,0 \%$ & $100,0 \%$ \\
\hline & V & 139 & 7 & 3 & 0 & 1 & 0 & 0 & 150 & $92,7 \%$ & $4,7 \%$ & $2,0 \%$ & $0,0 \%$ & $0,7 \%$ & $0,0 \%$ & $0,0 \%$ & $100,0 \%$ \\
\hline 22 & L & 144 & 6 & 1 & 0 & 0 & 0 & 0 & 151 & $95,4 \%$ & $4,0 \%$ & $0,7 \%$ & $0,0 \%$ & $0,0 \%$ & $0,0 \%$ & $0,0 \%$ & $100,0 \%$ \\
\hline & V & 141 & 7 & 3 & 0 & 0 & 0 & 0 & 151 & $93,4 \%$ & $4,6 \%$ & $2,0 \%$ & $0,0 \%$ & $0,0 \%$ & $0,0 \%$ & $0,0 \%$ & $100,0 \%$ \\
\hline 23 & L & 140 & 3 & 0 & 2 & 0 & 0 & 0 & 145 & $96,6 \%$ & $2,1 \%$ & $0,0 \%$ & $1,4 \%$ & $0,0 \%$ & $0,0 \%$ & $0,0 \%$ & $100,0 \%$ \\
\hline & V & 131 & 9 & 2 & 1 & 1 & 0 & 0 & 144 & $91,0 \%$ & $6,3 \%$ & $1,4 \%$ & $0,7 \%$ & $0,7 \%$ & $0,0 \%$ & $0,0 \%$ & $100,0 \%$ \\
\hline 24 & L & 121 & 16 & 10 & 4 & 0 & 0 & 0 & 151 & $80,1 \%$ & $10,6 \%$ & $6,6 \%$ & $2,6 \%$ & $0,0 \%$ & $0,0 \%$ & $0,0 \%$ & $100,0 \%$ \\
\hline & O & 99 & 24 & 13 & 3 & 0 & 0 & 0 & 139 & $71,2 \%$ & $17,3 \%$ & $9,4 \%$ & $2.2 \%$ & $0,0 \%$ & $0,0 \%$ & $0,0 \%$ & $100,0 \%$ \\
\hline & V & 120 & 18 & 8 & 3 & 1 & 1 & 0 & 151 & $79,5 \%$ & $11,9 \%$ & $5,3 \%$ & $2,0 \%$ & $0,7 \%$ & $0,7 \%$ & $0,0 \%$ & $100,0 \%$ \\
\hline 25 & L & 119 & 16 & 7 & 5 & 0 & 0 & 0 & 147 & $81,0 \%$ & $10,9 \%$ & $4,8 \%$ & $3,4 \%$ & $0,0 \%$ & $0,0 \%$ & $0,0 \%$ & $100,0 \%$ \\
\hline & 0 & 97 & 26 & 10 & 4 & 0 & 0 & 0 & 137 & $70,8 \%$ & $19,0 \%$ & $7,3 \%$ & $2,9 \%$ & $0,0 \%$ & $0,0 \%$ & $0,0 \%$ & $100,0 \%$ \\
\hline & V & 118 & 16 & 7 & 5 & 0 & 1 & 0 & 147 & $80,3 \%$ & $10,9 \%$ & $4,8 \%$ & $3,4 \%$ & $0,0 \%$ & $0,7 \%$ & $0,0 \%$ & $100,0 \%$ \\
\hline 26 & L & 130 & 10 & 4 & 1 . & 0 & 0 & 0 & 145 & $89,7 \%$ & $6,9 \%$ & $2,8 \%$ & $0,7 \%$ & $0,0 \%$ & $0,0 \%$ & $0,0 \%$ & $100,0 \%$ \\
\hline & 0 & 56 & 12 & 5 & 1 & 0 & 0 & 0 & 74 & $75,7 \%$ & $16,2 \%$ & $6,8 \%$ & $1,4 \%$ & $0,0 \%$ & $0,0 \%$ & $0,0 \%$ & $100,0 \%$ \\
\hline & V & 127 & 10 & 4 & 1 & 0 & 0 & 0 & 142 & $89,4 \%$ & $7,0 \%$ & $2,8 \%$ & $0,7 \%$ & $0,0 \%$ & $0,0 \%$ & $0,0 \%$ & $100,0 \%$ \\
\hline 27 & L & 107 & 12 & 9 & 2 & 0 & 1 & 0 & 131 & $81,7 \%$ & $9.2 \%$ & $6,9 \%$ & $1,5 \%$ & $0,0 \%$ & $0,8 \%$ & $0,0 \%$ & $100,0 \%$ \\
\hline & 0 & 91 & 15 & 10 & 4 & 0 & 0 & 0 & 120 & $75,8 \%$ & $12,5 \%$ & $8,3 \%$ & $3,3 \%$ & $0,0 \%$ & $0,0 \%$ & $0,0 \%$ & $100,0 \%$ \\
\hline & V & 105 & 14 & 8 & 4 & 0 & 0 & 0 & 131 & $80,2 \%$ & $10,7 \%$ & $6,1 \%$ & $3,1 \%$ & $0,0 \%$ & $0,0 \%$ & $0,0 \%$ & $100,0 \%$ \\
\hline 31 & L & 146 & 5 & 0 & 0 & 0 & 0 & 0 & 151 & $96,7 \%$ & $3,3 \%$ & $0,0 \%$ & $0,0 \%$ & $0,0 \%$ & $0,0 \%$ & $0,0 \%$ & $100,0 \%$ \\
\hline & V & 145 & 5 & 1 & 0 & 0 & 0 & 0 & 151 & $96,0 \%$ & $3,3 \%$ & $0,7 \%$ & $0,0 \%$ & $0,0 \%$ & $0,0 \%$ & $0,0 \%$ & $100,0 \%$ \\
\hline 32 & L & 146 & 5 & 0 & 0 & 0 & 0 & 0 & 151 & $96,7 \%$ & $3,3 \%$ & $0,0 \%$ & $0,0 \%$ & $0,0 \%$ & $0,0 \%$ & $0,0 \%$ & $100,0 \%$ \\
\hline & V & 145 & 5 & 1 & 0 & 0 & 0 & 0 & 151 & $6,0 \%$ & $3,3 \%$ & $0,7 \%$ & $0,0 \%$ & $0,0 \%$ & $0,0 \%$ & $0,0 \%$ & $100,0 \%$ \\
\hline 33 & L & 144 & 5 & 0 & 1 & 0 & 0 & 0 & 150 & $96,0 \%$ & $3,3 \%$ & $0,0 \%$ & $0,7 \%$ & $0,0 \%$ & $0,0 \%$ & $0,0 \%$ & $100,0 \%$ \\
\hline & V & 138 & 10 & 1 & 1 & 0 & 0 & 0 & 150 & $92,0 \%$ & $6,7 \%$ & $0,7 \%$ & $0,7 \%$ & $0,0 \%$ & $0,0 \%$ & $0,0 \%$ & $100,0 \%$ \\
\hline 34 & L & 123 & 19 & 5 & 4 & 0 & 0 & 0 & 151 & $81,5 \%$ & $12,6 \%$ & $3,3 \%$ & $2,6 \%$ & $0,0 \%$ & $0,0 \%$ & $0,0 \%$ & $100,0 \%$ \\
\hline & O & 103 & 29 & 9 & 3 & 0 & 0 & 0 & 144 & $1,5 \%$ & $20,1 \%$ & $6,3 \%$ & $2,1 \%$ & $0,0 \%$ & $0,0 \%$ & $0,0 \%$ & $100,0 \%$ \\
\hline & V & 120 & 22 & 5 & 4 & 0 & 0 & 0 & 151 & $79,5 \%$ & $14,6 \%$ & $3,3 \%$ & $2,6 \%$ & $0,0 \%$ & $0,0 \%$ & $0,0 \%$ & $100,0 \%$ \\
\hline 35 & L & 125 & 12 & 7 & 3 & 0 & 0 & 0 & 147 & $85,0 \%$ & $8,2 \%$ & $4,8 \%$ & $2,0 \%$ & $0,0 \%$ & $0,0 \%$ & $0,0 \%$ & $100,0 \%$ \\
\hline & $\mathrm{O}$ & 101 & 21 & 9 & 2 & 0 & 0 & 0 & 133 & $75,9 \%$ & $15,8 \%$ & $6,8 \%$ & $1,5 \%$ & $0,0 \%$ & $0,0 \%$ & $0,0 \%$ & $100,0 \%$ \\
\hline & V & 122 & 15 & 6 & 3 & 0 & 1 & 0 & 147 & $3,0 \%$ & $10,2 \%$ & $4,1 \%$ & $2,0 \%$ & $0,0 \%$ & $0,7 \%$ & $0,0 \%$ & $100,0 \%$ \\
\hline 36 & L & 112 & 11 & 3 & 1 & 0 & 0 & 0 & 127 & $88,2 \%$ & $8,7 \%$ & $2,4 \%$ & $0,8 \%$ & $0,0 \%$ & $0,0 \%$ & $0,0 \%$ & $100,0 \%$ \\
\hline & 0 & 50 & 9 & 3 & 0 & 0 & 0 & 0 & 62 & $80,6 \%$ & $14,5 \%$ & $4,8 \%$ & $0,0 \%$ & $0,0 \%$ & $0,0 \%$ & $0,0 \%$ & $100,0 \%$ \\
\hline & V & 94 & 11 & 3 & 1 & 0 & 0 & 0 & 109 & $6.2 \%$ & $10,1 \%$ & $2,8 \%$ & $0,9 \%$ & $0,0 \%$ & $0,0 \%$ & $0,0 \%$ & $100,0 \%$ \\
\hline 37 & L & 115 & 17 & 8 & 3 & 0 & & 0 & 143 &, $4 \%$ & $11,9 \%$ & $5,6 \%$ & $2,1 \%$ & $0,0 \%$ & $0,0 \%$ & $0,0 \%$ & $100,0 \%$ \\
\hline & $\mathrm{O}$ & 87 & 20 & 11 & 3 & 0 & 0 & 0 & 12 & $71,9 \%$ & $16,5 \%$ & $9,1 \%$ & $2,5 \%$ & $0,0 \%$ & $0,0 \%$ & $0 \%$ & $100,0 \%$ \\
\hline & V & 113 & 18 & 7 & 4 & 0 & 0 & 0 & 142 & $79,6 \%$ & $12,7 \%$ & $4,9 \%$ & $2,8 \%$ & $0,0 \%$ & $0,0 \%$ & $0,0 \%$ & $100,0 \%$ \\
\hline 41 & L & 146 & 5 & 0 & 0 & 0 & 0 & 0 & 151 & $96,7 \%$ & $3,3 \%$ & $0,0 \%$ & $0,0 \%$ & $0,0 \%$ & $0,0 \%$ & $0,0 \%$ & $100,0 \%$ \\
\hline & V & 145 & 5 & 1 & 0 & 0 & 0 & 0 & 1. & $96,0 \%$ & $3,3 \%$ & $0,7 \%$ & $0,0 \%$ & $0,0 \%$ & $0,0 \%$ & $0,0 \%$ & $100,0 \%$ \\
\hline 42 & L & 146 & 5 & 0 & 0 & 0 & 0 & & 1. & $96,7 \%$ & $3,3 \%$ & $0,0 \%$ & $0,0 \%$ & $0,0 \%$ & $0,0 \%$ & $0,0 \%$ & $100,0 \%$ \\
\hline & V & 145 & 5 & 1 & 0 & 0 & 0 & 0 & 151 & $96,0 \%$ & $3,3 \%$ & $0,7 \%$ & $0,0 \%$ & $0,0 \%$ & $0,0 \%$ & $0,0 \%$ & $100,0 \%$ \\
\hline 43 & L & 145 & 5 & 0 & 1 & 0 & 0 & 0 & 151 & $96,0 \%$ & $3,3 \%$ & $0,0 \%$ & $0,7 \%$ & $0,0 \%$ & $0,0 \%$ & $0,0 \%$ & $100,0 \%$ \\
\hline & V & 139 & 10 & 1 & 1 & 0 & 0 & 0 & 151 & $92,1 \%$ & $6,6 \%$ & $0,7 \%$ & $0,7 \%$ & $0,0 \%$ & $0,0 \%$ & $0,0 \%$ & $100,0 \%$ \\
\hline 44 & L & 123 & 20 & 4 & 4 & 0 & 0 & 0 & 15 & $81,5 \%$ & $13,2 \%$ & $2,6 \%$ & $2,6 \%$ & $0,0 \%$ & $0,0 \%$ & $0,0 \%$ & \\
\hline & 0 & 102 & 30 & 8 & 3 & 0 & 0 & 0 & 1 & $71,3 \%$ & $21,0 \%$ & $5,6 \%$ & $2,1 \%$ & $0,0 \%$ & $0,0 \%$ & $0,0 \%$ & $100,0 \%$ \\
\hline & V & 119 & 22 & 5 & 3 & 0 & 1 & 0 & 150 & $79,3 \%$ & $14,7 \%$ & $3,3 \%$ & $2,0 \%$ & $0,0 \%$ & $0,7 \%$ & $0, \infty \%$ & $100,0 \%$ \\
\hline 45 & L & 124 & 18 & 4 & 2 & 0 & 0 & 0 & 14 & $83,8 \%$ & $12,2 \%$ & $2,7 \%$ & $1,4 \%$ & $0,0 \%$ & $0,0 \%$ & $0,0 \%$ & $100,0 \%$ \\
\hline & $\mathrm{O}$ & 100 & 24 & 10 & 1 & 0 & 0 & 0 & 13 & $74,1 \%$ & $17,8 \%$ & $7,4 \%$ & $0,7 \%$ & $0,0 \%$ & $0,0 \%$ & $0,0 \%$ & $100,0 \%$ \\
\hline & V & 120 & 19 & 6 & 2 & 0 & 0 & 0 & 14 & $81,6 \%$ & $12,9 \%$ & $4,1 \%$ & $1,4 \%$ & $0,0 \%$ & $0,0 \%$ & $0,0 \%$ & $100,0 \%$ \\
\hline 46 & L & 108 & 13 & 2 & 0 & 0 & 0 & 0 & 123 & $87,8 \%$ & $10,6 \%$ & $1,6 \%$ & $0,0 \%$ & $0,0 \%$ & $0,0 \%$ & $0,0 \%$ & $100,0 \%$ \\
\hline & 0 & 50 & 10 & 4 & 0 & 0 & 0 & 0 & 64 & $78,1 \%$ & $15,6 \%$ & $6,3 \%$ & $0,0 \%$ & $0,0 \%$ & $0,0 \%$ & $0,0 \%$ & $100,0 \%$ \\
\hline & V & 97 & 14 & l & 0 & 0 & 0 & 0 & 112 & $86,6 \%$ & $12,5 \%$ & $0,9 \%$ & $0,0 \%$ & $0,0 \%$ & $0,0 \%$ & $0,0 \%$ & $100,0 \%$ \\
\hline 47 & L & 113 & 14 & 9 & 3 & 0 & 0 & 0 & 13 & $81,3 \%$ & $10,1 \%$ & $6,5 \%$ & $2,2 \%$ & $0,0 \%$ & $0,0 \%$ & $0,0 \%$ & $100,0 \%$ \\
\hline & O & 87 & 20 & 8 & 4 & 0 & 0 & 0 & 11 & $73,1 \%$ & $16,8 \%$ & $6,7 \%$ & $3,4 \%$ & $0,0 \%$ & $0,0 \%$ & $0,0 \%$ & $100,0 \%$ \\
\hline & V & 112 & 15 & 9 & 3 & 0 & 0 & 0 & 139 & $80,6 \%$ & $10,8 \%$ & $6,5 \%$ & $2,2 \%$ & $0,0 \%$ & $0,0 \%$ & $0,0 \%$ & $100,0 \%$ \\
\hline ta & & 8523 & 969 & 342 & 134 & 3 & 9 & 8 & 9981 & $85,4 \%$ & $9,7 \%$ & $3,4 \%$ & $1,3 \%$ & $0,0 \%$ & $0,1 \%$ & $0,0 \%$ & $100,0 \%$ \\
\hline
\end{tabular}


Anexo 4: Indice de DEAN por dente e superficie, Piracicaba.

\begin{tabular}{|c|c|c|c|c|c|c|c|c|c|c|c|c|c|}
\hline \multirow{2}{*}{ DENIE } & \multirow[b]{2}{*}{ Sup. } & \multicolumn{5}{|c|}{ Número de superticies } & \multicolumn{6}{|c|}{ Percentagem de superficies } & \multirow[b]{2}{*}{ Total } \\
\hline & & 0 & $T$ & 2 & 3 & 4 & Total & O & $T$ & 2 & 3 & 4 & \\
\hline$\pi$ & $\mathrm{L}$ & 139 & 2 & 0 & 0 & 0 & Tा1 & $98,6 \%$ & $1,4 \%$ & $0,0 \%$ & $0,0 \%$ & $0,0 \%$ & $100,0 \%$ \\
\hline & V & 136 & 3 & 0 & 0 & 0 & 139 & $97,8 \%$ & $2,2 \%$ & $0,0 \%$ & $0,0 \%$ & $0,0 \%$ & $100,0 \%$ \\
\hline 12 & L & 139 & 2 & 0 & 0 & 0 & 141 & $98,6 \%$ & $1,4 \%$ & $0,0 \%$ & $0,0 \%$ & $0,0 \%$ & $100,0 \%$ \\
\hline & V & 136 & 4 & 0 & 0 & 0 & 140 & $97,1 \%$ & $2,9 \%$ & $0,0 \%$ & $0,0 \%$ & $0,0 \%$ & $100,0 \%$ \\
\hline 13 & L & 133 & 3 & 0 & 0 & 0 & 136 & $97,8 \%$ & $2,2 \%$ & $0,0 \%$ & $0,0 \%$ & $0,0 \%$ & $100,0 \%$ \\
\hline & V & 126 & 9 & 0 & 0 & 0 & 135 & $93,3 \%$ & $6,7 \%$ & $0,0 \%$ & $0,0 \%$ & $0,0 \%$ & $100,0 \%$ \\
\hline 14 & L & 123 & 13 & 4 & 1 & 0 & 141 & $87,2 \%$ & $9,2 \%$ & $2,8 \%$ & $0,7 \%$ & $0,0 \%$ & $100,0 \%$ \\
\hline & O & 116 & 15 & 4 & 1 & 0 & 136 & $85,3 \%$ & $11,0 \%$ & $2,9 \%$ & $0,7 \%$ & $0,0 \%$ & $100,0 \%$ \\
\hline & V & 123 & 13 & 3 & 1 & 1 & 141 & $87,2 \%$ & $92 \%$ & $2,1 \%$ & $0,7 \%$ & $0,7 \%$ & $100,0 \%$ \\
\hline 15 & L & 121 & 13 & 4 & 1 & 0 & 139 & $87,1 \%$ & $9,4 \%$ & $2,9 \%$ & $0,7 \%$ & $0,0 \%$ & $100,0 \%$ \\
\hline & 0 & 115 & 15 & 4 & 1 & 0 & 135 & $85,2 \%$ & $11,1 \%$ & $3,0 \%$ & $0,7 \%$ & $0,0 \%$ & $100,0 \%$ \\
\hline & V & 121 & 13 & 4 & 1 & 0 & 139 & $87,1 \%$ & $9,4 \%$ & $2,9 \%$ & $0,7 \%$ & $0,0 \%$ & $100,0 \%$ \\
\hline 16 & $\mathrm{~L}$ & 137 & 3 & 0 & 0 & 0 & 140 & $97,9 \%$ & $2,1 \%$ & $0,0 \%$ & $0,0 \%$ & $0,0 \%$ & $100,0 \%$ \\
\hline & $\mathrm{O}$ & 91 & 3 & 0 & 0 & 0 & 94 & $96,8 \%$ & $32 \%$ & $0,0 \%$ & $0,0 \%$ & $0,0 \%$ & $100,0 \%$ \\
\hline & V & 138 & 3 & 0 & 0 & 0 & 141 & $97,9 \%$ & $2,1 \%$ & $0,0 \%$ & $0,0 \%$ & $0,0 \%$ & $100,0 \%$ \\
\hline 17 & $\mathrm{~L}$ & 96 & 14. & 4 & 1 & 0 & 115 & $83,5 \%$ & $12,2 \%$ & $3,5 \%$ & $0,9 \%$ & $0,0 \%$ & $100,0 \%$ \\
\hline & 0 & 89 & 13 & 5 & 1 & 0 & 108 & $82,4 \%$ & $12,0 \%$ & $4,6 \%$ & $0,9 \%$ & $0,0 \%$ & $100,0 \%$ \\
\hline & V & 96 & 14 & 4 & 1 & 0 & 115 & $83,5 \%$ & $12,2 \%$ & $3,5 \%$ & $0,9 \%$ & $0,0 \%$ & $100,0 \%$ \\
\hline 21 & L & 140 & 2 & 0 & 0 & 0 & 142 & $98,6 \%$ & $1,4 \%$ & $0,0 \%$ & $0,0 \%$ & $0,0 \%$ & $100,0 \%$ \\
\hline & V & 135 & 3 & 0 & 0 & 0 & 138 & $97,8 \%$ & $2,2 \%$ & $0,0 \%$ & $0,0 \%$ & $0,0 \%$ & $100,0 \%$ \\
\hline 22 & L & 139 & 2 & 0 & 0 & 0 & 141 & $98,6 \%$ & $1,4 \%$ & $0,0 \%$ & $0,0 \%$ & $0,0 \%$ & $100,0 \%$ \\
\hline & V & 134 & 4 & 0 & 0 & 0 & 138 & $97,1 \%$ & $2,9 \%$ & $0,0 \%$ & $0,0 \%$ & $0,0 \%$ & $100,0 \%$ \\
\hline 23 & L & 131 & 3 & 0 & 0 & 0 & 134 & $97,8 \%$ & $2,2 \%$ & $0,0 \%$ & $0,0 \%$ & $0,0 \%$ & $100,0 \%$ \\
\hline & V & 125 & 9 & 0 & 0 & 0 & 134 & $93,3 \%$ & $6,7 \%$ & $0,0 \%$ & $0,0 \%$ & $0,0 \%$ & $100,0 \%$ \\
\hline 24 & $\mathrm{~L}$ & 122 & 13 & 4 & 1 & 0 & 140 & $87,1 \%$ & $9,3 \%$ & $2,9 \%$ & $0,7 \%$ & $0,0 \%$ & $100,0 \%$ \\
\hline & $\mathrm{O}$ & 116 & 15 & 4 & 1 & 0 & 136 & $85,3 \%$ & $11,0 \%$ & $2,9 \%$ & $0,7 \%$ & $0,0 \%$ & $100,0 \%$ \\
\hline & V & 122 & 12 & 3 & 1 & 2 & 140 & $87,1 \%$ & $8,6 \%$ & $2,1 \%$ & $0,7 \%$ & $1,4 \%$ & $100,0 \%$ \\
\hline 25 & $\mathrm{~L}$ & 119 & 13 & 4 & 1 & 0 & 137 & $86,9 \%$ & $9,5 \%$ & $2,9 \%$ & $0,7 \%$ & $0,0 \%$ & $100,0 \%$ \\
\hline & 0 & 112 & 15 & 4 & 1 & 0 & 132 & $84,8 \%$ & $11,4 \%$ & $3,0 \%$ & $0,8 \%$ & $0,0 \%$ & $100,0 \%$ \\
\hline & V & 119 & 13 & 3 & 1 & 1 & 137 & $86,9 \%$ & $9,5 \%$ & $2,2 \%$ & $0,7 \%$ & $0,7 \%$ & $100,0 \%$ \\
\hline 26 & $\mathrm{~L}$ & 137 & 3 & 0 & 0 & 0 & 140 & $97,9 \%$ & $2,1 \%$ & $0,0 \%$ & $0,0 \%$ & $0,0 \%$ & $100,0 \%$ \\
\hline & 0 & 92 & 3 & 0 & 0 & 0 & 95 & $96,8 \%$ & $3,2 \%$ & $0,0 \%$ & $0,0 \%$ & $0,0 \%$ & $100,0 \%$ \\
\hline & V & 138 & 3 & 0 & 0 & 0 & 141 & $97,9 \%$ & $2,1 \%$ & $0,0 \%$ & $0,0 \%$ & $0,0 \%$ & $100,0 \%$ \\
\hline 27 & $\mathrm{~L}$ & 94 & 13 & 4 & 1 & 0 & 112 & $83,9 \%$ & $11,6 \%$ & $3,6 \%$ & $0,9 \%$ & $0,0 \%$ & $100,0 \%$ \\
\hline & 0 & 87 & 13 & 4 & 1 & 0 & 105 & $82,9 \%$ & $12,4 \%$ & $3,8 \%$ & $1,0 \%$ & $0,0 \%$ & $100,0 \%$ \\
\hline & V & 94 & 13 & 4 & 1 & 0 & 112 & $83,9 \%$ & $11,6 \%$ & $3,6 \%$ & $0,9 \%$ & $0,0 \%$ & $100,0^{\circ} \%$ \\
\hline 31 & $\mathrm{~L}$ & 141 & 1 & 0 & 0 & 0 & 142 & $99,3 \%$ & $0,7 \%$ & $0,0 \%$ & $0,0 \%$ & $0,0 \%$ & $100,0 \%$ \\
\hline & V & 141 & 1 & 0 & 0 & 0 & 142 & $99,3 \%$ & $0,7 \%$ & $0,0 \%$ & $0,0 \%$ & $0,0 \%$ & $100,0 \%$ \\
\hline 32 & $\mathrm{~L}$ & 141 & 1 & 0 & 0 & 0 & 142 & $99,3 \%$ & $0,7 \%$ & $0,0 \%$ & $0,0 \%$ & $0,0 \%$ & $100,0 \%$ \\
\hline & V & 141 & 1 & 0 & 0 & 0 & 142 & $99,3 \%$ & $0,7 \%$ & $0,0 \%$ & $0,0 \%$ & $0,0 \%$ & $100,0 \%$ \\
\hline 33 & $\mathrm{~L}$ & 138 & 2 & 0 & 0 & 0 & 140 & $98,6 \%$ & $1,4 \%$ & $0,0 \%$ & $0,0 \%$ & $0,0 \%$ & $100,0 \%$ \\
\hline & V & 133 & 7 & 0 & 0 & 0 & 140 & $95,0 \%$ & $5,0 \%$ & $0,0 \%$ & $0,0 \%$ & $0,0 \%$ & $100,0 \%$ \\
\hline 34 & $\mathrm{~L}$ & 122 & 13 & 4 & 1 & 0 & 140 & $87,1 \%$ & $9,3 \%$ & $2,9 \%$ & $0,7 \%$ & $0,0 \%$ & $100,0 \%$ \\
\hline & $\mathrm{O}$ & 120 & 14 & 4 & 1 & 0 & 139 & $86,3 \%$ & $10,1 \%$ & $2,9 \%$ & $0,7 \%$ & $0,0 \%$ & $100,0 \%$ \\
\hline & V & 122 & 13 & 4 & 1 & 0 & 140 & $87,1 \%$ & $9,3 \%$ & $2,9 \%$ & $0,7 \%$ & $0,0 \%$ & $100,0 \%$ \\
\hline 35 & $\mathrm{~L}$ & 119 & 10 & 4 & 1 & 0 & 134 & $88,8 \%$ & $7,5 \%$ & $3,0 \%$ & $0,7 \%$ & $0,0 \%$ & $100,0 \%$ \\
\hline & 0 & 113 & 12 & 4 & 1 & 0 & 130 & $86,9 \%$ & $9,2 \%$ & $3,1 \%$ & $0,8 \%$ & $0,0 \%$ & $100,0 \%$ \\
\hline & V & 119 & 10 & 4 & 1 & 0 & 134 & $88,8 \%$ & $7,5 \%$ & $3,0 \%$ & $0,7 \%$ & $0,0 \%$ & $100,0 \%$ \\
\hline 36 & L & 127 & 2 & 1 & 0 & 0 & 130 & $97,7 \%$ & $1,5 \%$ & $0,8 \%$ & $0,0 \%$ & $0,0 \%$ & $100,0 \%$ \\
\hline & 0 & 75 & 2 & 1 & 0 & 0 & 78 & $96,2 \%$ & $2,6 \%$ & $1,3 \%$ & $0,0 \%$ & $0,0 \%$ & $100,0 \%$ \\
\hline & V & 122 & 2 & 1 & 0 & 0 & 125 & $97,6 \%$ & $1,6 \%$ & $0,8 \%$ & $0,0 \%$ & $0,0 \%$ & $100,0 \%$ \\
\hline 37 & $\mathrm{~L}$ & 99 & 14 & 3 & 2 & 0 & 118 & $83,9 \%$ & $11,9 \%$ & $2,5 \%$ & $1,7 \%$ & $0,0 \%$ & $100,0 \%$ \\
\hline & 0 & 81 & 14 & 3 & 2 & 0 & 100 & $81,0 \%$ & $14,0 \%$ & $3,0 \%$ & $2,0 \%$ & $0,0 \%$ & $100,0 \%$ \\
\hline & V & 98 & 14 & 3 & 2 & 0 & 117 & $83,8 \%$ & $12,0 \%$ & $2,6 \%$ & $1.7 \%$ & $0,0 \%$ & $100,0 \%$ \\
\hline 41 & L & 141 & 1 & 0 & 0 & 0 & 142 & $99,3 \%$ & $0,7 \%$ & $0,0 \%$ & $0,0 \%$ & $0,0 \%$ & $100,0 \%$ \\
\hline & V & 141 & 1 & 0 & 0 & 0 & 142 & $99,3 \%$ & $0,7 \%$ & $0,0 \%$ & $0,0 \%$ & $0,0 \%$ & $100,0 \%$ \\
\hline 42 & L & 141 & 1 & 0 & 0 & 0 & 142 & $99,3 \%$ & $0,7 \%$ & $0,0 \%$ & $0,0 \%$ & $0,0 \%$ & $100,0 \%$ \\
\hline & V & 141 & 1 & 0 & 0 & 0 & 142 & $99,3 \%$ & $0,7 \%$ & $0,0 \%$ & $0,0 \%$ & $0,0 \%$ & $100,0 \%$ \\
\hline 43 & $\mathrm{~L}$ & 138 & 2 & 0 & 0 & 0 & 140 & $98,6 \%$ & $1,4 \%$ & $0,0 \%$ & $0,0 \%$ & $0,0 \%$ & $100,0 \%$ \\
\hline & V & 133 & 7 & 0 & 0 & 0 & 140 & $95,0 \%$ & $5,0 \%$ & $0,0 \%$ & $0,0 \%$ & $0,0 \%$ & $100,0 \%$ \\
\hline 44 & $\mathrm{~L}$ & 124 & 12 & 4 & 0 & 0 & 140 & $88,6 \%$ & $8,6 \%$ & $2,9 \%$ & $0,0 \%$ & $0,0 \%$ & $100,0 \%$ \\
\hline & 0 & 120 & 13 & 4 & 0 & 0 & 137 & $87,6 \%$ & $9,5 \%$ & $2,9 \%$ & $0,0 \%$ & $0,0 \%$ & $100,0 \%$ \\
\hline & V & 124 & 12 & 4 & 0 & 0 & 140 & $88,6 \%$ & $8,6 \%$ & $2,9 \%$ & $0,0 \%$ & $0,0 \%$ & $100,0 \%$ \\
\hline 45 & $\mathrm{~L}$ & 120 & 13 & 4 & 1 & 0 & 138 & $87,0 \%$ & $9,4 \%$ & $2,9 \%$ & $0,7 \%$ & $0,0 \%$ & $100,0 \%$ \\
\hline & 0 & 113 & 14 & 4 & 1 & 0 & 132 & $85,6 \%$ & $10,6 \%$ & $3,0 \%$ & $0,8 \%$ & $0,0 \%$ & $100,0 \%$ \\
\hline & V & 120 & 13 & 4 & 1 & 0 & 138 & $87,0 \%$ & $9,4 \%$ & $2,9 \%$ & $0,7 \%$ & $0,0 \%$ & $100,0 \%$ \\
\hline 46 & L & 131 & 2 & 1 & 0 & 0 & 134 & $97,8 \%$ & $1.5 \%$ & $0,7 \%$ & $0,0 \%$ & $0,0 \%$ & $100,0 \%$ \\
\hline & 0 & 76 & 2 & 1 & 0 & 0 & 79 & $96,2 \%$ & $2,5 \%$ & $1,3 \%$ & $0,0 \%$ & $0,0 \%$ & $100,0 \%$ \\
\hline & V & 122 & 2 & 1 & 0 & 0 & 125 & $97,6 \%$ & $1,6 \%$ & $0,8 \%$ & $0,0 \%$ & $0,0 \%$ & $100,0 \%$ \\
\hline 47 & L & 99 & 14 & 3 & 2 & 0 & 118 & $83,9 \%$ & $11,9 \%$ & $2,5 \%$ & $1,7 \%$ & $0,0 \%$ & $100,0 \%$ \\
\hline & O & 84 & 15 & 3 & 2 & 0 & 104 & $80,8 \%$ & $14,4 \%$ & $2,9 \%$ & $1,9 \%$ & $0,0 \%$ & $100,0 \%$ \\
\hline & V & 99 & 14 & 3 & 2 & 0 & 118 & $83,9 \%$ & $11,9 \%$ & $2,5 \%$ & $1,7 \%$ & $0,0 \%$ & $100,0 \%$ \\
\hline Tota & & 8650 & 579 & 142 & 39 & 4 & 9414 & $91,9 \%$ & $6,2 \%$ & $1,5 \%$ & $0.4 \%$ & $0,0 \%$ & $700,0 \%$ \\
\hline
\end{tabular}


Anexo 5: Indice T-F por dente e superficie, Piracicaba.

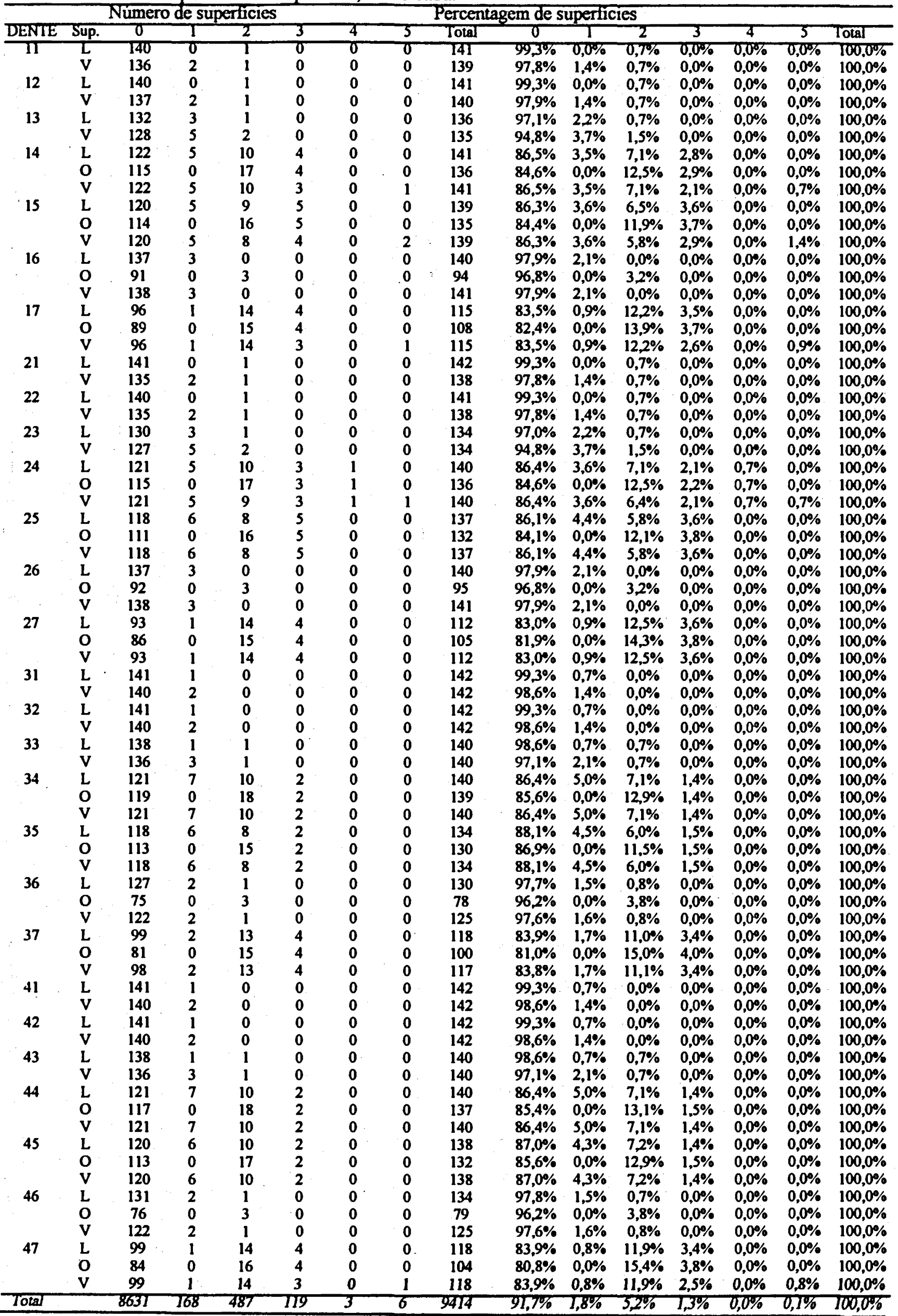


Anexo 6: TSIF por dente c superficie, Piracicaba.

\begin{tabular}{|c|c|c|c|c|c|c|c|c|c|c|c|c|c|}
\hline \\
\hline \multirow{3}{*}{$\frac{\text { DENTE }}{\pi}$} & sup. & 0 & I & 2 & 3 & 5 & Total & 0 & $T$ & 2 & 3 & 5 & Total \\
\hline & $\mathrm{L}$ & T39 & $T$ & $T$ & 0 & 0 & T4I & $98,6 \%$ & $0,7 \%$ & $0,1 \%$ & $0,0 \%$ & $0,0 \%$ & $100,0 \%$ \\
\hline & V & 136 & 2 & 1 & 0 & $u$ & 139 & $4 /, 8 \%$ & $1,4 \%$ & $0,1 \%$ & $0,0 \%$ & $0,0 \%$ & $100,0 \%$ \\
\hline \multirow[t]{2}{*}{12} & $L$ & 139 & 1 & 1 & 0 & 0 & 141 & $98,6 \%$ & $0,1 \%$ & $0, / \%$ & $0,0 \%$ & $u, u \%$ & $100,0 \%$ \\
\hline & v & 136 & 3 & 1 & 0 & 0 & 140 & $y /, 1 \%$ & $2,1 \%$ & $0,1 \%$ & $0, u \%$ & $0,0 \%$ & $100,0 \%$ \\
\hline \multirow[t]{2}{*}{13} & L & 129 & 5 & 2 & 0 & $u$ & 136 & $94,9 \%$ & $3,1 \%$ & $1,5 \%$ & $0,0 \%$ & $0,0 \%$ & $100,0 \%$ \\
\hline & v & 126 & $\%$ & 2 & 0 & 0 & 135 & $93,3 \%$ & $5,2 \%$ & $1,5 \%$ & $0,0 \%$ & $0,0 \%$ & $100,0 \%$ \\
\hline \multirow[t]{3}{*}{14} & L & 123 & 13 & 5 & 0 & 0 & 141 & $8 \%, 2 \%$ & $y, 2 \%$ & $3,5 \%$ & $0,0 \%$ & $u, v \%$ & IOU,U\% \\
\hline & $U$ & 116 & 15 & 3 & 0 & 0 & 136 & $85,3 \%$ & $11,0 \%$ & $3,1 \%$ & $0,0 \%$ & $0,0 \%$ & $100,0 \%$ \\
\hline & v & 123 & 13 & 4 & 0 & 1 & 141 & $8 \%, 2 \%$ & $9,2 \%$ & $2,8 \%$ & $0,0 \%$ & $0,1 \%$ & $100,0 \%$ \\
\hline 15 & L & 121 & 12 & 6 & 0 & 0 & $13 y$ & $8 \%, 1 \%$ & $8,6 \%$ & $4,3 \%$ & $u, u \%$ & $0,0 \%$ & $100,0 \%$ \\
\hline & $U$ & 115 & 14 & 6 & 0 & $u$ & 135 & $85,2 \%$ & $10,4 \%$ & $4,4 \%$ & $0,0 \%$ & $0,0 \%$ & $100,0 \%$ \\
\hline & v & 121 & 12 & 3 & 0 & 1 & 139 & $8 /, 1 \%$ & $8,6 \%$ & $3,6 \%$ & $0,0 \%$ & $0,1 \%$ & $100,0 \%$ \\
\hline 16 & L & 131 & 3 & 0 & 0 & u & 140 & $9 \%, y \%$ & $2,1 \%$ & $0,0 \%$ & $0,0 \%$ & $0,0 \%$ & $100,0 \%$ \\
\hline & $U$ & 91 & 3 & 0 & 0 & $u$ & 94 & $96,8 \%$ & $3,2 \%$ & $0,0 \%$ & $0,0 \%$ & $0,0 \%$ & $100,0 \%$ \\
\hline & v & 138 & 3 & 0 & 0 & 0 & 141 & $9 /, 9 \%$ & $2,1 \%$ & $0,0 \%$ & U,U\% & $0,0 \%$ & $100,0 \%$ \\
\hline $1 \%$ & L & 96 & 12 & $\%$ & 0 & 0 & 115 & $83,5 \%$ & $10,4 \%$ & $6,1 \%$ & $0,0 \%$ & $0,0 \%$ & $100,0 \%$ \\
\hline & $U$ & $8 y$ & 12 & $\%$ & 0 & U & 108 & $82,4 \%$ & $11,1 \%$ & $6,5 \%$ & $\mathrm{U}, \mathrm{U} \%$ & $0,0 \%$ & $100,0 \%$ \\
\hline & v & 96 & 12 & $\%$ & 0 & 0 & 115 & $83,5 \%$ & $10,4 \%$ & $6,1 \%$ & $0,0 \%$ & $0,0 \%$ & $100,0 \%$ \\
\hline 21 & L & 140 & 1 & 1 & 0 & 0 & 142 & $98,6 \%$ & $0,7 \%$ & $0,1 \%$ & $0,0 \%$ & $0,0 \%$ & $100,0 \% \%$ \\
\hline & V & 135 & 2 & 1 & 0 & u & 138 & $91,8 \%$ & $1,4 \%$ & $0,1 \%$ & $0, U \%$ & $u, u \%$ & $100,0 \%$ \\
\hline 22 & L & 139 & 1 & 1 & 0 & 0 & 141 & $98,6 \%$ & $0,1 \%$ & $0,1 \%$ & $0,0 \%$ & $0,0 \%$ & $100,0 \% \%$ \\
\hline & v & 134 & 3 & 1 & 0 & u & 138 & $9 \%, 1 \%$ & $2,2 \%$ & $0, \% \%$ & $U, u \%$ & $0,0 \%$ & $100,0 \%$ \\
\hline 23 & L & 121 & 5 & 2 & 0 & 0 & 134 & $94,8 \%$ & $3, / \%$ & $1,5 \%$ & U,U\% & $0,0 \%$ & $100,0 \%$ \\
\hline & v & 125 & $\%$ & 2 & 0 & U & 134 & $43,3 \%$ & $5,2 \%$ & $1,5 \%$ & $0,0 \%$ & $0,0 \%$ & $100,0 \%$ \\
\hline 24 & L & 122 & 14 & 4 & 0 & u & 140 & $8 /, 1 \%$ & $10,0 \% \%$ & $2, y \%$ & $0,0 \%$ & $0,0 \%$ & $100,0 \%$ \\
\hline & $u$ & 116 & 16 & 4 & 0 & U & 136 & $85,3 \%$ & $11,8 \%$ & $2,9 \%$ & $0,0 \%$ & $0,0 \%$ & $100,0 \%$ \\
\hline & v & 122 & 13 & 3 & 0 & 2 & 140 & $8 /, 1 \%$ & $9,3 \%$ & $2,1 \%$ & $0,0 \%$ & $1,4 \%$ & $100,0 \%$ \\
\hline 25 & L & 119 & 14 & 4 & $u$ & u & 137 & $86,4 \%$ & $10,2 \%$ & $2, y \%$ & $0,0 \%$ & $0,0 \%$ & $100,0 \%$ \\
\hline & $U$ & 112 & 16 & 4 & 0 & $u$ & 132 & $84,8 \%$ & $12,1 \%$ & $3,0 \%$ & $0,0 \%$ & $0,0 \%$ & $100,0 \%$ \\
\hline & v & 119 & 14 & 3 & 0 & 1 & $13 \%$ & $86,9 \%$ & $10,2 \%$ & $2,2 \%$ & $0,0 \%$ & $0,1 \%$ & $100,0 \%$ \\
\hline 26 & L & $13 \%$ & 2 & 1 & 0 & $u$ & 140 & $91,9 \%$ & $1,4 \%$ & $0,1 \%$ & $0,0 \%$ & $0,0 \%$ & $100,0 \%$ \\
\hline & $U$ & 92 & 2 & 1 & 0 & U & Y5 & $46,8 \%$ & $2,1 \%$ & $1,1 \%$ & $0,0 \%$ & $0,0 \%$ & $100,0 \% \%$ \\
\hline & v & 138 & 2 & 1 & 0 & U & 141 & $91,9 \%$ & $1,4 \%$ & $0,1 \%$ & $0,0 \%$ & $0,0 \%$ & $100,0 \%$ \\
\hline 21 & L & 94 & 11 & 7 & 0 & u & 112 & $83,4 \%$ & $9,8 \%$ & $6,3 \%$ & $0,0 \%$ & $u, u \%$ & $I 00,0 \%$ \\
\hline & $U$ & $8 \%$ & 11 & $\%$ & 0 & 0 & IUS & $82, y \%$ & $10,5 \%$ & $6,1 \%$ & $0,0 \%$ & $0,0 \%$ & $100,0 \%$ \\
\hline & v & 94 & 11 & $\%$ & 0 & U & 112 & $83,9 \%$ & $9,8 \%$ & $6,3 \%$ & $0,0 \%$ & $0,0 \%$ & $100,0 \%$ \\
\hline 31 & L. & 141 & 1 & $u$ & 0 & u & 142 & yy, $3 \%$ & $0,1 \%$ & $u, w \%$ & $u, u \%$ & $0,0 \%$ & $100,0 \%$ \\
\hline & v & 140 & 2 & 0 & 0 & U & 142 & $98,6 \%$ & $1,4 \%$ & $0,0 \%$ & $0,0 \%$ & $0,0 \%$ & $100,0 \%$ \\
\hline 32 & L & 141 & 1 & 0 & 0 & 0 & 142 & $99,3 \%$ & $0,1 \%$ & $0,0 \%$ & $0,0 \%$ & $0,0 \%$ & $100,0 \%$ \\
\hline & v & 140 & 2 & 0 & 0 & U & 142 & $98,6 \%$ & $1,4 \%$ & $0,0 \%$ & $0,0 \%$ & $0,0 \%$ & $100,0 \%$ \\
\hline 33 & L & 136 & 4 & U & 0 & u & 140 & $91,1 \%$ & $2,9 \%$ & $0,0 \%$ & $0,0 \%$ & $0,0 \%$ & $100,0 \%$ \\
\hline & v & 133 & $\%$ & u & 0 & u & 140 & Ys, & $5,0 \% \%$ & U,U\% & $u, 0 \%$ & $u, u \%$ & $100,0 \%$ \\
\hline 34 & L & 122 & 14 & 4 & 0 & 0 & 140 & $8 /, 1 \%$ & $10,0 \%$ & $2,9 \%$ & $0,0 \%$ & $U, U \%$ & $100,0 \%$ \\
\hline & $U$ & 120 & 15 & 4 & 0 & u & 139 & $86,3 \%$ & $10,8 \%$ & $2, y \%$ & $0,0 \%$ & $0,0 \%$ & $100,0 \%$ \\
\hline & v & 122 & 14 & 4 & 0 & U & 140 & $81,1 \%$ & $10,0 \%$ & $2, y \%$ & $0,0 \%$ & $0,0 \%$ & $100,0 \%$ \\
\hline 35 & L & 119 & 11 & 4 & 0 & 0 & 134 & $88,8 \%$ & $\gamma, 2 \%$ & $3,0 \%$ & $0,0 \%$ & $0,0 \%$ & $100,0 \%$ \\
\hline & $U$ & 113 & 13 & 4 & 0 & 0 & 130 & $86,4 \%$ & $10,0 \%$ & $3,1 \%$ & $0,0 \%$ & $U, W \%$ & $100,0 \%$ \\
\hline & v & 119 & 11 & 4 & 0 & u & 134 & $88,8 \%$ & $8,2 \%$ & $3,0 \%$ & $u, u \%$ & $0,0 \%$ & $100,0 \%$ \\
\hline 36 & L & 126 & 2 & 2 & 0 & 0 & 130 & $96,9 \%$ & $1,5 \%$ & $1,5 \%$ & $0,0 \%$ & $0,0 \%$ & $100,0 \%$ \\
\hline & $u$ & 74 & 2 & 2 & 0 & 0 & 18 & $94,4 \%$ & $2,6 \%$ & $2,6 \%$ & $0,0 \%$ & $0,0 \%$ & $100,0 \%$ \\
\hline & v & 121 & 2 & 2 & 0 & 0 & 125 & $96,8 \%$ & $1,6 \%$ & $1,6 \%$ & $0,0 \%$ & $0,0 \%$ & $100,0 \%$ \\
\hline 31 & L. & yy & 12 & 6 & 1 & 0 & 118 & $83,4 \%$ & $10,2 \%$ & $5,1 \%$ & $0,8 \%$ & $0,0 \%$ & $100,0 \%$ \\
\hline & $U$ & 81 & 12 & 6 & 1 & 0 & 100 & $81,0 \%$ & $12,0 \%$ & $6,0 \%$ & $1,0 \%$ & $0,0 \%$ & $I 00,0 \%$ \\
\hline & V & 98 & 12 & 6 & 1 & 0 & $11 \%$ & $83,8 \%$ & $10,3 \%$ & $3,1 \%$ & $0,4 \%$ & $0,0 \%$ & $100,0 \%$ \\
\hline 41 & $L$ & 141 & 1 & U & 0 & 0 & 142 & $99,3 \%$ & $0,1 \%$ & $0,0 \%$ & $0,0 \%$ & $0,0 \%$ & $100,0 \%$ \\
\hline & v & 140 & 2 & 0 & 0 & 0 & 142 & $98,6 \%$ & $1,4 \%$ & $0,0 \%$ & $u, u \%$ & $0,0 \%$ & $100,0 \%$ \\
\hline 42 & L & 141 & 1 & 0 & 0 & 0 & 142 & $99,3 \%$ & $0,1 \%$ & $0,0 \%$ & $0,0 \%$ & $0,0 \%$ & $100,0 \%$ \\
\hline & V & 140 & 2 & 0 & 0 & 0 & 142 & $98,6 \%$ & $1,4 \%$ & $0,0 \%$ & $0,0 \%$ & $0,0 \%$ & $100,0 \%$ \\
\hline 43 & L & 136 & 4 & u & 0 & u & 140 & $9 \%, 1 \%$ & $2,4 \%$ & $0,0 \%$ & $0,0 \%$ & $u, u \%$ & $100,0 \%$ \\
\hline & v & 133 & $\%$ & 0 & 0 & $u$ & 140 & ys, $0 \%$ & $5,0 \% \%$ & $0,0 \%$ & $u, u \%$ & $0,0 \%$ & $100,0 \%$ \\
\hline 44 & $L$ & 123 & 13 & 4 & 0 & 0 & 140 & $8 \%, 9 \%$ & $4,3 \%$ & $2,5 \%$ & $0,0 \%$ & $0,0 \%$ & $100,0 \% \%$ \\
\hline & $u$ & 119 & 14 & 4 & 0 & u & 137 & $86,9 \%$ & $10,2 \%$ & $2, y \%$ & $u, u \%$ & $0,0 \%$ & $100,0 \%$ \\
\hline & v & 123 & 13 & 4 & 0 & 0 & 140 & $8 /, 9 \%$ & $9,3 \%$ & $2,9 \%$ & $0,0 \%$ & $0,0 \%$ & $100,0 \% \%$ \\
\hline 45 & L & 121 & 13 & 4 & 0 & 0 & 138 & $81,1 \%$ & $9,4 \%$ & $2, y \%$ & $0,0 \%$ & $0,0 \%$ & $100,0 \%$ \\
\hline & $u$ & 114 & 14 & 4 & 0 & u & 132 & $86,4 \%$ & $10,6 \%$ & $3,0 \%$ & $U, U \%$ & $0,0 \%$ & $100,0 \%$ \\
\hline & v & 121 & 13 & 4 & 0 & 0 & 138 & $8 /, 1 \%$ & $y, 4 \%$ & $2, y \%$ & $0,0 \%$ & $0,0 \%$ & $100,0 \%$ \\
\hline 46 & L & 130 & 3 & 1 & 0 & U & 134 & $4 \%, 0 \%$ & $2,2 \%$ & $0,1 \%$ & $U, U \%$ & $0,0 \%$ & $I 00,0 \% \%$ \\
\hline & $u$ & 16 & 3 & u & 0 & $u$ & 19 & $4,2 \%$ & $3,8 \%$ & $0,0 \%$ & $u, u \%$ & $0,0 \%$ & $100,0 \%$ \\
\hline & v & 121 & 3 & 1 & 0 & 0 & 123 & $96,8 \%$ & $2,4 \%$ & $0,8 \%$ & $0,0 \%$ & $0,0 \%$ & $100,0 \%$ \\
\hline $4 \%$ & L & yy & 12 & 6 & 1 & $u$ & 118 & $83,4 \%$ & $10,2 \%$ & $5,1 \%$ & $0,8 \%$ & $0,0 \%$ & $100,0 \%$ \\
\hline & $u$ & 84 & 13 & 6 & 1 & u & 104 & $80,8 \%$ & $12,3 \%$ & $5,8 \%$ & $1,0 \%$ & $0,0 \%$ & $100,0 \%$ \\
\hline & v & yy & 12 & 6 & 1 & 0 & 118 & $83,9 \%$ & $10,2 \%$ & $5,1 \%$ & $0,8 \%$ & $0,0 \%$ & $100,0 \%$ \\
\hline Total & & 8629 & 368 & 206 & 6 & 5 & प्र414 & प्रा,7\% & $6,0 \%$ & $2,2 \%$ & $0,1 \%$ & $0,1 \%$ & Tए0,0\% \\
\hline
\end{tabular}


Anexo 7: Indice de DEAN por dente e superficie, Iracemápolis

\begin{tabular}{|c|c|c|c|c|c|c|c|}
\hline \multicolumn{4}{|c|}{ Numero de superticies } & \multicolumn{4}{|c|}{ Percentagem de superficies } \\
\hline DENTE & Sup. & 0 & $T$ & Total & 0 & $T$ & Total \\
\hline \multirow[t]{2}{*}{ II } & $\mathrm{L}$ & 164 & 0 & 164 & $100,0 \%$ & $0,0 \%$ & $100,0 \%$ \\
\hline & V & 152 & 0 & 152 & $100,0 \%$ & $0,0 \%$ & $100,0 \%$ \\
\hline \multirow[t]{2}{*}{12} & $\mathrm{~L}$ & 161 & 0 & 161 & $100,0 \%$ & $0,0 \%$ & $100,0 \%$ \\
\hline & v & 153 & 0 & 153 & $100,0 \%$ & $0,0 \%$ & $100,0 \%$ \\
\hline \multirow[t]{2}{*}{13} & $\mathrm{~L}$ & 156 & 0 & 156 & $100,0 \%$ & $0,0 \%$ & $100,0 \%$ \\
\hline & V & 156 & 0 & 156 & $100,0 \%$ & $0,0 \%$ & $100,0 \%$ \\
\hline \multirow[t]{3}{*}{14} & L & 162 & 2 & 164 & $98,8 \%$ & $1,2 \%$ & $100,0 \%$ \\
\hline & 0 & 131 & 4 & 135 & $97,0 \%$ & $3,0 \%$ & $100,0 \%$ \\
\hline & V & 162 & 2 & 164 & $98,8 \%$ & $1,2 \%$ & $100,0 \%$ \\
\hline \multirow[t]{3}{*}{15} & $\mathrm{~L}$ & 155 & 1 & 156 & $99,4 \%$ & $0,6 \%$ & $100,0 \%$ \\
\hline & O & 121 & 4 & 125 & $96,8 \%$ & $3,2 \%$ & $100,0 \%$ \\
\hline & V & 154 & 1 & 155 & $99,4 \%$ & $0,6 \%$ & $100,0 \%$ \\
\hline \multirow[t]{3}{*}{16} & L & 160 & 1 & 161 & $99,4 \%$ & $0,6 \%$ & $100,0 \%$ \\
\hline & o & 46 & 0 & 46 & $100,0 \%$ & $0,0 \%$ & $100,0 \%$ \\
\hline & v & 160 & 1 & 161 & $99,4 \%$ & $0,6 \%$ & $100,0 \%$ \\
\hline 17 & $\mathrm{~L}$ & 135 & 4 & 139 & $97,1 \%$ & $2,9 \%$ & $100,0 \%$ \\
\hline & O & 98 & 7 & 105 & $93,3 \%$ & $6,7 \%$ & $100,0 \%$ \\
\hline & V & 135 & 4 & 139 & $97,1 \%$ & $2,9 \%$ & $100,0 \%$ \\
\hline 21 & $\mathrm{~L}$ & 162 & 0 & 162 & $100,0 \%$ & $0,0 \%$ & $100,0 \%$ \\
\hline & V & 158 & 0 & 158 & $100,0 \%$ & $0,0 \%$ & $100,0 \%$ \\
\hline 22 & L & 161 & 0 & 161 & $100,0 \%$ & $0,0 \%$ & $100,0 \%$ \\
\hline & V & 154 & 0 & 154 & $100,0 \%$ & $0,0 \%$ & $100,0 \%$ \\
\hline 23 & L & 160 & 0 & 160 & $100,0 \%$ & $0,0 \%$ & $100,0 \%$ \\
\hline & V & 159 & 0 & 159 & $100,0 \%$ & $0,0 \%$ & $100,0 \%$ \\
\hline 24 & L & 162 & 2 & 164 & $98,8 \%$ & $1,2 \%$ & $100,0 \%$ \\
\hline & O & 127 & 5 & 132 & $96,2 \%$ & $3,8 \%$ & $100,0 \%$ \\
\hline & V & 162 & 2 & 164 & $98,8 \%$ & $1,2 \%$ & $100,0 \%$ \\
\hline 25 & $\mathrm{~L}$ & 156 & 1 & 157 & $99,4 \%$ & $0,6 \%$ & $100,0 \%$ \\
\hline & o & 129 & 3 & 132 & $97,7 \%$ & $2,3 \%$ & $100,0 \%$ \\
\hline & V & 156 & 1 & 157 & $99,4 \%$ & $0,6 \%$ & $100,0 \%$ \\
\hline 26 & L & 161 & 1 & 162 & $99,4 \%$ & $0,6 \%$ & $100,0 \%$ \\
\hline & O & 45 & 0 & 45 & $100,0 \%$ & $0,0 \%$ & $100,0 \%$ \\
\hline & V & 161 & 1 & 162 & $99,4 \%$ & $0,6 \%$ & $100,0 \%$ \\
\hline 27 & L & 136 & 4 & 140 & $97,1 \%$ & $2,9 \%$ & $100,0 \%$ \\
\hline & $\mathbf{O}$ & 104 & 7 & 111 & $93,7 \%$ & $6,3 \%$ & $100,0 \%$ \\
\hline & V & 136 & 4 & 140 & $97,1 \%$ & $2,9 \%$ & $100,0 \%$ \\
\hline 31 & L & 164 & 0 & 164 & $100,0 \%$ & $0,0 \%$ & $100,0 \%$ \\
\hline & V & 164 & 0 & 164 & $100,0 \%$ & $0,0 \%$ & $100,0 \%$ \\
\hline 32 & L & 165 & 0 & 165 & $100,0 \%$ & $0,0 \%$ & $100,0 \%$ \\
\hline & V & 165 & 0 & 165 & $100,0 \%$ & $0,0 \%$ & $100,0 \%$ \\
\hline 33 & L & 164 & 0 & 164 & $100,0 \%$ & $0,0 \%$ & $100,0 \%$ \\
\hline & V & 163 & 0 & 163 & $100,0 \%$ & $0,0 \%$ & $100,0 \%$ \\
\hline 34 & L & 158 & 2 & 160 & $98,8 \%$ & $1,3 \%$ & $100,0 \%$ \\
\hline & $\mathbf{O}$ & 143 & 4 & 147 & $97,3 \%$ & $2,7 \%$ & $100,0 \%$ \\
\hline & V & 158 & 2 & 160 & $98,8 \%$ & $1,3 \%$ & $100,0 \%$ \\
\hline 35 & L & 156 & 2 & 158 & $98,7 \%$ & $1,3 \%$ & $100,0 \%$ \\
\hline & O & 131 & 4 & 135 & $97,0 \%$ & $3,0 \%$ & $100,0 \%$ \\
\hline & V & 156 & 2 & 158 & $98,7 \%$ & $1,3 \%$ & $100,0 \%$ \\
\hline 36 & L & 149 & 1 & 150 & $99,3 \%$ & $0,7 \%$ & $100,0 \%$ \\
\hline & O & 34 & 0 & 34 & $100,0 \%$ & $0,0 \%$ & $100,0 \%$ \\
\hline & V & 138 & 1 & 139 & $99,3 \%$ & $0,7 \%$ & $100,0 \%$ \\
\hline 37 & L & 151 & 4 & 155 & $97,4 \%$ & $2,6 \%$ & $100,0 \%$ \\
\hline & 0 & 81 & 7 & 88 & $92,0 \%$ & $8,0 \%$ & $100,0 \%$ \\
\hline & V & 150 & 4 & 154 & $97,4 \%$ & $2,6 \%$ & $100,0 \%$ \\
\hline 41 & $\mathrm{~L}$ & 164 & 0 & 164 & $100,0 \%$ & $0,0 \%$ & $100,0 \%$ \\
\hline & V & 164 & 0 & 164 & $100,0 \%$ & $0,0 \%$ & $100,0 \%$ \\
\hline 42 & L & 164 & 0 & 164 & $100,0 \%$ & $0,0 \%$ & $100,0 \%$ \\
\hline & V & 165 & 0 & 165 & $100,0 \%$ & $0,0 \%$ & $100,0 \%$ \\
\hline 43 & L & 165 & 0 & 165 & $100,0 \%$ & $0,0 \%$ & $100,0 \%$ \\
\hline & V & 165 & 0 & 165 . & $100,0 \%$ & $0,0 \%$ & $100,0 \%$ \\
\hline 44 & $\mathrm{~L}$ & 164 & 2 & 166 & $98,8 \%$ & $1,2 \%$ & $100,0 \%$ \\
\hline & O & 147 & 5 & 152 & $96,7 \%$ & $3,3 \%$ & $100,0 \%$ \\
\hline & V & 164 & 2 & 166 & $98,8 \%$ & $1,2 \%$ & $100,0 \%$ \\
\hline 45 & L & 154 & 2 & 156 & $98,7 \%$ & $1,3 \%$ & $100,0 \%$ \\
\hline & o & 126 & 4 & 130 & $96,9 \%$ & $3,1 \%$ & $100,0 \%$ \\
\hline & V & 154 & 2 & 156 & $98,7 \%$ & $1,3 \%$ & $100,0 \%$ \\
\hline 46 & L & 151 & 1 & 152 & $99,3 \%$ & $0,7 \%$ & $100,0 \%$ \\
\hline & O & 23 & 0 & 23 & $100,0 \%$ & $0,0 \%$ & $100,0 \%$ \\
\hline & V & 133 & 1 & 134 & $99,3 \%$ & $0,7 \%$ & $100,0 \%$ \\
\hline 47 & L & 145 & 4 & 149 & $97,3 \%$ & $2,7 \%$ & $100,0 \%$ \\
\hline & O & 73 & 7 & 80 & $91,3 \%$ & $\mathbf{8 , 8 \%}$ & $100,0 \%$ \\
\hline & V & 145 & 4 & 149 & $97,3 \%$ & $2,7 \%$ & $100,0 \%$ \\
\hline Total & & 10306 & 129 & 10435 & $98,8 \%$ & $1,2 \%$ & $700,0 \%$ \\
\hline
\end{tabular}


Anexo 8: Indice T-F por dente e superficie, Iracemápolis.

\begin{tabular}{|c|c|c|c|c|c|c|c|c|c|}
\hline & \multicolumn{4}{|c|}{ Número de superficies } & \multicolumn{5}{|c|}{ Percentagem de superficies } \\
\hline DENTE & Sup. & 0 & $T$ & 2 & Total & 0 & $T$ & 2 & Tota \\
\hline \multirow[t]{2}{*}{$\pi$} & $\mathbf{L}$ & 164 & 0 & 0 & 764 & $700,0 \%$ & $0,0 \%$ & $0,0 \%$ & $700,0 \%$ \\
\hline & v & 152 & 0 & $\mathbf{0}$ & 152 & $100,0 \%$ & $0,0 \%$ & $0,0 \%$ & $100,0 \%$ \\
\hline \multirow[t]{2}{*}{12} & $\mathrm{~L}$ & 161 & $\mathbf{0}$ & 0 & 161 & $100,0 \%$ & $0,0 \%$ & $0,0 \%$ & $100,0 \%$ \\
\hline & V & 153 & $\mathbf{0}$ & 0 & 153 & $100,0 \%$ & $0,0 \%$ & $0,0 \%$ & $100,0 \%$ \\
\hline \multirow[t]{2}{*}{13} & L & 156 & 0 & $\mathbf{0}$ & 156 & $100,0 \%$ & $0,0 \%$ & $0,0 \%$ & $100,0 \%$ \\
\hline & $\mathrm{v}$ & 156 & $\mathbf{0}$ & 0 & 156 & $100,0 \%$ & $0,0 \%$ & $0,0 \%$ & $100,0 \%$ \\
\hline \multirow[t]{3}{*}{14} & L & 162 & 1 & 1 & 164 & $98,8 \%$ & $0,6 \%$ & $0,6 \%$ & $100,0 \%$ \\
\hline & 0 & 130 & $\mathbf{0}$ & 5 & 135 & $96,3 \%$ & $0,0 \%$ & $\mathbf{3 , 7} \%$ & $100,0 \%$ \\
\hline & V & 162 & 1 & 1 & 164 & $98,8 \%$ & $0,6 \%$ & $0,6 \%$ & $100,0 \%$ \\
\hline \multirow[t]{3}{*}{15} & L & 155 & $\mathbf{0}$ & 1 & 156 & $99,4 \%$ & $0,0 \%$ & $0,6 \%$ & $100,0 \%$ \\
\hline & 0 & 121 & 0 & 4 & 125 & $96,8 \%$ & $0,0 \%$ & $3,2 \%$ & $100,0 \%$ \\
\hline & V & 154 & 0 & 1 & 155 & $99,4 \%$ & $0,0 \%$ & $0,6 \%$ & $100,0 \%$ \\
\hline 16 & L & 159 & 1 & 1 & 161 & $98,8 \%$ & $0,6 \%$ & $0,6 \%$ & $100,0 \%$ \\
\hline & O & 45 & 0 & 1 & 46 & $97,8 \%$ & $0,0 \%$ & $2,2 \%$ & $100,0 \%$ \\
\hline & V & 159 & 1 & 1 & 161 & $98,8 \%$ & $0,6 \%$ & $0,6 \%$ & $100,0 \%$ \\
\hline 17 & L & 135 & 1 & 3 & 139 & $97,1 \%$ & $0,7 \%$ & $2,2 \%$ & $100,0 \%$ \\
\hline & 0 & 98 & 0 & 7 & 105 & $93,3 \%$ & $0,0 \%$ & $6,7 \%$ & $100,0 \%$ \\
\hline & V & 135 & 1 & 3 & 139 & $97,1 \%$ & $0,7 \%$ & $2,2 \%$ & $100,0 \%$ \\
\hline 21 & L & 162 & 0 & 0 & 162 & $100,0 \%$ & $0,0 \%$ & $0,0 \%$ & $100,0 \%$ \\
\hline & V & 158 & 0 & 0 & 158 & $100,0 \%$ & $0,0 \%$ & $0,0 \%$ & $100,0 \%$ \\
\hline 22 & L & 161 & 0 & 0 & 161 & $100,0 \%$ & $0,0 \%$ & $0,0 \%$ & $100,0 \%$ \\
\hline & V & 154 & 0 & 0 & 154 & $100,0 \%$ & $0,0 \%$ & $0,0 \%$ & $100,0 \%$ \\
\hline 23 & L & 160 & 0 & 0 & 160 & $100,0 \%$ & $0,0 \%$ & $0,0 \%$ & $100,0 \%$ \\
\hline & V & 159 & 0 & 0 & 159 & $100,0 \%$ & $0,0 \%$ & $0,0 \%$ & $100,0 \%$ \\
\hline 24 & L & 162 & 1 & 1 & 164 & $98,8 \%$ & $0,6 \%$ & $0,6 \%$ & $100,0 \%$ \\
\hline & 0 & 127 & 0 & 5 & 132 & $96,2 \%$ & $0,0 \%$ & $3,8 \%$ & $100,0 \%$ \\
\hline & V & 162 & 1 & 1 & 164 & $98,8 \%$ & $0,6 \%$ & $0,6 \%$ & $100,0 \%$ \\
\hline 25 & L & 156 & 0 & 1 & 157 & $99,4 \%$ & $0,0 \%$ & $0,6 \%$ & $100,0 \%$ \\
\hline & 0 & 129 & 0 & 3 & 132 & $97,7 \%$ & $0,0 \%$ & $2,3 \%$ & $100,0 \%$ \\
\hline & V & 156 & 0 & 1 & 157 & $99,4 \%$ & $0,0 \%$ & $0,6 \%$ & $100,0 \%$ \\
\hline 26 & L & 160 & 1 & 1 & 162 & $98,8 \%$ & $0,6 \%$ & $0,6 \%$ & $100,0 \%$ \\
\hline & 0 & 44 & 0 & 1 & 45 & $97,8 \%$ & $0,0 \%$ & $2,2 \%$ & $100,0 \%$ \\
\hline & V & 160 & 1 & 1 & 162 & $98,8 \%$ & $0,6 \%$ & $0,6 \%$ & $100,0 \%$ \\
\hline 27 & L & 136 & 1 & 3 & 140 & $97,1 \%$ & $0,7 \%$ & $2,1 \%$ & $100,0 \%$ \\
\hline & 0 & 104 & 0 & 7 & 111 & $93,7 \%$ & $0,0 \%$ & $6,3 \%$ & $100,0 \%$ \\
\hline & V & 136 & 1 & 3 & 140 & $97,1 \%$ & $0,7 \%$ & $2,1 \%$ & $100,0 \%$ \\
\hline 31 & L & 164 & 0 & 0 & 164 & $100,0 \%$ & $0,0 \%$ & $0,0 \%$ & $100,0 \%$ \\
\hline & V & 164 & 0 & 0 & 164 & $100,0 \%$ & $0,0 \%$ & $0,0 \%$ & $100,0 \%$ \\
\hline 32 & L & 165 & 0 & 0 & 165 & $100,0 \%$ & $0,0 \%$ & $0,0 \%$ & $100,0 \%$ \\
\hline & V & 165 & 0 & 0 & 165 & $100,0 \%$ & $0,0 \%$ & $0,0 \%$ & $100,0 \%$ \\
\hline 33 & L & 164 & 0 & 0 & 164 & $100,0 \%$ & $0,0 \%$ & $0,0 \%$ & $100,0 \%$ \\
\hline & V & 163 & 0 & 0 & 163 & $100,0 \%$ & $0,0 \%$ & $0,0 \%$ & $100,0 \%$ \\
\hline 34 & L & 158 & 1 & 1 & 160 & $98,8 \%$ & $0,6 \%$ & $0,6 \%$ & $100,0 \%$ \\
\hline & 0 & 142 & 0 & 5 & 147 & $96,6 \%$ & $0,0 \%$ & $3,4 \%$ & $100,0 \%$ \\
\hline & V & 158 & 1 & 1 & 160 & $98,8 \%$ & $0,6 \%$ & $0,6 \%$ & $100,0 \%$ \\
\hline 35 & L & 156 & 1 & 1 & 158 & $98,7 \%$ & $0,6 \%$ & $0,6 \%$ & $100,0 \%$ \\
\hline & 0 & 130 & 0 & 5 & 135 & $96,3 \%$ & $0,0 \%$ & $3,7 \%$ & $100,0 \%$ \\
\hline & V & 156 & 1 & 1 & 158 & $98,7 \%$ & $0,6 \%$ & $0,6 \%$ & $100,0 \%$ \\
\hline 36 & L & 148 & 1 & 1 & 150 & $98,7 \%$ & $0,7 \%$ & $0,7 \%$ & $100,0 \%$ \\
\hline & O & 33 & 0 & 1 & 34 & $97,1 \%$ & $0,0 \%$ & $2,9 \%$ & $100,0 \%$ \\
\hline & V & 137 & 1 & 1 & 139 & $98,6 \%$ & $0,7 \%$ & $0,7 \%$ & $100,0 \%$ \\
\hline 37 & L & 151 & 1 & 3 & 155 & $97.4 \%$ & $0,6 \%$ & $1,9 \%$ & $100,0 \%$ \\
\hline & 0 & 81 & 0 & 7 & 88 & $92,0 \%$ & $0,0 \%$ & $8,0 \%$ & $100,0 \%$ \\
\hline & V & 150 & 1 & 3 & 154 & $97,4 \%$ & $0,6 \%$ & $1,9 \%$ & $100,0 \%$ \\
\hline 41 & L & 164 & 0 & 0 & 164 & $100,0 \%$ & $0,0 \%$ & $0,0 \%$ & $100,0 \%$ \\
\hline & $\mathbf{V}$ & 164 & 0 & 0 & 164 & $100,0 \%$ & $0,0 \%$ & $0,0 \%$ & $100,0 \%$ \\
\hline 42 & L & 164 & 0 & 0 & 164 & $100,0 \%$ & $0,0 \%$ & $0,0 \%$ & $100,0 \%$ \\
\hline & $\mathbf{V}$ & 165 & 0 & 0 & 165 & $100,0 \%$ & $0,0 \%$ & $0,0 \%$ & $100,0 \%$ \\
\hline 43 & L & 165 & 0 & 0 & 165 & $100,0 \%$ & $0,0 \%$ & $0,0 \%$ & $100,0 \%$ \\
\hline & $\vec{V}$ & 165 & 0 & 0 & 165 & $100,0 \%$ & $0,0 \%$ & $0,0 \%$ & $100,0 \%$ \\
\hline 44 & L & 164 & 1 & 1 & 166 & $98,8 \%$ & $0,6 \%$ & $0,6 \%$ & $100,0 \%$ \\
\hline & 0 & 147 & 0 & 5 & 152 & $96,7 \%$ & $0,0 \%$ & $3,3 \%$ & $100,0 \%$ \\
\hline & V & 164 & 1 & 1 & 166 & $98,8 \%$ & $0,6 \%$ & $0,6 \%$ & $100,0 \%$ \\
\hline 45 & L & 154 & 1 & 1 & 156 & $98,7 \%$ & $0,6 \%$ & $0,6 \%$ & $100,0 \%$ \\
\hline & 0 & 126 & 0 & 4 & 130 & $96,9 \%$ & $0,0 \%$ & $3,1 \%$ & $100,0 \%$ \\
\hline & V & 154 & 1 & 1 & 156 & $98,7 \%$ & $0,6 \%$ & $0,6 \%$ & $100,0 \%$ \\
\hline 46 & $\mathrm{~L}$ & 150 & 1 & 1 & 152 & $98,7 \%$ & $0,7 \%$ & $0,7 \%$ & $100,0 \%$ \\
\hline & 0 & 22 & 0 & 1 & 23 & $95,7 \%$ & $0,0 \%$ & $4,3 \%$ & $100,0 \%$ \\
\hline & V & 132 & 1 & 1 & 134 & $98,5 \%$ & $0,7 \%$ & $0,7 \%$ & $100,0 \%$ \\
\hline 47 & L & 145 & 1 & 3 & 149 & $97,3 \%$ & $0,7 \%$ & $2,0 \%$ & $100,0 \%$ \\
\hline & 0 & 73 & 0 & 7 & 80 & $91,3 \%$ & $0,0 \%$ & $8,8 \%$ & $100,0 \%$ \\
\hline & V & 145 & 1 & 3 & 149 & $97,3 \%$ & $0,7 \%$ & $2,0 \%$ & $100,0 \%$ \\
\hline Total & & 70291 & 28 & 116 & 10435 & $98,6 \%$ & $0,3 \%$ & $1,1 \%$ & $100,0 \%$ \\
\hline
\end{tabular}


Anexo 9: TSIF por dente e superficie, Iracemápolis.

\begin{tabular}{|c|c|c|c|c|c|c|c|}
\hline & \multicolumn{3}{|c|}{ Número de superticies } & \multicolumn{3}{|c|}{ Percentagem de superficies } & \multirow[b]{2}{*}{ Total } \\
\hline DENIE & Sup. & 0 & $T$ & Tota & 0 & $\mathrm{~T}$ & \\
\hline \multirow[t]{2}{*}{$\pi$} & $\mathrm{L}$ & 164 & 0 & 164 & $100,0 \%$ & $0,0 \%$ & $700,0 \%$ \\
\hline & V & 152 & $\mathbf{0}$ & 152 & $100,0 \%$ & $0,0 \%$ & $100,0 \%$ \\
\hline \multirow[t]{2}{*}{12} & L & 161 & $\mathbf{0}$ & 161 & $100,0 \%$ & $0,0 \%$ & $100,0 \%$ \\
\hline & V & 153 & $\mathbf{0}$ & 153 & $100,0 \%$ & $0,0 \%$ & $100,0 \%$ \\
\hline \multirow[t]{2}{*}{13} & L & 156 & 0 & 156 & $100,0 \%$ & $0,0 \%$ & $100,0 \%$ \\
\hline & $\mathrm{v}$ & 156 & 0 & 156 & $100,0 \%$ & $0,0 \%$ & $100,0 \%$ \\
\hline \multirow[t]{3}{*}{14} & $\mathbf{L}$ & 162 & 2 & 164 & $98,8 \%$ & $1,2 \%$ & $100,0 \%$ \\
\hline & $\mathbf{O}$ & 131 & 4 & 135 & $97,0 \%$ & $3,0 \%$ & $100,0 \%$ \\
\hline & v & 162 & 2 & 164 & $98,8 \%$ & $1,2 \%$ & $100,0 \%$ \\
\hline \multirow[t]{3}{*}{15} & L & 155 & 1 & 156 & $99,4 \%$ & $0,6 \%$ & $100,0 \%$ \\
\hline & $\mathbf{o}$ & 121 & 4 & 125 & $96,8 \%$ & $3,2 \%$ & $100,0 \%$ \\
\hline & V & 154 & 1 & 155 & $99,4 \%$ & $0,6 \%$ & $100,0 \%$ \\
\hline 16 & L & 159 & 2 & 161 & $98,8 \%$ & $1,2 \%$ & $100,0 \%$ \\
\hline & 0 & 45 & 1 & 46 & $97,8 \%$ & $2,2 \%$ & $100,0 \%$ \\
\hline & V & 159 & 2 & 161 & $98,8 \%$ & $1,2 \%$ & $100,0 \%$ \\
\hline 17 & L & 135 & 4 & 139 & $97.1 \%$ & $2,9 \%$ & $100,0 \%$ \\
\hline & $\mathbf{O}$ & 98 & 7 & 105 & $93,3 \%$ & $6,7 \%$ & $100,0 \%$ \\
\hline & V & 135 & 4 & 139 & $97,1 \%$ & $2,9 \%$ & $100,0 \%$ \\
\hline 21 & L & 162 & 0 & 162 & $100,0 \%$ & $0,0 \%$ & $100,0 \%$ \\
\hline & V & 158 & 0 & 158 & $100,0 \%$ & $0,0 \%$ & $100,0 \%$ \\
\hline 22 & L & 161 & 0 & 161 & $100,0 \%$ & $0,0 \%$ & $100,0 \%$ \\
\hline & $\bar{v}$ & 154 & 0 & 154 & $100,0 \%$ & $0,0 \%$ & $100,0 \%$ \\
\hline 23 & L & 160 & $\mathbf{0}$ & 160 & $100,0 \%$ & $0,0 \%$ & $100,0 \%$ \\
\hline & V & 159 & 0 & 159 & $100,0 \%$ & $0,0 \%$ & $100,0 \%$ \\
\hline 24 & L & 162 & 2 & 164 & $98,8 \%$ & $1,2 \%$ & $100,0 \%$ \\
\hline & o & 127 & 5 & 132 & $96,2 \%$ & $3,8 \%$ & $100,0 \%$ \\
\hline & V & 162 & 2 & 164 & $98,8 \%$ & $1,2 \%$ & $100,0 \%$ \\
\hline 25 & L & 156 & 1 & 157 & $99,4 \%$ & $0,6 \%$ & $100,0 \%$ \\
\hline & O & 129 & 3 & 132 & $97,7 \%$ & $2,3 \%$ & $100,0 \%$ \\
\hline & V & 156 & 1 & 157 & $99.4 \%$ & $0,6 \%$ & $100,0 \%$ \\
\hline 26 & L & 160 & 2 & 162 & 98,8\% & $1,2 \%$ & $100,0 \%$ \\
\hline & 0 & 44 & 1 & 45 & $97,8 \%$ & $2,2 \%$ & $100,0 \%$ \\
\hline & V & 160 & 2 & 162 & $98,8 \%$ & $1,2 \%$ & $100,0 \%$ \\
\hline 27 & L & 136 & 4 & 140 & $97,1 \%$ & $2,9 \%$ & $100,0 \%$ \\
\hline & O & 104 & 7 & 111 & $93,7 \%$ & $6,3 \%$ & $100,0 \%$ \\
\hline & V & 136 & 4 & 140 & $97,1 \%$ & $2,9 \%$ & $100,0 \%$ \\
\hline 31 & L & 164 & 0 & 164 & $100,0 \%$ & $0,0 \%$ & $100,0 \%$ \\
\hline & V & 164 & 0 & 164 & $100,0 \%$ & $0,0 \%$ & $100,0 \%$ \\
\hline 32 & L & 165 & 0 & 165 & $100,0 \%$ & $0,0 \%$ & $100,0 \%$ \\
\hline & v & 165 & 0 & 165 & $100,0 \%$ & $0,0 \%$ & $100,0 \%$ \\
\hline 33 & L & 164 & 0 & 164 & $100,0 \%$ & $0,0 \%$ & $100,0 \%$ \\
\hline & V & 163 & 0 & 163 & $100,0 \%$ & $0,0 \%$ & $100,0 \%$ \\
\hline 34 & L & 158 & 2 & 160 & $98,8 \%$ & $13 \%$ & $100,0 \%$ \\
\hline & $\mathbf{O}$ & 142 & 5 & 147 & $96,6 \%$ & $3.4 \%$ & $100,0 \%$ \\
\hline & V & 158 & 2 & 160 & $98,8 \%$ & $1,3 \%$ & $100,0 \%$ \\
\hline 35 & L & 156 & 2 & 158 & $98,7 \%$ & $1,3 \%$ & $100,0 \%$ \\
\hline & 0 & 130 & 5 & 135 & $96,3 \%$ & $3,7 \%$ & $100,0 \%$ \\
\hline & V & 156 & 2 & 158 & $98,7 \%$ & $1,3 \%$ & $100,0 \%$ \\
\hline 36 & L & 148 & 2 & 150 & $98,7 \%$ & $1,3 \%$ & $100,0 \%$ \\
\hline & O & 33 & 1 & 34 & $97,1 \%$ & $2,9 \%$ & $100,0 \%$ \\
\hline & V & 137 & 2 & 139 & $98,6 \%$ & $1,4 \%$ & $100,0 \%$ \\
\hline 37 & L & 151 & 4 & 155 & $97.4 \%$ & $2,6 \%$ & $100,0 \%$ \\
\hline & $\mathbf{O}$ & 81 & 7 & 88 & $92,0 \%$ & $8,0 \%$ & $100,0 \%$ \\
\hline & V & 150 & 4 & 154 & $97,4 \%$ & $2,6 \%$ & $100,0 \%$ \\
\hline 41 & L & 164 & 0 & 164 & $100,0 \%$ & $0,0 \%$ & $100,0 \%$ \\
\hline & V & 164 & 0 & 164 & $100,0 \%$ & $0,0 \%$ & $100,0 \%$ \\
\hline 42 & L & 164 & 0 & 164 & $100,0 \%$ & $0,0 \%$ & $100,0 \%$ \\
\hline & V & 165 & 0 & 165 & $100,0 \%$ & $0,0 \%$ & $100,0 \%$ \\
\hline 43 & L & 165 & 0 & 165 & $100,0 \%$ & $0.0 \%$ & $100,0 \%$ \\
\hline & v & 165 & 0 & 165 & $100,0 \%$ & $0,0 \%$ & $100,0 \%$ \\
\hline 44 & $\mathbf{L}$ & 164 & 2 & 166 & $98,8 \%$ & $1,2 \%$ & $100,0 \%$ \\
\hline & 0 & 147 & 5 & 152 & $96,7 \%$ & $3,3 \%$ & $100,0 \%$ \\
\hline & V & 164 & 2 & 166 & $98,8 \%$ & $1,2 \%$ & $100,0 \%$ \\
\hline 45 & L & 154 & 2 & 156 & $98,7 \%$ & $1,3 \%$ & $100,0 \%$ \\
\hline & 0 & 126 & 4 & 130 & $96,9 \%$ & $3,1 \%$ & $100,0 \%$ \\
\hline & V & 154 & 2 & 156 & $98,7 \%$ & $1,3 \%$ & $100,0 \%$ \\
\hline 46 & L & 150 & 2 & 152 & $98,7 \%$ & $1,3 \%$ & $100,0 \%$ \\
\hline & O & 22 & 1 & 23 & $95,7 \%$ & $4,3 \%$ & $100,0 \%$ \\
\hline & V & 132 & 2 & 134 & $98,5 \%$ & $1,5 \%$ & $100,0 \%$ \\
\hline 47 & L & 145 & 4 & 149 & $97,3 \%$ & $2,7 \%$ & $100,0 \%$ \\
\hline & o & 73 & 7 & 80 & $91,3 \%$ & $8,8 \%$ & $100,0 \%$ \\
\hline & V & 145 & 4 & 149 & $97,3 \%$ & $2,7 \%$ & $100,0 \%$ \\
\hline Tota & & 70292 & 143 & 10435 & $98,6 \%$ & $1,4 \%$ & $100,0 \%$ \\
\hline
\end{tabular}


Sexo: Idade:

Classe

Período: Escola: Cidade: Exame:

Ficha: Obs:

O V L O V L O V L O V L $\frac{\square}{17} \underset{16}{\frac{15}{14}}$ $\frac{\mathrm{V} \mathrm{L}}{13}$ $\frac{v_{12}^{\mathrm{VL}}}{\mathrm{V}_{11}^{\mathrm{VL}}}$

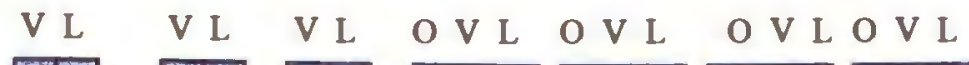

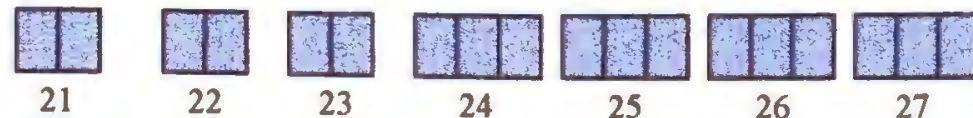
O V L O V L O V L O V L

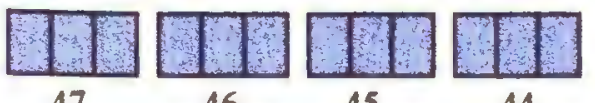
V L V L V L VL VL VL O VL O VL OVLOVL. 47 $46 \quad 45$ 44

DI

Q1
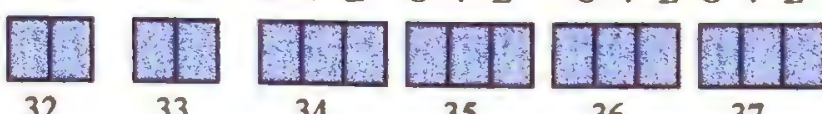

Indice ing

O V L O V L O V L O V L $\frac{\square D W}{17} \frac{15}{15}$
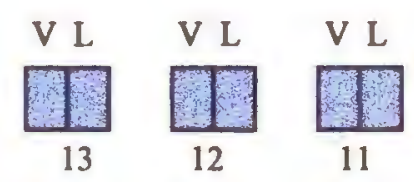

O V L O V L O V L O V L

प1

V L

V L

V L

PD
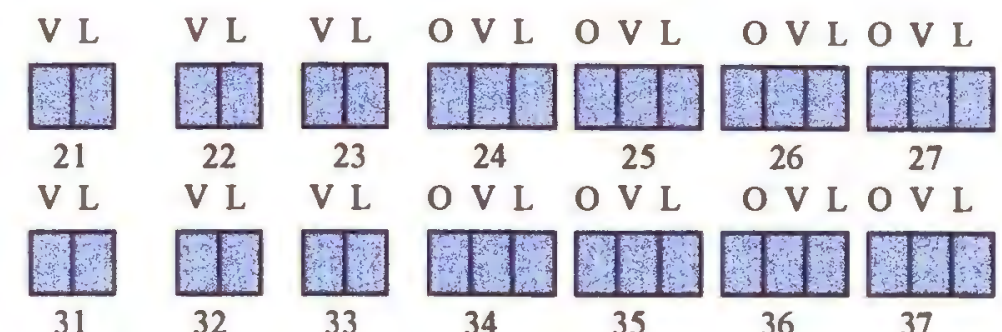
$\begin{array}{rrrrrrr}22 & 23 & 24 & 25 & 26 & 27 \\ V L & V L & \text { O V L } & \text { O V L } & \text { O V L O V L }\end{array}$ 31

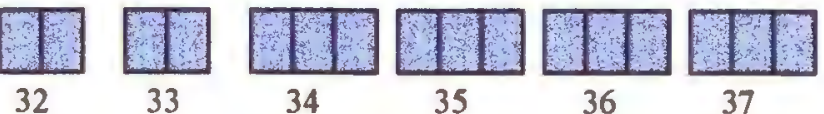

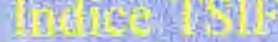

O V L O V L O V L O V L $\frac{17}{17} \underset{15}{\frac{\square}{14}}$

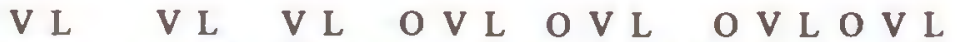
$\begin{array}{llll}17 & 16 & 15 & 14 \\ 0 \mathrm{VL} & \text { O V L } & \text { O V L O V }\end{array}$ I. 11

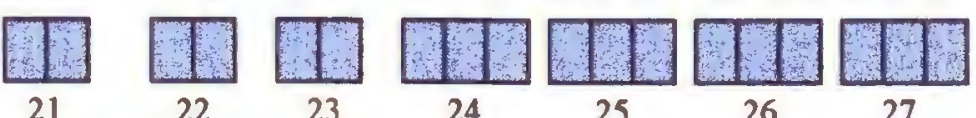
$\begin{array}{cccccccc}21 & 22 & 23 & 24 & 25 & 26 & 27 \\ \text { VL } & \text { V L } & \text { V L } & \text { O V L } & \text { O V L } & \text { O V L O V L }\end{array}$

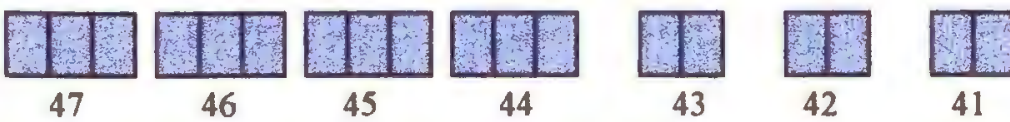

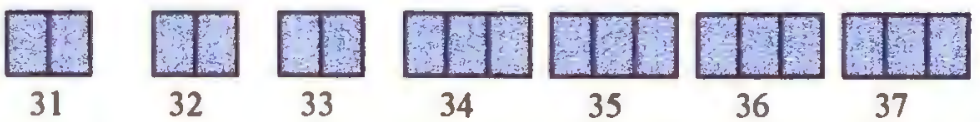

